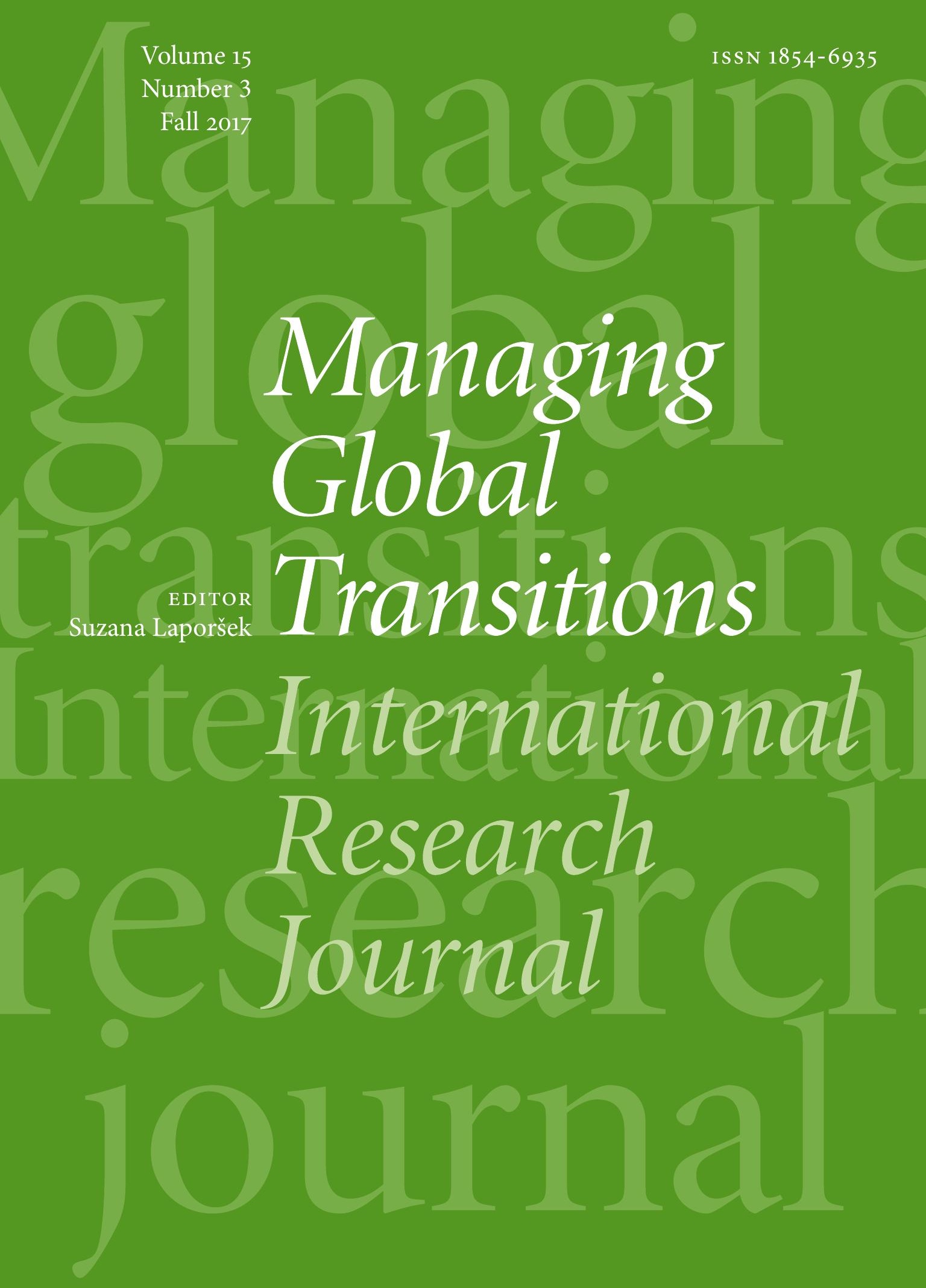




\section{Managing Global Transitions International Research Journal}

ISSN 1854-6935 - www.mgt.fm-kp.si

EDITOR

Suzana Laporsek, University of Primorska, Slovenia, suzana.laporsek@fm-kp.si

ASSOCIATE EDITOR

Robert D. Hisrich, Thunderbird School of Global Management, USA, rhisric1@kent.edu

MANAGING AND PRODUCTION EDITOR

Alen Ježovnik, University of Primorska, Slovenia, alen.jezovnik@fm-kp.si

EDITORIAL BOARD

Jani Bekő, Univerza v Mariboru, Slovenia, jani.beko@uni-mb.si

Heri Bezić, University of Rijeka, Croatia, bezic@efri.hr

Guido Bortoluzzi, University of Trieste, Italy, guido.bortoluzzi@deams.units.it

Branko Bučar, Walsh University, USA, bbucar@walsh.edu

Suzanne Catana, State University of New York, Plattsburgh, UsA, catanasl@plattsburgh.edu

David L. Deeds, University of St. Thomas, usA,david.deeds@gmail.com

Evan Douglas, Griffith Universitiy, Australia, e.douglas@griffith.edu.au

Dean Fantazzini, Moscow School of Economics, Russia fantazzini@mse-msu.ru

Jeffrey Ford, The Ohio State University, USA, ford.1@osu.edu

William C. Gartner, University of Minnesota, usA,wcg@umn.edu

Noel Gough, La Trobe University, Australia, n.gough@latrobe.edu.au

Henryk Gurgul, A GH University of Science and Technology, Poland, henryk.gurgul@gmail.com

José Solana Ibáñez, University Centre of Defence San Javier - Technical University of Cartagena, Spain, jose.solana@cud.upct.es
András Inotai, Hungarian Academy of Sciences, Hungary, inotai.andras@krtk.mta.hu

Hun Joon Park, Yonsei University, South Korea,hjpark@yonsei.ac.kr

Renata Karkowska, University of Warsaw, Poland,rkarkowska@wz.uw.edu.pl

Tanja Kosi Antolič, Institute of Macroeconomic Analysis and Development, Slovenia, tanja.kosi-antolic@gov.si

Leonard H. Lynn, Case Western Reserve University, usA, leonard.lynn@case.edu

Monty Lynn, Abilene Christian University, USA, monty.lynn@coba.acu.edu

Massimiliano Marzo, University of Bologna, Italy,massimiliano.marzo@unibo.it

Luigi Menghini, University of Trieste, Italy, menghini@univ.trieste.it

Karim Moustaghfir, Al Akhawayn University in Ifrane, Morocco, k.moustaghfir@aui.ma

Kevin O'Neill, State University of New York, Plattsburgh, USA, kevin.oneill@plattsburgh.edu

Hazbo Skoko, Charles Sturt University, Australia,hskoko@csu.edu.au

David Starr-Glass, State University of New York - Empire State College, Us A, david.starr-glass@esc.edu

Ian Stronach, The University of Manchester, UK, ian.stronach@manchester.uk

Marinko Škare, University of Pula, Croatia, mskare@unipu.hr

Nada Trunk Širca, International School of Social and Business Studies, Slovenia, trunk.nada@gmail.com

Irena Vida, Univerza v Ljubljani, Slovenia, irena.vida@ef.uni-lj.si

Manfred Weiss, Johann Wolfgang Goethe University, Germany, m.weiss@jur.uni-frankfurt.de

INDEXING AND ABSTRACTING

Managing Global Transitions is indexed/ listed in the International Bibliography of the Social Sciences, EconLit, DOAJ, Erih Plus, EconPapers, Cabell's, в в sco, and ProQuest. 


\section{Managing Global Transitions International Research Journal}

VOLUME 15 - NUMBER 3·FALL 2017 · ISSN 1854-6935

215 Maximizing Decision Making Style and Managerial Effectiveness: Understanding How Maximizing and Locus of Control Impact Managers' Performance on the Job Brandon William Soltwisch and Keiko Krahnke

231 The Unemployment-Stock Market Relationship in South Africa: Evidence from Symmetric and Asymmetric Cointegration Models Andrew Phiri

255 Business Model Concept: An Integrative Framework Proposal Marko Perić, Vanja Vitezić, and Jelena Đurkin

275 Clusters in the Renewable Energy Sector in Poland Michat Staszków, Michał Borychowski, and Filip Nowacki

291 The Growth Challenge of Western smes in Emerging Markets: An Exploratory Framework and Policy Implications

Mitja Ruzzier, Yusaf H. Akbar, Guido Bortoluzzi, and Andrea Tracogna

315 Abstracts in Slovene 
AIMS AND SCOPE

Transition is the widely accepted term for the thorough going political, institutional, organizational, social, and technological changes and innovations as well as economy-wide and sector changes in societies, countries and businesses to establish and enhance a sustainable economic environment.

Managing Global Transitions is a social sciences' interdisciplinary research journal. The aim of this journal is to publish research articles which analyse all aspects of transitions and changes in societies, economies, cultures, networks, organizations, teams, and individuals, and the processes that are most effective in managing large scale transitions from dominant structures to more evolutionary, developmental forms, in a global environment. The journal seeks to offer researchers and professionals the opportunity to discuss the most demanding issues regarding managing of those transitions to establish and enhance a sustainable economic environment.

\section{TOPICS COVERED}

- Business (accounting, entrepreneurship, finance, marketing, informatics, technology, innovations, ...)

- Business law, law and economics, business ethics

- Demographic and labour economics, human resources, knowledge management

- Econometric and mathematical modelling of business and economic processes, operations research

- Globalisation, international economics

- Historical transitions, transition experiments, transition pathways and mechanisms, visions of the future

- Macroeconomics (growth, development, business cycles, government regulation, fiscal policy, monetary and public economics, welfare, ...)

- Microeconomics (theory and applications, industrial organisation, market structure, competition, innovation, ...)
- Sociological, psychological and politological issues of transitions

- Sustainability issues, environmental business and economics

- Urban, rural, regional economics

CONTENTS

Managing Global Transitions publishes original and review articles and case studies.

\section{SUBMISSIONS}

The manuscripts should be submitted as e-mail attachment to the editorial office at mgt@fm-kp.si. Detailed guide for authors and publishing ethics statement are available at www.mgt.fm-kp.si.

Managing Global Transitions is an open access journal distributed under the terms of the Creative Commons CC BY-NC-ND 4.o License. No author fees are charged.

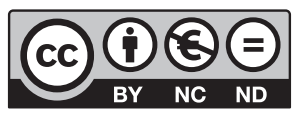

EDITORIAL OFFICE

University of Primorska

Faculty of Management

Cankarjeva 5, 6104 Koper, Slovenia

mgt@fm-kp.si·www.mgt.fm-kp.si

PUBLISHED BY

University of Primorska Press

Titov trg 4, 6ooo Koper, Slovenia

zalozba@upr.si·www.hippocampus.si

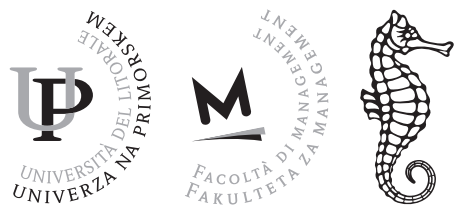

Revija Managing Global Transitions je namenjena mednarodni znanstveni javnosti; izhaja $v$ angleščini s povzetki $v$ slovenščini. Izid revije je finančno podprla Javna agencija za raziskovalno dejavnost Republike Slovenije iz sredstev državnega proračuna iz naslova razpisa za sofinanciranje izdajanja domačih znanstvenih periodičnih publikacij. 


\section{Maximizing Decision Making Style}

and Managerial Effectiveness: Understanding

How Maximizing and Locus of Control Impact

Managers' Performance on the Job

Brandon William Soltwisch

University of Northern Colorado, USA

brandon.soltwisch@unco.edu

Keiko Krahnke

University of Northern Colorado, USA

keiko.krahnke@unco.edu

This study investigates the impact of maximizing decision-making style on managerial effectiveness with a group of 319 working managers in the Us. Findings suggest that managers who apply a maximizing decision making style were more effective than those who satisfice. It was also found that locus of control plays a mediating role in this relationship. Maximizers who have an internal locus of control were significantly more likely to be effective in their positions. The results suggest that the combination of maximizing and internality of control provide a powerful recipe for managerial success. Results, implications, and future research directions are discussed in relation to the current findings.

Key Words: maximizing, satisficing, decision making, managerial effectiveness

JEL Classification: L2, M12

https://doi.org/10.26493/1854-6935.15.215-230

\section{Introduction}

As individuals face overwhelming amounts of information, they are less likely to find the optimal solution due to information processing limitations (Simon 1972). At the time, bounded rationality was proposed as a cognitive constraint hindering decision makers from finding the best choice. Research has recently built on Simon's earlier work to show that individuals differ in their preference toward finding the optimal solution (see Schwartz et al. 2002; Diab, Gillespie, and Highhouse 2008; Lai 2010). Maximizers prefer to spend more time and energy to find the best possible choice, while satisficers tend to settle for 'good enough' options that meet their minimum criteria (Schwarz et al. 2002). 
For example, a maximizer may search extensively to find the best camera by browsing many different consumer reports and product features before selecting. On the other hand, a satisficer would be less likely to investigate as many products, and more likely to select the first product that meets their minimum standards. Because of their intensive search, maximizers sometimes experience negative psychological outcomes associated with a decision because they may look at what could have been done differently. This 'grass is greener on the other side of the fence' philosophy may cause maximizers to be less happy with their decision outcomes (Bergman, Nyland, and Burns, 2007; Polman 2010; Schwartz at al. 2002) and experience more post decision regret (Schwartz et al. 2002; Parker, Bruine de Bruin, and Fischhoff 2007; Purvis, Howell, and Iyer 2011).

However, there are also some benefits to a maximizing approach. Maximizers prefer to have more options available when making decisions (Chowdury, Ratnershwar and Mohanty 2009) and identify a greater number of potential outcomes of those options, both positive and negative (Polman 2010). Their additional effort to seek out more options pays off in the career search process by landing better jobs. By applying for more jobs, maximizers ended up with starting salaries of about $\$ 7,500$ higher than satisficers (Iyengar, Wells and Schwartz 2006). Maximizers play an important role as devil's advocate since they are more likely to compare options (Schwartz et al. 2002) and engage in counterfactual thinking to produce alternative arguments (Leach and Patall 2013). They also have a more optimistic life view as they see positive results within their reach (Lai 2010). Although most of the work on this topic thus far has focused on psychological processes and outcomes, this study provides a first look at how this decision-making preference impacts managers' performance. Specifically, it investigates the relationship between decision making styles and managers' effectiveness on the job using a sample of 319 working managers in the us. The data suggest that managers who apply a maximizing decision making style are more effective than those who satisfice. In addition, this study identifies the role of locus of control in mediating the relationship, finding that the combination of a maximizing decision making style and internal locus of control provides a powerful recipe for effective managers.

\section{Maximizing and Managerial Effectiveness}

Broadly, effective managers deliver results and add value to the company. They do this by tackling many different challenges and roles within 
the company. Mintzberg (1973) observed that all managerial jobs share similar characteristics and can be described by three broad roles: interpersonal, informational, and decisional. He noted that managers can be effective in different jobs by exuding various combinations of skills in these categories. Others have identified that effective managers work on both current and future performance issues simultaneously. For example, Gupta $(1996,399)$ has defined managerial effectiveness as 'the ability of a manager to carry out the activities required of his position while achieving the results both current and in terms of developing further potential.' This forward-thinking mentality helps managers develop future strategies to achieve long-term performance.

Personal characteristics that make it easier to get along with others increase managerial effectiveness (Nair and Yuvaraj 2000). Successful managers are able to find a match between their personality type and managerial role. For example, Rastogi and Dave (2004) found that type B personalities are more effective at managing production departments, and type A personalities are better suited to manage marketing departments. They note that constructive management requires a clear formulation of goals and specific steps to achieve them, including motivating others to work toward those goals. Interestingly, they found that type B personalities are often more successful than type As in top management positions because they are more patient and take a broader perspective on problems (Rastogi and Dave 2004).

In the last few decades, management scholars have applied positive psychology knowledge to management in order to better understand how people can flourish in organizational context. Positive organizational behavior shifted leaders' focus from fixing problems and weaknesses to leveraging strengths, and positive psychological resources have been considered to have desirable outcomes on work performance (Luthans 2002; Youssef and Luthans 2007).

The social and emotional climate of the workplace has a large influence on how people interact and engage with their work. Positive environments increase motivation, allowing managers to achieve superior performance. On the other hand, negative environments make workers uncomfortable, leading to worse performance. Because of this, conscientious leaders have more productive exchanges with their subordinates, allowing them to be more effective (Deluga 1998). A successful manager knows how their workforce is feeling at any given time. Emotional intelligence is the ability to control one's own and others' emotions in so- 
cial situations (Mayer et al. 1997). A study of 305 managers showed that emotionally intelligent managers are more effective than those who are not (Gupta 2010). The ability to empathize with others and control their own emotions during heated situations allows managers to better navigate complex social interactions, creating positive and productive working environments.

Managers need to understand how their decisions will impact those around them in addition to themselves. They must take a broad focus to understand how different alternatives may impact various stakeholder groups, and their business moving forward. Individuals who are emotionally intelligent are more likely to apply a maximizing decision making style as they search for more information to identify the best solutions for themselves and others over time (Soltwisch and Krahnke in press). Thus, those who take more time to analyze their options may be more in tune with how their decisions impact their own and others' emotional states. This is a critical skill for successfully leading teams through difficult projects where the results may not be achieved for some time. Being aware of their own actions and the impact of their decisions is an important skill for leaders facing increasingly complex challenges. Taking time to reflect on their options and possibilities would allow us to put ourselves in the shoes of others who operate in other systems. Senge and Krahnke (2013) call this ability transcendent empathy.

Effective management has also been associated with specific decision making processes. Understanding counterarguments and others point of view allows managers to make more informed decisions. Research has found that the practices of dialectic inquiry (Mason and Mitroff 1981) and devil's advocate (Cosier and Rechner 1985) have produced better decision making results than consensus building (Schwenk 1988). The basic idea is that analyzing competing ideas and understanding different perspectives or arguments helps the decision maker to discover the truth. Managers who ignore counterarguments are more likely to overlook significant obstacles that may hinder performance. Others have linked decision making process to effectiveness, showing that a more rational decision making process leads to more effective decision outcomes. In a longitudinal field study of 52 major decisions in 24 companies, Dean and Sharfman (1996) found that managers who applied procedural rationality, meaning that they took more time to collect information and use that information in making a choice, were far more effective in making strategic decisions that met performance objectives. Applying a rational process allows decision makers to form theories about which strategies will be successful 
as they gather information about different options (Dean and Sharfman 1996).

Maximizers tend to utilize a rational decision making process as they search for more information to reach optimal solutions (Schwarz et al. 2002). They engage in more counterfactual thinking by producing multiple arguments to inform their decisions (Leach and Patall 2013). This role of devil's advocate may help them more accurately evaluate the opportunities and threats in their environment before making a decision. Maximizers prefer to have additional options available when making decisions (Chowdury, Ratnershwar, and Mohanty 2009), and identify more potential outcomes of those options (Polman 2010). Doing so is not easy in our fast-paced society, but maximizers take the time to look at issues more deeply and critically. They practice mindfulness by not making reactive, quick judgments and jumping to premature conclusions. In addition, maximizers are more emotionally intelligent (Soltwisch and Krahnke in press), allowing them to have more positive interactions with colleagues and build support to achieve their goals. Because of this, it is predicted that managers who apply a maximizing decision making style will achieve superior performance than those who satisfice:

H1 Managers who maximize will be more effective than those who satisfice.

\section{Locus of Control and Leadership Behavior}

Locus of control plays an important role in individuals' behavior and decision making, and its effects have been studied in a number of disciplines. Rotter (1990) defined the internal locus of control as 'the degree to which persons expect that a reinforcement or an outcome of their behavior is contingent on their own behavior or personal characteristics' and the external locus of control as 'the degree to which persons expect that the reinforcement or outcome is a function of chance, luck, or fate, is under the control of powerful others, or is simply unpredictable' (p. 489). In other words, those with internal locus of control tend to believe that they can make a difference and also accept the blame for negative situations or failures. People with external locus of control may assume that they cannot do anything to control the situation and attribute both their successes and failures to the external circumstances or luck.

Studies conducted to date have revealed that internal locus of control is associated with positive leadership behavior. Leaders with internal locus of control were found to cope with stress better and use taskcentered coping behaviors more than those with external locus of control 
(Anderson 1977). Miller and Toulouse's (1986) empirical investigation on the relationship between CEOS personalities and their performance indicated that CEOS with internal locus of control were more innovative and future-oriented. A more recent study by Howell and Avolio (1993) discovered that transformational leadership measures; such as charisma, intellectual stimulation, and individualized consideration; were associated with high internal locus of control and positive business unit performance. Baldacchino et al. (2016) investigated the impact of organizational culture and individual audit personnel characteristics on dysfunctional audit practices. People with external locus of control tend to feel powerless because they perceive that they have no control. A possible explanation is that these individuals may manipulate or deceive others to practice some control over the environment (Gabe and Dangello 1994). Baldacchino et al's study (2016) confirmed the earlier research and concluded that external locus of control was a significant predictor of dysfunctional audit behavior, meaning that individuals with external locus of control are more accepting of dysfunctional audit behavior than those with internal locus of control.

Forte's study (2005) investigated managers' locus of control and the likelihood of each individual's engaging in unethical behavior in an organization. The study revealed that managers with internal locus of control thought that they themselves decided what was ethical and appropriate but those with external locus of control relied on others to determine what was appropriate (Forte 2005). Implications of this study are significant. Internal or external locus of control in managers influences their moral reasoning and ultimately their ethical decision making. Looking to others for moral reasoning can be a concern.

Internal locus of control has also been found to be positively linked to concern for global warming (Mostafa 2016), and this finding is consistent with previous studies. Individuals with internal locus of control believe that their actions will make a difference and have demonstrated more concern for the environment than those with external locus of control who tend to feel lack of control. Generally, research has shown that internal locus of control is associated with positive behavior in managers and leaders.

\section{Locus of Control and Culture}

Although cultural discussions are not within the scope of this paper, it is important to keep in mind that locus of control and its effects can have 
different meaning in other parts of the world. Individuals' need for control over their environment varies from culture to culture (Adler 2000). For example, Japanese are more likely to adjust their feelings and reaction to the environment in stressful situations, while Americans tend to change the environment (Morling, Kitayama, and Miyamoto 2002). Americans generally believe that they have direct control over what happens in their lives, while people in other cultures think that they have little control over what happens to them. They attribute life's events to circumstances. One of the values in the American culture is creating one's own reality and building one's future. We make things happen. It's a 'doing' culture. In such cultures, individuals are encouraged to be the 'doer', who can control the environment and the outcome. On the other hand, in 'being' cultures, people value relationships and believe that they do not have much control over the environment. In planning, 'being' people tend to believe that change occurs at its own pace and feel that things will happen if and when they are meant to happen. Evans' (1981) study using word association responses examined the phenomenological dimensions of locus of control among Japanese and American students, and the results showed that Japanese students gave more external word associations. Although research to date has found internal locus of control to be associated with positive behavior, there may be exceptions. External and internal locus of control may manifest differently from culture to culture. Japanese people are known to cope with traumatic natural disasters in an orderly, stoic manner (Rees 2011). They may accept fate more readily (external locus of control) than those in most Western cultures, but with an emphasis on the sense of community, Japanese people accept what has already happened and do the best they can to move forward and rebuild their community. A Japanese phrase, 'Shikata ga nai' meaning 'It can't be helped' or 'It is what it is. We can't do anything about it', is often heard after an undesirable or unfortunate incident. It may sound weak or helpless in a Western mindset, it may be the sense of accepting fate and constant change in nature, which is an underlying concept in Buddhism (Rees 2011).

\section{Locus of Control and Managerial Effectiveness}

Managerial effectiveness can vary depending on the nature of industry and the type of organization. Although Mintzberg's (1973) ten managerial roles in three categories (interpersonal, informational, and decisional) suggest a common set of skills in all managerial jobs, managerial effec- 
tiveness is considered to be different in various settings and based on different needs. Both organizational culture and national culture should influence the norms and expectations of an effective manager. National culture, for example, significantly influences what constitutes managerial effectiveness, and it is an important variable in determining managerial and leadership effectiveness (Javidan and Carl 2004). An effective manager in Japan is a manager who focuses on both goal attainment and social stability (Misumi 1989). In Taiwan and Mexico, directive leadership style has positive impact on employees according to a study by Dorfman et al. 1997). There is a plethora of models of managerial effectiveness that focus on managers' skills and competencies. Locus of control has gained some attention as a personality trait that impacts managerial effectiveness.

Being entrepreneurial and innovative is an increasingly important aspect of managerial effectiveness. Mueller and Thomas' study (2001) examined two entrepreneurial traits, internal locus of control and innovativeness, with culture as a contextual factor. The results of this study conducted in nine countries showed that people in individualistic cultures, who generally have an internal locus of control, were more entrepreneurial and innovative. Similar results were found in a study by Miller, Kets de Vries, and Toulouse (1982), and they noted that chief executives with internal control pursue innovation, take more risks, and lead competitors. Brownell's study (1981) with a group of undergraduate accounting students and a group of managers from a large manufacturing company found that budgetary participation has a positive effect for people with internal locus of control. The result implies that being able to participate appeal to the internal locus individuals' sense of ownership and control over the outcome. Brownell (1981) also noted in his study that managers were far more internal than students, which leads us to ask the question about the effects of age on locus of control. One agerelated study on locus of control by Bradley and Webb (1976) found that individuals over 60 were more external and those who were $35-50$; therefore, locus of control may be affected by age. It can be explained by the fact that we are physically and emotionally affected by inevitable effects of aging, over which we have no control.

A maximizer attempts to find the best option rather than settling for 'good enough' solutions (Schwartz et al. 2002). In doing this, they exude more effort and energy during the search process. Managers who expend more energy to find the best results would be likely to expect that out- 
comes are related to their own doing rather than by happenstance. Therefore, the following hypothesis is offered.

$\mathrm{H} 2$ Managers who maximize will have a more internal locus of control than those who satisfice.

Several studies have correlated locus of control with organizational variables. Individuals having an internal locus of control are more motivated to work (Lief and Pritchard 1976), more involved in their work (Nair and Yuvaraj 2000), and more likely to emerge as leaders (Schneier 1978). Another study investigated the relationship between locus of control and managerial effectiveness using the Managerial Effectiveness Questionnaire (Gupta 1996). The data from 72 executives and managers found that those with an internal locus of control were significantly more effective than those with an external locus of control (Nair and Yuvaraj 2000). The authors note that 'since internals believe in their own skills and abilities, feel more responsible and exercise more control in situations, they are more likely to be effective managers.' (Nair and Yuvaraj 2000, 44). In line with this finding, it is expected that internality of locus of control will be significantly related to managerial effectiveness (Nair and Yuvaraj 2000):

$\mathrm{H} 3$ Managers who have an internal locus of control will be more effective than those who have an external locus of control.

Taking hypotheses 2 and 3 together suggests that locus of control may mediate the relationship between maximizing decision making style and managerial effectiveness. A manager who exudes additional effort to find the best option (maximizer) and believes that they are in control of following through on that option to produce results (internal locus of control) may provide a powerful combination for getting things done. Therefore, it is predicted that internal locus of control will mediate the relationship between maximization and managerial effectiveness:

$\mathrm{H} 4$ Locus of control will mediate the relationship between maximizing and managerial effectiveness.

\section{Methods and Results}

Data was gathered from a sample of 319 working managers in various fields including: food service, sales, entertainment, logistics, government, and healthcare. Respondents had an average of 10 years of experience as a manager and were in the age group of 21 to 78 , with a mean age of 40 . Thirty eight percent of the responding managers were female. The Managerial Effectiveness Questionnaire (Gupta 1996) was used to measure 
TABLE 1 Correlations of Key Variables

\begin{tabular}{lrrrrr}
\hline Variables & 1 & 2 & 3 & 4 & 5 \\
\hline 1. Gender & 1 & & & & \\
2. Maximization & 0.069 & 1 & & & \\
3. Locus of Control & 0.011 & $0.554^{* *}$ & 1 & & \\
4. Managerial Effectiveness & $0.116^{\star}$ & $0.460^{* *}$ & $0.564^{* *}$ & 1 & \\
5. Happiness with Position & 0.061 & $0.254^{* *}$ & $0.283^{* *}$ & $0.118^{*}$ & 1 \\
\hline NOTES ${ }^{\star} p<0.05,{ }^{* *} p<0.01$. & & & & &
\end{tabular}

managerial effectiveness. Respondents were asked to indicate how frequently they behave or act in a specific way using a five point Likert scale with ratings $(5=$ Always; $4=$ Usually; $3=$ Doubtful; $2=$ Sometimes; $1=$ never). A high score indicates high overall managerial effectiveness. This scale has shown satisfactory reliability and validity (Gupta 1996; Nair and Yuvaraj 2000). Managers were also asked how satisfied they were with their current position on a scale of $(0=$ not at all satisfied, $100=$ very satisfied). This Maximization was measured using the Maximization Tendency Scale (Diab, Gillespie, and Highhouse 2008). Example items on this scale included: (1) No matter what it takes, I always try to choose the best thing; (2) I never settle; (3) My decisions are well thought through (1 = completely disagree; $7=$ completely agree). This scale has shown satisfactory reliability and validity (Diab, Gillespie, and Highhouse 2008). A high score indicates maximizing and a low score indicates satisficing. Locus of control was measured using the Internality subscale of Levenson's (1981) Internal, Powerful Others and Chace (IPC) Scale. This scale has shown good reliability (Judge et al. 2002) and has been used to predict outcomes in a variety of samples (Levenson 1981; Judge et al. 2002). Example items included (1) When I make plans, I am almost certain to make them work. (2) My life is determined by my own actions $(1=$ strongly disagree; $7=$ strongly agree).

Multiple regression analysis was used to test the hypotheses. Gender was controlled for in the model as it was significantly correlated with managerial effectiveness. Hypothesis one investigated the relationship between maximization and managerial effectiveness. Results indicate a significant positive relationship between maximizing and managerial effectiveness $(\beta=0.45, p<0.01)$. Thus, hypothesis 1 is supported suggesting that managers who apply a maximizing decision making approach are significantly more likely to be effective than managers who apply a 


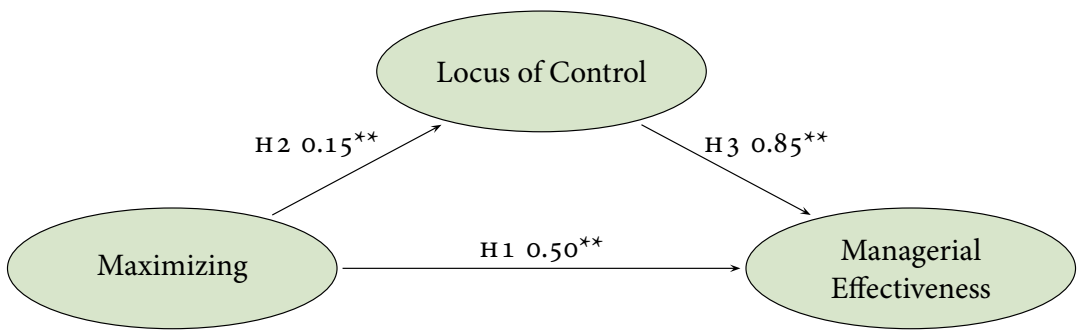

FIGURE 1 Mediation Model - Locus of Control Mediating the Relationship Between Maximizing and Managerial Effectiveness

satisficing style. Maximizers were significantly more likely to apply an internal locus of control $(\beta=0.55, p<0.01)$, suggesting support for $\mathrm{H} 2$. Results indicate that managers who have an internal locus of control are significantly more likely to be effective $(\beta=0.56, p<0.01)$, supporting H3. Preacher and Hayes (2013) mediation analysis was conducted using Process. Sobel's test indicated a significant decrease $\left(z=6.71, p<0.01, k^{2}\right.$ $=0.17)$ in the relationship between maximizing and managerial effectiveness when locus of control was added. Thus, indicating support for $\mathrm{H} 4$.

\section{Conclusions, Implications and Future Research Directions}

This study has several implications for management theory and practice. First, this study extends the existing literature on maximizing and satisficing by investigating the relationship between decision making styles (maximizing or satisficing) and managerial performance using a sample of working managers in the field. Prior studies have recognized that maximizers land better jobs post-graduation (Iyengar, Wells, and Schwartz 2006). This study extends this work by looking at the upper echelon of organizations to understand how decision making styles impact managers' performance. The results suggest that managers who maximize are significantly more effective because they spend additional time and effort to find optimal strategies. Since maximizers are more emotionally intelligent (Soltwisch and Krahnke in press), it is likely that they utilize this forward-thinking ability to build support and commitment for projects early on, making them more likely to succeed.

Interestingly, a spotlight analysis revealed that managers were significantly $(p>0.05)$ more likely to apply a maximizing decision making style than a sample of 218 college students. This suggests that those who are decision optimizing are more likely to advance through the ranks within 
their organizations. The question of whether this is the product of selfselection or performance needs to be further examines. A longitudinal field study could improve our understanding of how managers utilize this information competency to get things done by investigating managerial decisions over time.

This study also explores the role that locus of control plays in assisting maximizers to be more effective. The results suggest that maximizers are more likely to have an internal locus of control. Thus, managers who are looking for more information are also more likely to follow through on that information as they see themselves personally responsible for their own outcomes. Managers with internality of control were also more likely to be effective, replicating previous work by Nair and Yuvaraj (2000). These findings together suggest that maximizers with an internal locus of control provides a powerful recipe for managerial performance. This makes sense from a logical standpoint. Managers who spend more effort to find the 'best' option will be more likely to follow through on that option if they feel in control of their own destiny. Since implementation is so critical to success, following through on the best option will likely produce better results.

This study may open many new outlets of inquiry in the management field. For example, the length of time available to decide could be another important variable to investigate. Eisenhardt (1989) found that fast decision makers utilize more information and develop a greater amount of options than slower decision makers. Future studies could investigate whether maximizers are willing to satisfice when needed, or if they are more likely to become overwhelmed by information overload. Another interesting question is whether maximizers process information faster than satisficers? Alternatively, they may simply be willing to spend more time gathering information during the search process.

This research stream may also open new outlets to advance the literature on top management teams. What is the right combination of maximizers and satisficers among top management teams? One could guess that too many maximizers in a room may produce information overload, leading to analysis paralysis. Perhaps having a balance of maximizers and satisficers on the team offers complementary skillsets that enhance group decision making. For practitioners, understanding differences in decision making styles may provide another tool to help identify employees who are ready to take on leadership roles within the company. A maximization questionnaire could be administered to help find employees who have the 
decision-making skills necessary to be effective leaders. Although this study has taken some important first steps toward understanding how managers utilize decision-making styles to be more effective, there are likely many new and interesting opportunities for researchers to explore. Hopefully this study will open many new areas of inquiry, enhancing our understanding of what makes managers successful.

\section{References}

Adler, N. J. 200o. International Dimensions of Organizational Behavior. Cincinnati, он: South-Western.

Anderson, C. R. 1977. 'Locus of Control, Coping Behaviors, and Performance in a Stress Setting: A Longitudinal Study.' Journal of Applied Psychology 62 (4): 446-51.

Baldacchino, P., N. Tabone, J. Agius, and F. Bezzina. 2016. 'Organizational Culture, Personnel Characteristics and Dysfunctional Audit Behavior.' IUP Journal of Accounting Research and Audit Practice 15 (3): 34-63.

Bergman, A. J., J. E. Nyland, and L. R. Burns. 2007. 'Correlates with Perfectionism and the Utility of a Dual Process Model.' Personality and Individual Differences 43 (2): 389-99.

Bradley, R. H., and R. Webb. 1976. 'Age-Related Differences in Locus of Control Orientation in Three Behavior Domains.' Human Development 19 (1): 49-55.

Brownell, P. 1981. 'Participation in Budgeting, Locus of Control and Organizational Effectiveness.' The Accounting Review 56 (4): 844-60.

Chowdhury, T. G., S. Ratneshwar, P. Mohanty. 2009. 'The Time-Harried Shopper: Exploring the Differences between Maximizers and Satisficers.' Marketing Letters 20 (2): 155-67.

Cosier, R. A., and P. L. Rechner. 1985. 'Inquiry Method Effects on Performance in a Simulated Business Environment.' Organizational Behavior and Human Decision Processes 36 (1): 79-95.

Dean, J. W., and M. P. Sharfman. 1996. 'Does Decision Process Matter? A Study of Strategic Decision-Making Effectiveness.' Academy of Management Journal 39 (2): 368-92.

Deluga, R. J. 1998. 'Leader-Member Exchange Quality and Effectiveness Ratings the Role of Subordinate-Supervisor Conscientiousness Similarity.' Group and Organization Management 23 (2): 189-216.

Diab, D. L., M. A. Gillespie, and S. Highhouse. 2008. 'Are Maximizers Really Unhappy? The Measurement of Maximizing Tendency.' Judgment and Decision Making 3 (5): 364-70.

Dorfman, P. W., J. P. Howell, S. Hibino, J. K. Lee, U. Tate, and A. Bautista. 1997. 'Leadership in Western and Asian Countries: Commonalities and 
Differences in Effective Leadership Processes across Cultures.' Leadership Quarterly 8 (3): 233-74.

Eisenhardt, K. M. 1989. 'Making Fast Strategic Decisions in High-Velocity Environments.' Academy of Management Journal 32 (3): 543-76.

Forte, A. 2005. 'Locus of Control and the Moral Reasoning of Managers.' Journal of Business Ethics 58 (1-3): 65-77.

Evans, H. M. (1981). 'Internal-External Locus of Control and Word Association.' Journal of Cross-Cultural Psychology 12 (3): 372-82.

Gable, M., and F. Dangello. 1994. 'Locus of Control, Machiavellianism, and Managerial Job Performance.' The Journal of Psychology 128 (5): 599608.

Gupta, S. 1996. 'Managerial Effectiveness: Conceptual Framework and Scale Development.' Indian Journal of Industrial Relations 31 (3): 392409.

Howell, J. M., and B. J. Avolio. 1993. 'Transformational Leadership, Transactional Leadership, Locus of Control, and Support for Innovation: Key Predictors of Consolidated-Business-Unit Performance.' Journal of Applied Psychology 78 (6): 891-902.

Iyengar, S. S., R. E. Wells, and B. Schwartz. 2006. 'Doing Better But Feeling Worse Looking for the "Best” Job Undermines Satisfaction.' Psychological Science 17 (2): 143-50.

Javidan, M., and D. E. Carl. 2004. 'East Meets West: A Cross-Cultural Comparison of Charismatic Leadership Among Canadian and Iranian Executives.' Journal of Management Studies 41 (4): 665-91.

Judge, T. A., A. Erez, J. E. Bono, and C. J. Thoresen. 2002. 'Are Measures of Self-Esteem, Neuroticism, Locus of Control, and Generalized SelfEfficacy Indicators of a Common Core Construct?' Journal of Personality and Social Psychology 83 (3): 693-710.

Lai, L. 2010. 'Maximizing without Difficulty: A Modified Maximizing Scale and its Correlates.' Judgment and Decision Making 5 (3): 164-75.

Leach, J. K., E. A. Patall. 2013. 'Maximizing and Counterfactual Thinking in Academic Major Decision Making.' Journal of Career Assessment 21 (3): 414-29.

Levenson, H. 1981. 'Differentiating among Internality, Powerful Others, and Chance.' In Research with the Locus of Control Construct, edited by H. Lefcourt, 15-63. New York: Academic Press.

Lied, T. R., and R. D. Pritchard. 1976. 'Relationships between Personality Variables and Components of the Expectancy-Valence Model.' Journal of Applied Psychology 61 (4): 463-7.

Luthans, F. 2002. 'The Need for and Meaning of Positive Organizational Behavior.' Journal of Organizational Behavior 23 (6): 695-706. 
Mason, R. O., and I. I. Mitroff. 1981. 'The Metaphysics of Policy and Planning: A reply to Cosier.' Academy of Management Review 6 (4): 649-51.

Mayer, J. D., P. Salovey, D. R. Caruso, and G. Sitarenios. 2001. 'Emotional Intelligence as a Standard Intelligence.' Emotion 1 (3): 232-42.

Miller, D., M. Kets de Vries, and J. M. Toulouse. 1982. 'Top Executives Locus of Control and its Relationship to Strategy-Making, Structure, and Environment.' Academy of Management Journal 25 (2): 237-53.

Miller, D., and J. M. Toulouse. 1986. 'Strategy, Structure, CEO Personality and Performance in Small Firms.' American Journal of Small Business 15:47-62.

Mintzberg, H. 1973. 'Strategy-Making in Three Modes.' California Management Review 16 (2): 44-53.

Misumi, J. 1989. 'Research on Leadership and Group Decision in Japanese Organisations.' Applied Psychology 38:321-36.

Mueller, S. L., and A. S. Thomas. 2001. 'Culture and Entrepreneurial Potential: A Nine Country Study of Locus of Control and Innovativeness.' Journal of Business Venturing 16 (1): 51-75.

Morling, B., S. Kitayama, and Y. Miyamoto. 2002. 'Cultural Practices Emphasize Influence in the United States and Adjustments in Japan.' Personality and Social Psychology Bulletin 28 (23): 311-23.

Mostafa, M. M. 2016. 'Post-Materialism, Religiosity, Political Orientation, Locus of Control and Concern for Global Warming: A Multilevel Analysis Across 40 Nations.' Social Indicators Research 128 (3): 1273-98.

Nair, S. K., and S. Yuvaraj. 20oo. 'Locus of Control and Managerial Effectiveness.' Indian Journal of Industrial Relations 36:41-52.

Parker, A. M., W. B. De Bruin, and B. Fischhoff. 2007. 'Maximizers Versus Satisficers: Decision-Making Styles, Competence, and Outcomes.' Judgment and Decision Making 2 (6): 342-50.

Polman, E. 2010. 'Why Are Maximizers Less Happy than Satisficers? Because They Maximize Positive and Negative Outcomes.' Journal of Behavioral Decision Making 23 (2): 179-90.

Preacher, K. J., and A. F. Hayes. 2004. 's Ps and s As Procedures for Estimating Indirect Effects in Simple Mediation Models.' Behavior Research Methods 36 (4): 717-31.

Purvis, A., R. T. Howell, and R. Iyer. 2011. 'Exploring the Role of Personality in the Relationship between Maximization and Well-Being.' Personality and Individual Differences 50 (3): 370-5.

Rastogi, R., and V. Dave. 2004. 'Managerial Effectiveness: A Function of Personality Type and Organisational Components.' Singapore Management Review 26 (2): 79-87.

Rees, G. 2011. 'Japan: How resilient a nation.' Dart Center, 14 March. https://dartcenter.org/content/how-resilient-is-japan 
Rotter, J. B. 1990. 'Internal Versus External Control of Reinforcement.' American Psychological Association 45 (4): 489-93.

Schneier, C. E. 1978. 'The Contingency Model of Leadership: An Extension to Emergent Leadership and Leader's Sex.' Organizational Behavior and Human Performance 21 (2): 220-39.

Schwartz, B., A. Ward, J. Monterosso, S. Lyubomirsky, K. White, and D. R. Lehman. 2002. 'Maximizing versus Satisficing: Happiness is a Matter of Choice.' Journal of Personality and Social Psychology 83 (5): 1178-97.

Schwenk, C. R. 1988. 'The Cognitive Perspective on Strategic Decision Making.' Journal of management studies 25 (1): 41-55.

Senge, P., and K. Krahnke. 2013. 'Transcendent Empathy' In Organizing through Empathy, edited by K. Pavlovich and K. Krahnke, 185-202. New York: Routledge.

Simon, H. A. 1972. 'Theories of Bounded Rationality'. Decision and Organization 1 (1): 161-76.

Soltwisch, B. W., and K. Krahnke. In press. 'Maximizing or Satisficing Decision Making Styles and Emotional Intelligence: An Empirical Investigation.' International Journal of Business and Applied Sciences.

Youssef, C. M., and F. Luthans. 2007. Emerging Positive Organizational Behavior. Journal of Management 33 (3): 321-49. 


\title{
The Unemployment-Stock Market Relationship in South Africa: Evidence from Symmetric and Asymmetric Cointegration Models
}

\author{
Andrew Phiri \\ Nelson Mandela University, South Africa \\ phiricandrew@gmail.com
}

In this study, we examine linear and nonlinear cointegration and causal relations between unemployment and stock market returns in South Africa using quarterly data collected between 1994:Q1 and 2016:Q1. Our empirical results reveal significant cointegration effects between the time series in both linear and nonlinear models, even though both frameworks ultimately reject the notion of any causal relations between the variables. Collectively, our study rejects the notion of unemployment being a good predictor for stock market returns and neither do developments in the stock market have any effect on the unemployment rate. Such evidence advocates for weak-form efficiency in the JSE equity prices whereby unemployment data cannot help investors to predict the movement of future share prices and further suggests that policymakers cannot rely on stock market development as an avenue towards lowering the prevailingly high levels of unemployment as set in current macroeconomic policy objectives.

Key Words: stock market returns, unemployment, cointegration, causality effects, MTA R model, South Africa

JEL Classification: C13, C22, C52, E24, E 44

https://doi.org/10.26493/1854-6935.15.231-254

\section{Introduction}

The Johannesburg Stock Exchange (JSE) is the 2nd oldest stock market in Africa, the 17th largest stock exchange in the world, the sixth largest among emerging economies and the largest within the African continent, with over 400 listed companies, over 900 securities and a market capitalization of over 900 billion us dollars in 2013 (Hussan 2013). The JSE also has the largest number of cross-listed firms compared to other African stock exchanges and conducts trade on international platforms such as the London Stock Exchange (LSE), the New York Stock Exchange (NYSE), the Frankfurt Stock Exchange (FSE) and the sIX Swiss Exchange. Moreover, the JSE has recently introduced collation centres countrywide 
which allows for trades to be conducted 400 times faster and currently the number of trades is up by 57 percent, volumes are up by 4 percent and the value of trades up by almost 21 percent (Yartey 2008). Notwithstanding the relative size and increasing sophistication of the JSE, unemployment and poverty in South Africa remains one of the highest in the world due to the lingering effects of the previous Apartheid legacy. The South African government is currently embarking on macroeconomic policies such as the New Growth Path (NGP), which aims to reduce unemployment from its current figure of 25 percent to 15 percent by the year 2020. It would therefore be of great interest to policymakers and investors alike to deduce an empirical relationship between stock market development and unemployment in South Africa, with the hope that stock market returns could help foster a macroeconomic environment conducive towards lowering unemployment or that stock returns can be used as an indicator for future movements in stock returns.

Even though the current literature contends that stock market development is an important condition for economic growth in South Africa (Nyasha and Odhiambo 2015; Phiri 2015b), very little is known concerning the relationship between stock market activity and unemployment in the country. This is highly noteworthy since unemployment is traditionally known as a measure of the health of an economy and of recent has been viewed as a highly efficient predictor of stock market behaviour especially in developed stock market exchanges (Boyd, $\mathrm{Hu}$, and Jagannathan 2005).

There are two viewpoints to this debate. On one hand, unemployment can be found to granger cause stock market returns. Such evidence would violate the conventional view of the JSE being weak-form efficient (see Appiah-Kusi and Menyah 2003; Phiri 2015a) and implies that investors can base their future investment decisions on actual or expected unemployment data. On the other hand, if stock market returns are found to lead unemployment, stock market development can be thought of as a vehicle towards eradicating unemployment and poverty in the country. In also considering the historical combination of constant growth in stock returns and South Africa's high unemployment rate in postApartheid regime, it would not seem unreasonable to speculate that unemployment and stock market activity are positively correlated for the economy. Notably, South Africa's situation is similar to that of Nigeria where high stock performance has been accompanied with soaring unemployment rates (Bamidele 2015). Yet, South Africa’s situation is contra- 
dictory to that of other leading African stock exchanges such as in Mauritius (Stock Exchange of Mauritius), Egypt (Egyptian Stock exchange) and Morocco (Casablanca Stock Exchange) which have highly developed stock exchanges in combination with low unemployment rates of 7,9 and 13 percent, respectively.

Thus far, the bulk of the current empirical literature examining the relationship between unemployment and stock exchange activity is concentrated on industrialized economies (Farmer 2015 for the Us; Farsio and Fazel 2013 for the Us, China and Japan, and Fitoussi et al. 2000 for 19 OECD countries). With exception of the work of Bamidele (2015) for Nigeria, there is virtually no other empirical research existing for other African countries on the subject matter. Moreover, a majority of previous empirical works have traditionally conducted their investigations by relying on symmetric cointegration frameworks of Engle and Granger (1987) and Johansen (1991) (see Jagannathan and Wang 1993; Jagannathan, Kubota, and Takehara 1998; Farsio and Fazel 2013; Farmer 2015; Bamidele 2015). It has recently become well known that these linear cointegration frameworks have low testing power and inferior size properties in the presence of asymmetric adjustment between a pair of time series. Besides, previous empirical evidence of nonlinearity existing in the individual times series of unemployment and stock market returns data for South Africa has also been recently provided in the studies of Phiri (2014) and Phiri (2015a), respectively. Primarily motivated by this, our current study contributes to the literature by examining cointegration and causal relations between unemployment and stock market returns for South African data. In order to increase the robustness of our study we employ two empirical frameworks for our analysis; the first being the linear cointegration framework of Engle and Granger (1987) supplemented with cointegration tests proposed by Johansen (1991), and second is the momentum threshold autoregressive model of Engle and Granger (1998) and Enders and Silkos (2001). We conduct our empirical analysis on quarterly data collected post-Apartheid period of 1994:Q1 to 2016:Q1.

Against this background, we structure the remainder of the paper as follows. The next section provides a synopsis of the relationship between stock returns and unemployment in the form of a literature review. The third section of the paper focuses on stock market and unemployment developments in South Africa from a historic perspective. The research methodology is outlined in the fourth section of the paper whilst the data and the empirical results are given in the fifth section of the paper. The 
study is concluded in the sixth section in the form of policy discussions as well as avenues for future research.

\section{Literature Review}

Mainstream economy theory depicts on a strong link between stock market activity and unemployment. The capital asset price model (C A PM) as pioneered by Sharpe (1964), Lintner (1965a; 1965b), Mossin (1966) and Black (1972) as well as the discounted cash flow (DCF) model of Graham and Dodd (1934) were amongst the first frameworks used to depict a causal relation between stock prices and unemployment. Within the CAPM model, correlating movements between stock market prices and unemployment is facilitated through one or more of the following three primitive factors; (i) the risk-free rate of interest, (ii) the expected growth rate of corporate earnings and dividends, and (iii) the equity risk premium (Boyd, $\mathrm{Hu}$, and Jagannathan 2005). On the other hand, the standard DCF model equates the stock price to the discounted present value of a firm's future cash flows, which in turn is linked to the labour demand of firms through the wage curve. A number of empirical papers have provided support for an equilibrium relationship between unemployment and stock market variables based on the channels depicted in the CAPM and DCF models. For instance, the earlier studies such as Fama (1981), Chen, Roll, and Ross (1986), Geske and Roll (1983) and Mandelker and Tandon (1985) were able to demonstrate that a large number of economic and non-equity financial variables affect discount rates, the ability of firm's to generate cash flows, and future dividend payments. A latter group of studies exclusively found an equilibrium relationship between stock market returns and unemployment. Amongst these studies are the works of Jagannathan and Wang (1993), Jagannathan, Kubota, and Takehara (1998), Phelps (1999), Farsio and Fazel (2013), Farmer (2015) and Bamidele (2015).

Another theoretical proposition linking stock market prices and unemployment is based on the sectoral shift hypothesis of Lilien (1982). According to this theory, unemployment is, in part, the result of labour shifts from those sectors where relative wages are declining to those sectors were relative wages are expanding. Initially Lilien (1982) demonstrated that the dispersion of unemployment across industries was a useful proxy in explaining movements in the unemployment rate. However, Lilien's (1982) index was criticized by Abraham and Katz (1986) on the basis of being contaminated with by aggregate demand influences. Consequen- 
tially, Black (1987), Loungani, Rush, and Tave (1990), Brainard and Cutler (1993), Fourtin and Thivierge (1997) and Loungani and Trehan (1997) improved on Lilien's (1982) index by demonstrating that stock market dispersion is a much better proxy for the volume of intersectoral shifts since it gives an early signal of shocks that affect sectors differently and puts more weight on shocks that investors expect to be permanent. These developments resulted in a handful of studies investigating the effects of stock market diversion on unemployment and the evidence provided so far can at best be described as inconclusive. For instance, Dopke and Pierdzioch (2000) find that the influence of stock market diversion on output and unemployment is significant but rather small. Conversely, Chehal, Loungani, and Trehal (2010) find that stock market dispersion leads to unemployment over the short-run but not over the long-run. On the other hand, Chen et al. (2011) find that stock market dispersion accounts for a significant portion of both long-term and short-term us unemployment even after controlling for aggregate factors, such that an increase in stock market dispersion leads to an increase in the unemployment level. Furthermore, Jorgensen, Li, and Sadka (2012) find a positive but weak effect from us earnings dispersion to unemployment for the data and this result is similar to that obtained in Dopke and Pierdzioch (2000). And even more recently, Kalay, Nallareddy, and Sadka (2015) found that us earnings dispersion is associated with higher unemployment and lower industrial production during recession periods, whereas during expansions dispersion has an insignificant impact on unemployment and production.

The final theoretical propositions linking unemployment to stock returns can be attributed to two framework's, the first being Blanchard's (1981) Is-LM model and the second being the Diamond-MortensenPissarides (DMP) model of Diamond (1982), Mortensen and Pissarides (1994) and Pissarides (1985). On one hand, Blanchard (1981) develop an IS-LM model which in equilibrium, macroeconomic news can be good or bad depending on the state of the economy. Cutler, Poterba, and Summers (1988), Orphanides (1992), McQueen and Roley (1993), Veronesi (1999), Boyd, Hu, and Jagannathan (2005), Cakan (2012), Krueger and Fortson (2003), and Cakan, Doytch, and Upadhyaya (2015) all offer support on the notion that stock returns react to unemployment news. On the other hand, the DMP model specifically relates unemployment to job-creation incentives. When the incentive for job creation falls, the labour market slackens and unemployment increases. The DMP model has been 
recently used as a theoretical workhorse to demonstrate the effects of unemployment on the stock market. For instance, Mukoyama (2009) demonstrate that discount factors of either entrepreneurs or workers are procyclical and these procyclical discount factors can magnify labour market volatility and thus influence unemployment. In particular, the author discovers that entrepreneurs discount factors exerts a larger influence on labour market volatilities compared to the discount factors for workers. In a different study, Kuehn, Petrosky-Nadeau, and Zhang (2012) build a general-equilibrium model, which combines a DMP labour market with full treatment of financial markets. In the model, volatility in allocations resulting from amplified productivity shocks in the labour market causes financial volatility, which then widens the equity premium in financial markets. The authors demonstrate that equity premium is countercyclical and can be predicted by labour market tightness. Furthermore, Hall (2014) use a DMP labour market to show that discount rate is the driving force of unemployment such that stock market falls during recessionary periods because the discount rate rises. However, the author is unable to account for why the discount rate falls so much during recessionary periods like the 2009 global recessionary period. Meanwhile, Kilic and Wachter (2015) develop a model with a DMP labour market with an ad-hoc sticky-wage specification as a means of further investigating the underlying force behind the cyclical behaviour and unemployment and vacancies in relation to equity markets. The authors find that during rare disaster events such as the global recession period, high-unlevered equity premium is the source of labour and stock market volatility, which simultaneously lowers stock market valuation and rises unemployment. Finally, Miao, wang, and Xu (2016) introduce credit constraint within a DMP labour market, which produces multiple equilibria positions. In one equilibrium, there exists bubble in the stock market, which relaxes credit constraints and allows firms to increase investment and hire more workers. However, when the bubble bursts credit constraints tighten causing firms to decreasing investment and cut workers hence creating unemployment.

\section{Stock Market and Unemployment Developments in South Africa: A Post-Apartheid Synopsis}

From a historical perspective, both stock market returns and the unemployment rate in the post-apartheid era appear to have been more-or-less positively correlated, with increases in stock market activity appearing 
to go hand-in-hand with increases in the unemployment rate. Following South Africa's democratic transition of 1994, unemployment in the country averaged just above 16 percent and at this time JSE stock returns averaged slightly over 2 percent. In 1994, the JSE proposed amendments to national government, which were designed to improve the efficiency and the liquidity of the stock exchange. On the other hand, fiscal authorities implemented two policy programmes; firstly the Reconstruction and Development Programme (RDP) in 1994, and then secondly the Growth, Employment and Redistribution (GEAR) programme in 1996. The later programme was seen as an upgrade of the former and aimed to specifically create 400 ooo new jobs every year through various public works programmes. However, between 1996 and 1998, unemployment had risen from 19 percent to just under 26 percent whilst at the same time JSE market returns increased from 2.5 percent to 3.5 percent. According to Von Fintel and Burger (2014), this sharp increase in unemployment in early post-Apartheid period is a result of long-run generational changes in which older 'more-employable' generations were exiting the labour market whilst the younger generation entered the labour market with a greater probability of remaining unemployed and this created a new high unemployment equilibrium. Improvements experienced in stock market returns during the 1996 to 1998 period can be attributed to (i) the introduction of the electronic trading system, the JET system, which was an upgrade from the previous outcry system; (ii) the launching of the realtime stock exchange news service (SENS) which enhanced transparency and investor confidence and (iii) the opening of trading to foreign nationals. Collectively, this resulted in a drastic increase in stock trades volumes and market liquidity.

However, following the Asian financial crisis in 1998, stock prices returns in South Africa averaged -0.7 percent between 1998 and early 1999, and then picked up to 3.5 percent in late 1999. In 2001, the JSE entered into an agreement with the LSE and in 2002 began trading on the LSE using the LSE stock exchange electronic trading system (SETS). This was accompanied with exceptional stock market performance with returns averaging over 4 percent between 2001 and 2003 except for the period immediately following the September 11 attacks on the World Trade Center, when the JSE experienced a slump averaging -0.45 percent in stock returns. Also in the aftermath of the $9 / 11$ event, South Africa experienced her worst unemployment rates, averaging a record-high 30 percent in 2002, thus ranking it as the 5 th highest in the world. Further contributing 
to South Africa's woes was the shrinking mining sector, which further exacerbated the already increasing unemployment rates. In 2004, the GEAR policy programme was phased out and ultimately replaced by Accelerated and Growth Initiative for South Africa (ASGISA). This government programme was mandated to halve unemployment by the year 2014 mainly through the vehicle of job creation. Unemployment rates fell from averages of 28 percent to 21 percent between 2004 and 2007 , which partially reflected the implementation of the ASGISA programme. On the other hand, stock prices were on an upward trend from 2003 up until early 2006 averaging 2 percent returns. In 2007 , the JSE experienced a significant shift in her trading mechanism when the LSE leased yet another trading platform to JSE, the JSE TradeElect trading system. However, the collapse of Lehman Brothers in September 2008 eventually took a toll on the South African economy. During the period of 2007 to 2009, market return averages fell from 1.7 percent to -3 percent and unemployment increased from 21 to 25 percent with over 1 million jobs being lost during the recessionary period of 2009.

Nevertheless, the JSE began to recover from the recession in late 2009 averaging 1.9 percent in stock returns whilst unemployment slightly decreased to an average rate of 24 percent. In 2010, government announced the New Growth Path (NGP) programme, which set explicit goals of creating 5 million jobs and reducing unemployment to 15 percent by 2030 . However, between 2010 and 2013 unemployment and stock market returns both remained more-or-less at steady levels averaging 25 percent and 1.2 percent respectively during this period. In 2013, the JSE decided to shift the trading platform from London back to Johannesburg under a new trading platform, the Millennium exchange-trading platform. It is under this platform that the JSE ushered in collation facilities, which increased transactions by almost 400 times faster than the previous TradeElect system. This consequentially resulted in stock returns increasing to rates as high as 6 percent in 2015. On the other hand, government introduced the national development plan (NDP) in 2013 and this programme is working on a long-term plan to reduce poverty and eliminate inequality by 2030 through sectoral employment programmes. Nevertheless, unemployment has not improved since then and is currently averaging 25.1 percent thus ranking the country as having the eighth highest unemployment rate in the world. Figure 1 presents a graphical depiction of the seemingly positive co-movement between JSE stock market prices and unemployment in the post-Apartheid era. 


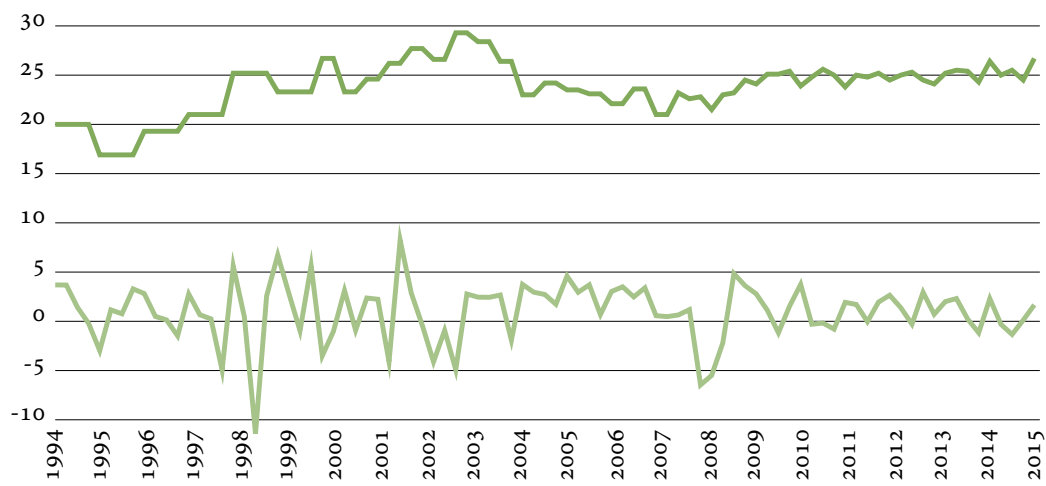

FIGURE 1 JSE Stock Returns (Light) and Unemployment (Dark) (1994-2015)

\section{Empirical Framework}

\section{LINEAR COINTEGRATION MODEL}

Since it is well known that both unemployment and stock returns are endogenous variables, we base our empirical framework on the premise of specifying two long-run bivariate regression equations. Under the first regression, stock returns is set-up as the dependent variable, i.e.

$$
s m r_{t}=\alpha_{t}+\beta \text { Buemp } t_{t}+e_{t},
$$

where $s m r_{t}$ are stock market returns, unemp $p_{t}$ is the unemployment rate and $e_{t}$ is the long-run regression error term. Under the second regression, unemployment is specified as the dependent variable, i.e.

$$
\text { unempt } \alpha_{t}=\alpha_{t}+\beta s m r_{t}+e_{t} .
$$

According to Engle and Granger (1987), any long-run regression which is estimated for a pair of time series variables will produce spurious results if the times series are not found to be cointegrated over time. Therefore, Engle and Granger (1987) suggest that cointegration within the system of equations can be validated if the individual time series are first difference stationary (i.e. integrated of order I(1)) and the cointegration residuals are found to be levels stationary (i.e. integrated of order I(o)) such there exists a cointegration vector comprising of a linear combination of the time series. Furthermore, the residuals of the cointegration vector can be normalized for the time series through an error correction model (ECM) which measures the deviation of the series from its steady-state equilibrium. In its simplest form, a bi-variate error correction model (ЕС tween the two time series, $s m r_{t}$ and unemp $p_{t}$, assumes the following functional form: 


$$
\frac{\Delta s m r_{t}}{\Delta u n e m p_{t}}=\gamma e c t_{t-1}+\sum_{i=1}^{p} \alpha \Delta s m r_{t-i}+\sum_{i=1}^{p} \beta \Delta u n e m p_{t-i}+\mu_{t},
$$

where $e c t_{t-1}$ is the error correction term of the time series towards its long-run equilibrium and the coefficients $\alpha$ and $\beta$ measure the short-run effects of the time series variables on the dynamic model. Granger causality can further facilitated under the ЕС $\mathrm{M}$ framework. In particular, $s m r_{t}$ granger cause unemp $p_{t}$ if the $\alpha$ coefficients are found to be significantly different from zero whereas unemp $p_{t}$ granger cause $s m r_{t}$ if the $\beta$ coefficients are significantly different from zero.

\section{THRESHOLD COINTEGRATION MODEL}

Even though Engle and Granger's (1987) cointegration procedure is usually appraised for it's computational ease, it has come under severe criticism by the likes of Enders and Granger (1998) and Enders and Silkos (2001), who demonstrate that the conventional linear cointegation framework exhibits low power and poor size properties in the presence of asymmetric adjustment. As a means of circumventing this issue, Enders and Silkos (2001) allow the residual deviations $\left(\xi_{t i}\right)$ of the long-run cointegration regression to behave as threshold processes. In particular, these authors propose two variants of the threshold process. The first process is the TAR model, which captures deep movements in the equilibrium errors and is specified as follows:

$$
e_{t}=\rho_{1} e_{t}\left(e_{t}<\tau\right)+\rho_{2} e_{t}\left(e_{t} \geq \tau\right)+v_{t} .
$$

The second process is the MTAR and is designed to capture sharp movements in the equilibrium errors:

$$
e_{t}=\rho_{1} e_{t}\left(\Delta e_{t}<\tau\right)+\rho_{2} e_{t}\left(\Delta e_{t}<\tau\right)+v_{t},
$$

where $\tau$ is unknown threshold level which is estimated using the minimization criterion proposed by Hansen (2000), $\rho_{1}$ measures asymmetric adjustment when the equilibrium error is below its threshold and $\rho_{2}$ measures asymmetric adjustment when the equilibrium error is below its threshold. For both TAR and MTAR versions of the model, Enders and Silkos (2001) advice on the testing of two hypothesis, namely, for cointegration relations between the time series and then for asymmetric cointegration relations. The null hypothesis of no cointegration is given as $\mathrm{H}_{10}: \rho_{1}=\rho_{2}$ and is tested against the alternative of cointegration amongst the variables (i.e. $\mathrm{H}_{11}: \rho_{1} \neq \rho_{2}$ ) using a standard $F$-test denoted as $\Phi$. If the null hypothesis of no cointegration is rejected, then one can proceed to further test for the null hypothesis of linear cointegration (i.e. 
$\mathrm{H}_{20}: \rho_{1}=\rho_{2}=\mathrm{o}$ ) against the alternative of asymmetric cointegration $\left(\mathrm{H}_{21}: \rho_{1} \neq \rho_{2} \neq \mathrm{O}\right)$ using a modified $F$-test denoted as $\Phi^{\star}$. Once the null hypothesis linear cointegration is rejected in favour of asymmetric cointergation, then corresponding threshold error correction (TEC) models can be specified as follows:

$$
\begin{aligned}
& \frac{\Delta s m r_{t}}{\Delta u n e m p_{t}}=\gamma_{1} e c t_{t-1}\left(e c t_{t}<\tau\right)+\sum_{i=1}^{p} \alpha \Delta s m r_{t-i}+\sum_{i=1}^{p} \beta \Delta u n e m p_{t-i} \\
& +\left\{\gamma_{2} e c t_{t-1}\left(e c t_{t} \geq \tau\right)+\sum_{i=1}^{p} \alpha \Delta s m r_{t-i}\right. \\
& \left.+\sum_{i=1}^{p} \beta \Delta u n e m p_{t-i}\right\}+v_{t} \\
& \frac{\Delta s m r_{t}}{\Delta u n e m p_{t}}=\gamma_{1} e c t_{t-1}\left(e c t_{t}<\Delta \tau\right)+\sum_{i=1}^{p} \alpha \Delta s m r_{t-i}+\sum_{i=1}^{p} \beta \Delta u n e m p_{t-i} \\
& +\left\{\gamma_{2} e c t_{t-1}\left(e c t_{t} \geq \Delta \tau\right)+\sum_{i=1}^{p} \alpha \Delta s m r_{t-i}\right. \\
& \left.+\sum_{i=1}^{p} \beta \Delta u n e m p_{t-i}\right\}+v_{t} .
\end{aligned}
$$

Regressions (7) and (8) are formally known as the TAR-TEC and MTARTEC regressions, respectively. Based on these threshold error correction (TEC) regressions, two main sets of hypothesis can be tested for. Firstly, the null hypothesis of no asymmetric error correction model (i.e. $\left.\mathrm{H}_{30}: \gamma_{1} \neq \gamma_{2}\right)$ can be tested against the alternative of threshold error correction model (i.e. $\mathrm{H}_{31}: \gamma_{1}=\gamma_{2}$ ). Secondly, the direction of causality amongst the time series can be evaluated by testing whether the coefficient values of $\Delta s m r_{t-i}$ and $\Delta u n e m p_{t-i}$ are significantly different from zero. In particular, the null hypothesis that $s m r_{t}$ does not granger cause unemp $_{t}$ is tested as $\mathrm{H}_{40}: \alpha_{i}=\mathrm{o}$ whereas the null hypothesis that unemp $p_{t}$ does not granger cause $s m r_{t}$ is tested as $\mathrm{H}_{50}: \beta_{i}=0$. The aforementioned granger tests are facilitated through $F$-tests.

\section{Empirical Analysis}

\section{DATA AND UNIT ROOT TESTS}

Our empirical analysis makes use of quarterly time series data of percentage change in the total share prices for all shares in South Africa 
TABLE 1 Unit Root Test Results

\begin{tabular}{|c|c|c|c|c|}
\hline \multirow[t]{3}{*}{ Time series } & \multicolumn{4}{|c|}{ Unit root test } \\
\hline & \multicolumn{2}{|l|}{$s p$} & \multicolumn{2}{|c|}{ ers } \\
\hline & $\hat{\tau}_{\tau}$ & $\hat{\rho}_{\tau}$ & Constant & Trend \\
\hline$s m r_{t}$ & $\begin{array}{l}-2.58 \\
(7.12)^{*}\end{array}$ & $\begin{array}{c}-8.47 \\
(205.09)^{\star}\end{array}$ & $\begin{array}{c}-2.47 \\
(-6.37)^{\star}\end{array}$ & $\begin{array}{c}-3.18 \\
(-6.45)^{*}\end{array}$ \\
\hline unemp $_{t}$ & $\begin{array}{l}-2.13 \\
(6.89)^{*}\end{array}$ & $\begin{array}{c}-8.73 \\
(12.54)^{*}\end{array}$ & $\begin{array}{c}-1.16 \\
(-4.88)^{\star}\end{array}$ & $\begin{array}{l}-2.05 \\
(-4.11)^{\star}\end{array}$ \\
\hline
\end{tabular}

NOTES ${ }^{\star} 1 \%$ significance level. Test statistics for first differences provided in parentheses.

and the unemployment rate for people aged 15 to 64 years old which is collected from 1994:Q1 to 2016:Q1 from the Federal Reserve Economic Data (FRED) online database. All analysis is performed on the raw data and we do not employ any transformations on the time series. As a preliminary step towards our cointegration analysis, we firstly test the time series for unit roots. Since it is well known that conventional unit root tests such as the ADF and PP tests suffer from distortions when the data generating process is close to a unit root, we opt to rely on the so-called 'second-generation' unit root tests of Schmidt and Phillips (1992) as well as that of Elliot, Rothenberg, and Stock (1996). The Schmidt and Phillips (1992) tests have been performed with $r$ and $p$ statistics whereas the Elliot, Rothenberg, and Stock (1996) DF-GLS tests are performed with a constant and a trend. The results of the performed unit root tests on the time series variables are recorded in table 1 and show that in their level none of the test statistics for either time series variables is able to reject the null hypothesis of a unit root at a 1 percent level of significance. However, in their first differences all test statistics manage to reject the unit root hypothesis for all the time series. Evidently, our empirical results verify that both the stock market returns and unemployment variables are integrated of order I(1) which is a preliminary condition for cointegration.

\section{LINEAR COINTEGRATION ANALYSIS}

In light of verifying that both stock market returns and the unemployment rate are first difference stationary variables, we proceed to test for linear cointegration effects between the time series variables. The number of cointegration vectors $(r)$ within the system of variables is examined through two likelihood ratio tests proposed by Johansen (1991). The first test is the lambda-maximum test which tests the null hypothesis that the 
TABLE 2 Maximum Eigen and Trace Cointegration Test Results

\begin{tabular}{llrrrr}
\hline $\mathrm{H}_{\mathrm{o}}$ & $\mathrm{H}_{1}$ & $J_{\max }$ & $99 \%$ c.v. & $J_{\text {trace }}$ & $99 \%$ c.v. \\
\hline \multicolumn{2}{l}{ With a constant } & & & & \\
$r \geq 1$ & $r=1(r \geq 2)$ & 4.59 & 12.91 & 4.09 & 11.65 \\
$r \geq 0$ & $r=\mathrm{o}(r \geq 1)$ & 35.30 & 20.20 & 39.39 & 23.52 \\
\hline With a trend & & & & & \\
$r \geq 1$ & $r=1(r \geq 2)$ & 4.76 & 16.26 & 4.76 & 16.26 \\
$r \geq 0$ & $r=\mathrm{o}(r \geq 1)$ & 36.86 & 23.65 & 41.62 & 30.45 \\
\hline
\end{tabular}

NOTES Lag length for the maximum Eigen and trace tests have is $3 \mathrm{~s}$ determined by the AIC and BIC.

cointegration rank is equal to $r$ against the alternative that the cointegration rank is equal to $r+1$. The test statistic used is a maximum generalized eigenvalue, which is computed as:

$$
J_{\text {max }}=-T \operatorname{In}\left(1-\hat{\lambda}_{i}\right),
$$

where $T$ is the sample size and $\hat{\lambda}_{i}$ is the $i$ th largest canonical correlation. The second cointegration test is the trace test, which tests the null hypothesis that the cointegration matrix is equal to $r$ against an alternative of the cointegration rank being equal to $k$. The test statistic used is the trace of a diagonal matrix of generalized eigenvalue and is computed as:

$$
J_{\text {trace }}=-T \sum_{r+1}^{n} \operatorname{In}\left(1-\hat{\lambda}_{i}\right)
$$

Two versions of aforementioned cointegration tests have been performed on our data, the first with a drift and the second with a trend, with the results being reported in table 2 .

As can be observed from the cointegration test results reported in table 2, the computed Eigen and Trace statistics advocate for at least one cointegration vector between the time series variables. In particular, when testing the null of no cointegration effects for cointegration rank $r=0$ inclusive of a constant, we obtain $J_{\max }$ and $J_{\text {trace }}$ statistics values of 35.30 and 39.39, respectively. Notably these values exceed their corresponding critical values at all levels of significance hence rejecting the null hypothesis of no cointegration vectors. Similarly, when the testing procedure is inclusive of a trend, the $J_{\max }$ and $J_{\text {trace }}$ statistics exceed their critical values at all significance levels, with values of 36.86 and 41.62, respectively. However, in proceeding to test the null hypothesis of one cointegration relation against the alternative of two cointegration vectors, we obtain 
TA B LE 3 Long-Run Regression Results and Linear Error Correction Model Analysis

\begin{tabular}{|c|c|c|c|c|}
\hline & \multicolumn{2}{|l|}{$s m r_{t}$} & \multicolumn{2}{|l|}{ unempt } \\
\hline$\Psi_{\mathrm{o}}$ & \multicolumn{2}{|l|}{$0.72(0.81)$} & \multicolumn{2}{|c|}{$23.72(0.00)^{\star * *}$} \\
\hline \multirow[t]{2}{*}{$\Psi_{1}$} & \multicolumn{2}{|c|}{$0.02(0.88)$} & \multicolumn{2}{|c|}{$0.01(0.88)$} \\
\hline & $\Delta s m r_{t}$ & $\Delta u e m p_{t}$ & $\Delta s m r_{t}$ & $\Delta u n e m p_{t}$ \\
\hline$\Delta s m r_{t-1}$ & $\begin{array}{c}0.21 \\
(0.31)\end{array}$ & $\begin{array}{c}0.06 \\
(0.49)\end{array}$ & $\begin{array}{l}-0.57 \\
(0.00)^{* * *}\end{array}$ & $\begin{array}{c}0.03 \\
(0.54)\end{array}$ \\
\hline$\Delta s m r_{t-2}$ & $\begin{array}{c}0.03 \\
(0.84)\end{array}$ & $\begin{array}{c}0.06 \\
(0.38)\end{array}$ & $\begin{array}{l}-0.51 \\
(0.00)^{* * *}\end{array}$ & $\begin{array}{c}0.04 \\
(0.37)\end{array}$ \\
\hline$\Delta s m r_{t-3}$ & $\begin{array}{c}0.09 \\
(0.44)\end{array}$ & $\begin{array}{l}-0.01 \\
(0.81)\end{array}$ & $\begin{array}{l}-0.20 \\
(0.08)^{*}\end{array}$ & $\begin{array}{c}-0.02 \\
(0.62)\end{array}$ \\
\hline$\Delta u n e m p_{t-1}$ & $\begin{array}{l}-0.05 \\
(0.87)\end{array}$ & $\begin{array}{c}-0.16 \\
(0.17)\end{array}$ & $\begin{array}{c}0.08 \\
(0.81)\end{array}$ & $\begin{array}{l}-0.10 \\
(0.40)\end{array}$ \\
\hline$\Delta u n e m p_{t-2}$ & $\begin{array}{l}-0.62 \\
(0.03)^{*}\end{array}$ & $\begin{array}{l}-0.17 \\
(0.13)^{*}\end{array}$ & $\begin{array}{l}-0.65 \\
(0.04)\end{array}$ & $\begin{array}{c}-0.13 \\
(0.27)\end{array}$ \\
\hline$\Delta u n e m p_{t-3}$ & $\begin{array}{l}-0.38 \\
(0.18)\end{array}$ & $\begin{array}{l}-0.13 \\
(0.26)\end{array}$ & $\begin{array}{l}-0.30 \\
(0.35)\end{array}$ & $\begin{array}{c}-0.09 \\
(0.45)\end{array}$ \\
\hline$e c t_{t-1}$ & $\begin{array}{l}-1.03 \\
(0.00)^{\star * *}\end{array}$ & $\begin{array}{l}-0.05 \\
(0.61)\end{array}$ & $\begin{array}{c}0.13 \\
(0.38)\end{array}$ & $\begin{array}{l}-0.10 \\
(0.07)^{x}\end{array}$ \\
\hline$R^{2}$ & 0.46 & 0.08 & 0.46 & 0.08 \\
\hline DW & $\begin{array}{c}1.96 \\
(0.77)\end{array}$ & $\begin{array}{c}1.88 \\
(0.58)\end{array}$ & $\begin{array}{c}1.96 \\
(0.77)\end{array}$ & $\begin{array}{c}1.88 \\
(0.58)\end{array}$ \\
\hline LB & 0.06 & 0.79 & 0.06 & 0.79 \\
\hline $\mathrm{H}_{\mathrm{o} 1}: j s e \rightarrow$ unemp & & $0.37(0.55)$ & & \\
\hline $\mathrm{H}_{\mathrm{o} 2}:$ unemp $\rightarrow$ jse & & $0.26(0.61)$ & & \\
\hline
\end{tabular}

NOTES

$J_{\text {max }}$ and $J_{\text {trace }}$ statistics of 4.59 and 4.09, respectively, when the test is performed with a constant, whereas both $J_{\max }$ and $J_{\text {trace }}$ statistic produce a similar value of 4.76 when the test is performed with a trend. We note that these statistics, performed with a constant and a trend, fail to reject the null of one cointegration relation at all significance levels. Nevertheless, in view of verifying one cointegration relation, we conclude on unanimous evidence of linear cointegration existing among the variables and that the estimation of long-run and short-run relations can be conducted without concern of obtaining spurious results. We therefore proceed to estimate the long-run regression equations (1) and (2) and their corresponding error correction model equations (3) and (4) for the time se- 
ries variables and report the results of this empirical exercise in table 3.

In referring to our long-run regression estimates, the slope regression coefficients are reported in the top portion of table 3 . We particularly find that when stock returns is the dependent variable we obtain an estimate of 0.02 whereas when unemployment is the dependent variable the coefficient estimate is 0.01 . However, based on the corresponding $p$-values these estimates are rendered as being insignificant. The error correction terms, as report in the middle of table 3 , produce a significant negative estimate of -1.03 when stock market returns is the dependent variable and the driving variable in the system. This implies that 103 percent of deviations are corrected each quarter when shock is induced on stock returns. On the other hand, when unemployment is both the dependent variable and the driving variable in the system the error correction term produces a significant negative coefficient of -0.10 , which implies that 10 percent of deviations from the steady state are corrected each quarter. Furthermore, we note the lack of significant short run effects in the error correction models hence implying there are no short-term equilibrium reverting effects between stock returns and unemployment. In finally turning to our causality results, as reported at the bottom of table 3, we find $F$-values of 0.37 when testing the null that stock returns does not ganger cause unemployment and a $F$-value of 0.26 when testing the other null hypothesis that unemployment does not granger cause stock returns. Based on the $p$ values associated with both test statistics, we are unable to reject both null hypotheses thus implying that there are no causality effects between both time series variables. We note that this result in line with that obtained in Farsio and Fazel (2013) who also find that no causality effects between unemployment and stock returns for the more developed economies of the USA, Chain and Japan.

\section{THRESHOLD REGRESSION ANALYSIS}

Having examined linear cointegration effects between the time series, we now turn our attention towards possible nonlinear cointegration relations between the variables. To do so, we firstly perform the two threshold cointegration tests of Enders and Siklos (2001). To recall, the first test is testing the null hypothesis of no cointegration effects against the alternative of linear cointegration effects using the $\Phi$ statistics whereas the second test is testing the null hypothesis of linear cointegation against the alternative of threshold cointegration using the $\Phi^{\star}$ statistic. As reported in the top panel of table 5, we find that the $\Phi$ statistics produces values of 26.36 and 25.38 
for the TAR and MTAR regressions, respectively when stock returns variable is employed as the endogenous variable in the system. Notably, these statistics indicate that we must reject the null of no cointegration at all significance levels. On the other hand, we obtain weaker $\Phi$ statistic values of 3.40 and 2.79 for the TAR and MTAR regressions, respectively, when unemployment is the dependent variable and these statistics manage to reject the null of no cointegration at a 10 percent significance level. In proceeding to test for threshold cointegration effects we observe that the $\Phi^{*}$ statistic produces values of 6.05 and 4.77 for the TAR and MTAR regressions, respectively when stock returns is the dependent variable whereas we find values of 1.94 and 0.78 for TAR and MTAR regressions, respectively, when unemployment is the dependent variable. Both $\Phi^{*}$ statistics for the stock market regressions reject the linearity hypothesis at a 10 percent level of significance whereas both statistics under the unemployment regressions fail to reject the linearity hypothesis.

Considering that we find significant TAR and MTAR cointegration effects for the stock market returns regressions, we then exclusively estimate the associated long-run regression coefficients and the threshold error correction terms for these particular regressions. In similarity to the long-run coefficient obtained under our linear cointegration analysis, we find a positive yet insignificant estimate of 0.72 . In turning to the estimates of our threshold error terms, we report significant estimates of -1.13 and -0.59 for $\rho_{1}$ and $\rho_{2}$, respectively under the TAR model whereas we also obtain significant estimates of -1.05 and -0.74 for $\rho_{1}$ and $\rho_{2}$ for the MTAR specification. Notably, these estimates satisfy the asymmetric equilibrium convergence condition $\rho_{1}, \rho_{2}<0$, which, according to Enders and Silkos (2001) ensures that the equilibrium error terms are stationary and yet exhibit asymmetric behaviour. In paying closer attention to the threshold equilibrium error term estimates we further note that for both TAR and MTAR specifications, $\rho_{2}<\rho_{1}$, hence implying that positive deviations from the equilibrium are corrected quicker than negative deviations. Interpretively, our results imply that the variables revert to their steady state position by 113 percent in the case of a negative deviation and by 59 percent for a positive deviation, for the case of the TAR model. On the other hand, equilibrium reversion occurs by 105 percent for negative deviations and by 74 percent for positive deviations when dictated by mта R dynamics. Overall, this implies that negative shocks, commonly in the form of adverse external shocks, to either stock returns or the unemployment rate are quickly absorbed in the system in com- 
TABLE 4 TAR and mTAR Cointegration Tests and Estimates

\begin{tabular}{lccccc}
\hline & $s m r_{t}$ & & & unempt & \\
\cline { 2 - 3 } \cline { 5 - 6 } & TAR & MTAR & & TAR & MTAR \\
\hline $\mathrm{H}_{\mathrm{OO}}: \rho_{1}=\rho_{2}=0$ & 26.36 & 25.38 & & 3.40 & 2.79 \\
\hline$\Phi^{*}$ & $(0.00)^{* * *}$ & $(0.00)^{* * *}$ & $(0.04)^{*}$ & $(0.07)^{*}$ \\
$\mathrm{H}_{\mathrm{O} 1}: \rho_{1}=\rho_{2}$ & 6.05 & 4.77 & 1.94 & 0.78 \\
\hline$\tau$ & $(0.01)^{*}$ & $(0.03)^{*}$ & $(0.17)$ & $(0.38)$ \\
\hline$\Psi_{\mathrm{O}}$ & 1.58 & 1.82 & 2.72 & 0.04 \\
\hline$\Psi_{1}$ & 0.72 & 0.72 & & \\
\hline$\rho_{1}$ & $(0.81)$ & $(0.81)$ & & \\
\hline$\rho_{2}$ & 0.02 & 0.02 & & \\
& $(0.88)$ & $(0.88)$ & & \\
\hline
\end{tabular}

NOTES $p$-values are reported in parentheses. ${ }^{* *},{ }^{* *}$ and ${ }^{\star}$ represent $1 \%, 5 \%$ and $10 \%$ significance levels, respectively.

parison to positive shocks, which may be in the form of government and other regulatory policies.

In light of evidence supporting asymmetric adjustment existing between JSE stock returns and the unemployment rate, we present the threshold error correction (TEC) test and model estimates of the TAR and MTAR variants using the consistent threshold estimates obtained in our previous threshold cointegration regressions. In firstly testing the null hypothesis of no threshold error correction effects against the alternative of threshold error correction effects, we find insignificant statistics of 1.45 and 1.41, respectively, for TAR and MTAR variants of the TEC specifications when unemployment is the driving variable in the system. This result implies that there are no significant TEC effects when unemployment is the driving variable in the system. Conversely, when stock returns is the driving variable in the system, the statistics of 4.25 and 2.65, respectively obtained for the TAR and MTAR models are significant and hence imply that we cannot reject the null hypothesis of TEC effects. Moreover, when stock returns is the driving variable in the system we find a negative and significant error correction terms of -1.18 and -1.11 respectively for the TAR and MTAR models in the lower regime of the TEC specifications. On the other hand, the error correction terms for the TAR 
TAB LE 5 Threshold Error Correction Tests and Estimates

\begin{tabular}{|c|c|c|c|c|}
\hline & \multicolumn{2}{|l|}{ TAR } & \multicolumn{2}{|l|}{ MTAR } \\
\hline & $\Delta s m r_{t}$ & $\Delta u n e m p_{t}$ & $\Delta s m r_{t}$ & $\Delta u n e m p_{t}$ \\
\hline$\Delta s m r_{t-1}^{-}$ & $\begin{array}{c}0.11 \\
(0.63)\end{array}$ & $\begin{array}{c}0.04 \\
(0.67)\end{array}$ & $\begin{array}{c}0.07 \\
(0.77)\end{array}$ & $\begin{array}{c}0.04 \\
(0.70)\end{array}$ \\
\hline$\Delta u n e m p_{t-1}^{-}$ & $\begin{array}{c}0.43 \\
(0.36)\end{array}$ & $\begin{array}{l}-0.06 \\
(0.75)\end{array}$ & $\begin{array}{c}0.42 \\
(0.38)\end{array}$ & $\begin{array}{l}-0.05 \\
(0.78)\end{array}$ \\
\hline$e c t_{t-1}^{-}$ & $\begin{array}{l}-1.18 \\
(0.00)^{\star * *}\end{array}$ & $\begin{array}{c}-0.04 \\
(0.58)\end{array}$ & $\begin{array}{l}-1.11 \\
(0.00)^{\star \star \star}\end{array}$ & $\begin{array}{l}-0.04 \\
(0.62)\end{array}$ \\
\hline$\Delta s m r_{t-1}^{+}$ & $\begin{array}{c}0.15 \\
(0.33) \\
\end{array}$ & $\begin{array}{c}-0.01 \\
(0.88) \\
\end{array}$ & $\begin{array}{c}0.17 \\
(0.28) \\
\end{array}$ & $\begin{array}{c}-0.01 \\
(0.87)\end{array}$ \\
\hline$\Delta u n e m p_{t-1}^{+}$ & $\begin{array}{l}-0.11 \\
(0.79)\end{array}$ & $\begin{array}{l}-0.13 \\
(0.46)\end{array}$ & $\begin{array}{c}-0.02 \\
(0.97)\end{array}$ & $\begin{array}{c}-0.11 \\
(0.55)\end{array}$ \\
\hline$e c t_{t-1}^{+}$ & $\begin{array}{l}-0.60 \\
(0.01)^{* *}\end{array}$ & $\begin{array}{c}0.09 \\
(0.30)\end{array}$ & $\begin{array}{l}-0.57 \\
(0.03)^{*}\end{array}$ & $\begin{array}{c}0.12 \\
(0.26)\end{array}$ \\
\hline$R^{2}$ & 0.46 & 0.04 & 0.45 & 0.04 \\
\hline DW & $\begin{array}{c}1.89 \\
(0.63)\end{array}$ & $\begin{array}{c}2.03 \\
(0.88)\end{array}$ & $\begin{array}{c}1.93 \\
(0.77)\end{array}$ & $\begin{array}{c}2.05 \\
(0.86)\end{array}$ \\
\hline LB & 0.01 & 0.97 & 0.01 & 0.97 \\
\hline $\mathrm{H}_{30}: \gamma_{1} \rightarrow \gamma_{2}$ & $\begin{array}{l}4.25 \\
(0.04)^{\star \star}\end{array}$ & $\begin{array}{c}1.45 \\
(0.23)\end{array}$ & $\begin{array}{c}2.65 \\
(0.10)^{*}\end{array}$ & $\begin{array}{c}1.41 \\
(0.24)\end{array}$ \\
\hline $\mathrm{H}_{40}: s m r \rightarrow$ unemp & $\begin{array}{c}0.72 \\
(0.49) \\
\end{array}$ & $\begin{array}{c}0.09 \\
(0.91)\end{array}$ & $\begin{array}{c}0.41 \\
(0.67)\end{array}$ & $\begin{array}{c}0.27 \\
(0.77) \\
\end{array}$ \\
\hline $\mathrm{H}_{50}:$ unemp $\rightarrow s m r$ & $\begin{array}{c}0.43 \\
(0.65)\end{array}$ & $\begin{array}{c}0.42 \\
(0.66)\end{array}$ & $\begin{array}{c}0.74 \\
(0.48)\end{array}$ & $\begin{array}{c}0.08 \\
(0.92)\end{array}$ \\
\hline
\end{tabular}

NOTES $p$-values are reported in parentheses. ${ }^{* \star},{ }^{* *}$, and ${ }^{\star}$ represent $1 \%, 5 \%$ and $10 \%$ significance levels, respectively. The Durbin Watson (DW) statistic for serial correlation indicates that all regressions are free from serial correlation whereas the Ljung-Box ( ( в) statistic for autocorrelation shows that only the regressions with stock market returns $(s m r)$ are free from autocorrelation.

and MTAR specifications in the upper regime of the TEC system produce negative and significant estimates of -0.60 and -0.57 , respectively, when stock returns is the driving variable in the system. Collectively, we treat this as evidence of long-run equilibrium reverting behaviour in the face of shock to the system. We also observe insignificant short-run coefficients regardless of whether stock returns or unemployment is the driving variable in the system for both TAR and MTAR variants of the TEC regressions. Note that this result is on par with that obtained in our linear error correction model estimates. In lastly testing for causality effects be- 
tween unemployment and stock returns, none of the test statistics for the TAR and MTAR models is able to reject neither null that unemployment does not granger cause stock returns or that stock returns does not cause unemployment. Once again, these results are in coherence with those presented in our linear cointegration analysis and with those presented by Farsio and Fazel (2013) for the U SA, China and Japan.

\section{Conclusion}

This study becomes the first to investigate the empirical relationship between stock market returns and unemployment for the South African economy using post-Apartheid quarterly data collected from 1994:01 to 2016:01. To ensure a considerable level of robustness the empirical analysis was performed using both linear and nonlinear cointegration frameworks. Linear cointegration was conducted using Engle and Granger (1987) two-step cointegration procedure and this was supplemented with Johansen (1991) cointegration tests. On the other hand, nonlinear cointegration analysis was done through the testing and estimation of TAR and MTAR models as outlined in Enders and Granger (1987) as well as in Enders and Silkos (2001).

Overall, our empirical results reveal the following. First, we find that both linear and nonlinear cointegration frameworks validate the presence of long-run steady-state equilibrium between the time series. However, we are unable to find any short-term cointegration effects between the variables under both frameworks. Secondly, the long-run relationship found between stock market returns and unemployment is positive and yet insignificant. This finding implies that any seemingly positive stock returns-unemployment relationship that may be visually observed by chartists is purely coincidental. Thirdly, we do not find any causality effects between the time series; that is to say that the information from past values of stock market returns do not feed into the unemployment rate, and vice versa. Therefore, whereas we have established cointegration relations between the time series, changes in these variables will not affect the counter variable.

There are a number of interesting phenomenon that policymakers, investors and academics can derive from the empirical results obtained in our study. For instance, policymakers must be aware that the insignificant relationship between stock market returns and unemployment implies that the JSE cannot be used in any direct way to alleviate the evertroublesome problem of high unemployment in the country. In other 
words, policymakers are encouraged to stick to their more direct conventional methods of dealing with unemployment such as infrastructural spending and other labour market related strategies. Another implication, which can be drawn from our study, is that investors or speculators cannot use the domestic unemployment rate to predict or to 'beat' the stock market and thus gain superior returns on their investments. This also implies that the JSE displays elements of weak-form efficiency in the sense that publically available information concerning unemployment cannot be used to predict the direction of stock market returns and this is not surprising given that the JSE has been recently ranked as the most efficiently regulated exchange in the world by the World Economic Forum. However, this matter concerning the weak-form efficiency of the JSE is not all conclusive seeing that the unemployment rate was the only macroeconomic variable that was tested for a relationship with stock returns. Therefore future research endeavours may directed towards testing the predictability of the stock market returns against a host of other financial and macroeconomic variables such as the exchange rate, the inflation rate, interest rates, economic growth.

\section{References}

Abraham, K., and L. Katz. 1986. 'Cyclical Unemployment: Sectoral Shifts or Aggregate Disturbances?' Journal of Political Economy 94:507-22.

Appiah-Kusi, J., and K. Menyah. 2003. 'Return Predictability in African Stock Markets.' Review of Financial Economics 12:247-70.

Bamidele, I. 2015. 'Capital Market and Unemployment in Nigeria.' Acta Universitatis Dabubius 11 (5): 129-40.

Black, F. 1972. 'Capital Market Equilibrium with Restricted Borrowing.' Journal of Business 45 (3): 444-55.

Black, F. 1987. Business Cycles and Equilibrium. New York: Blackwell.

Blanchard, O. 1981. 'Output, the Stock Market and Interest Rates.' The American Economic Review 11:177-85.

Boyd, J., J. Hu, and R. Jagannathan. 2005. 'The Stock Market's Reaction to Unemployment News: Why Bad News is Usually Good for Stocks.' The Journal of Finance 60 (2): 649-72.

Brainard, S., and D. Cutler. 1993. 'Sectoral Shifts and Cyclical Unemployment Reconsidered. The Quarterly Journal of Economics 108 (1): 21943.

Cakan, E. 2012. 'The Business Cycle and Impacts of Economic News on Financial Markets.' Journal of Business and Economics Research 10 (6): 385-90. 
Cakan, E., N. Doytch, and K. Upadhyaya. 2015. 'Does us Macroeconomic News Make Emerging Financial Markets Riskier.' Borsa Instanbul Review 15 (1): 37-43.

Chehal, P., P. Loungani, and B. Trehan. 2010. 'Stock-Market-Based Measures of Sectoral Shocks and the Unemployment Rate.' F RB SF Economic Letter 2010-23, Federal Reserve Bank of San Francisco, San Francisco.

Chen, N., R. Roll, and S. Ross. 1986. 'Economic Forces and Stock Market.' Journal of Business 39:313-29.

Chen, J., P. Kannan, P. Loungani, and B. Trehan. 2011. 'New Evidence on Cyclical and Structural Sources of Unemployment.' I m F Working Paper 11-106, International Monetary Fund, Washington, DC.

Cutler, D., J. Poterba, and L. Summers. 1988. 'What Moves Stock Prices?' NBER Working Paper 2538, National Bureau of Economic Research, Cambridge, MA.

Diamond, P. 1982. 'Wage Determination and Efficiency in Search Equilibrium.' The Review of Economic Studies 49:217-27.

Dopke, J., and C. Pierdzioch. 2000. 'Stock Market Dispersion, Sectoral Shocks, and the German Business Cycle.' Kiel Working Paper 966, Kiel Institute of World Economics, Kiel.

Duca, G. 2007. 'The Relationship between the Stock Market and the Economy: Experience from International Financial Markets.' Bank of Valleta Review, no. 36: 1-12.

Elliot, G., T. Rothenberg, and J. Stock. 1996. 'Efficient Tests for an Autoregressive Time Series with a Unit Root.' Econometrica 64:813-36.

Enders, W., and C. Granger. 1998. 'Unit Root Tests and Asymmetric Adjustment with an Example Using the Term Structure of Interest Rates.' Journal of Business and Economic Statistics 16 (3): 304-11.

Enders, W., and P. Siklos. 2001. 'Cointegration and Threshold Adjustment.' Journal of Business and Economic Statistics 19 (2): 166-76.

Engle, R., and C. Granger. 1987. 'Co-Integration and Error Correction: Representation, Estimation and Testing.' Econometrica 55 (2): 251-76.

Fama, E. 1981. 'Stock Returns, Real Activity, Inflation and Money'. American Economic Review 71 (4): 383-403.

Farmer, R. 2015. 'The Stock Market Crash Really Did Cause the Great Recession.' Oxford Bulletin of Economics and Statistics 77 (5): 617-33

Farsio, F., and S. Fazel. 2013. 'The Stock Market/Unemployment Relationship in Us, China and Japan.' International Journal of Economics and Finance 5 (3): 24-9.

Fourtin, M., and C. Thivierge. 1997. 'Sectoral Shifts, Stock Market Dispersion and Unemployment in Canada.' Applied Economics 29 (6): 829-39.

Fitoussi, J., D. Jestaz, E. Phelps, and G. Zoega. 200o. 'Roots of the Recent 
Recoveries: Labor Reforms or Private Sector Forces.' Brookings Papers on Economic Activity, no. 1: 237-312.

Geske, R., and R. Roll. 1983. 'The Fiscal and Monetary Linkage between Stock Returns and Inflation.' Journal of Finance 38 (1): 7-33.

Graham, B., and D. Dodd. 1934. 'Security Analysis: Principles and Techniques.' New York: McGraw-Hill.

Hall, R. 2014. 'High Discounts and High Unemployment.' n B E R Working Paper 19871, National Bureau of Economic Research, Cambridge, m A.

Hansen, B. 200o. 'Sample Splitting and Threshold Estimation.' Econometrica 68 (3): 575-603.

Hussan, S. 2013. 'South African Capital Markets: An Overview. Working Paper 2013-04, South African Reserve Bank, Pretoria.

Jagannathan, R., K. Kubota, and H. Takehara. 1998. 'Relationship between Labor-Income Risk and Average Return: Empirical Evidence from the Japanese Stock Market.' Journal of Business 71 (3): 319-47.

Jagannathan, R., and Z. Wang. 1993. 'The CAPM is Alive and Well.' Staff Paper 165, Federal Reserve Bank of Minneapolis, Minneapolis, MN.

Jorgensen, B., J. Li, and G. Sadka. 2012. 'Earnings Dispersion and Aggregate Stock Returns.' Journal of Accounting and Economics 53 (1-2): 1-20.

Johansen, S. 1991. 'Estimation and Hypothesis Testing of Cointegration Vectors in Gaussian Vector Autoregressive Models.' Econometrica 59 (6): 1551-80.

Kalay, A., S. Nallareddy, and G. Sadka. 2015. 'Conditionally Earnings Dispersion, the Macroeconomy and Aggregate Stock Returns.' Working Paper, Colombia University and the University of Texas at Dallas.

Kilic, M., and J. Wachter. 2015. 'Risk, Unemployment, and the Stock Market: A Rare-Event-Based Explanation of Labor Market Volatility.' N B E R Working Paper 21575, National Bureau of Economic Research, Cambridge, MA.

Krueger, A., and K. Fortson. 2003. 'Do Markets Respond More to More Reliable Labor Market Data? A Test of Market Rationality.' Journal of European Economic Association 1 (4): 931-57.

Kuehn, L., N. Petrosky-Nadeau, and L. Zhang. 2012. 'An Equilibrium Asset Pricing Model with Labour Search.' N B E R Working Paper 17742, National Bureau of Economic Research, Cambridge, M A.

Lilien, D. 1982. 'Sectoral Shifts and Cyclical Unemployment.' Journal of Political Economy 90 (4): 777-93.

Lintner, J. 1965a. 'The Valuation of Risk Assets and the Selection of Risky Investments in Stock Portfolios and Capital Budgets.' The Review of Economics and Statistics 47:13-37.

- 1965b. 'Securities Prices, Risk, and Maximal Gains from Diversification.' The Journal of Finance 20 (4): 587-615. 
Loungani, P., M. Rush, and W. Tave. 1990. 'Stock Market Dispersion and Unemployment.' Journal of Monetary Economics 25 (3): 367-88

Loungani, P., and B. Trehan. 1997. 'Explaining Unemployment: Sectoral vs. Aggregate Shocks.' FRBSF Economic Review 97 (1): 3-15.

Mandelker, G., and K. Tandon. 1985. 'Common Stock Returns, Real Activity, Money and Inflation: Some International Evidence.' Journal of International Money and Finance 4 (2): 267-86.

McQueen, G., and V. Roley. 1993. 'Stock Prices, News, and Business Conditions.' Review of Financial Studies 6:683-707.

Miao, J., P. Wang, and L. Xu. 2016. 'Stock Market Bubbles and Unemployment.' Economic Theory 61 (2): 273-307.

Mukoyama, T. 2009. 'A Note on Cyclical Discount Factors and Labour Market Volatility'. M P R A Paper 74101, Munich Personal Repec Archive, Munich.

Mortensen, D., and C. Pissarides. 1994. 'Job Creation and Job Destruction in the Theory of Unemployment.' The Review of Economic Studies 61:397-415.

Mossin, J. 1966. 'Equilibrium in a Capital Asset Market.' Econometrica 34 (4): $768-83$.

Nyasha, S., and N. Odhiambo. 2015. 'Banks, Stock Market Development and Economic Growth in South Africa.' Applied Economic Letters 22 (18): $1480-5$.

Orphanides, A. 1992. 'When Good News is Bad News: Macroeconomic News and the Stock Market.' Working Paper, Board of Governors of the Federal Reserve System, Washington, DC.

Phelps, E. 1999. 'Behind this Structural Boom: The Role of Asset Valuations.' American Economic Review 89 (2): 63-8.

Phiri, A. 2014. 'Nonlinear Cointegration between Unemployment and Economic Growth in South Africa.' Managing Global Transitions 12 (4), 303-24.

- 2015a. 'Efficient Market Hypothesis in South Africa: Evidence from Linear and Nonlinear Unit Root Tests.' Managing Global Transitions 13 (4): 369-87.

- 2015b. 'Asymmetric Cointegraiton and Causality Effects between Financial Development and Economic Growth in South Africa.' Journal of Economic Studies 32 (4): 464-84.

Pissarides, C. 1985. 'Short-Run Equilibrium Dynamics of Unemployment, Vacancies, and Real Wages.' American Economic Review 85:676-9o.

Schmidt, P., and P. Phillips. 1992. 'Testing for a Unit Root in the Presence of Deterministic Trends.' Oxford Bulletin of Economics and Statistics 54:257-88. 
Sharpe, W. 1964. 'Capital Asset Prices: A Theory of Market Equilibrium under Conditions of Risk.' The Journal of Finance 19 (3): 425-42.

Veronesi, P. 1999. 'Stock Market Overreaction to Bad News in Good Times: A Rationale Expectations Equilibrium Model.' Review of Financial Studies 12 (5): 975-1007.

Von Fintel, D., and R. Burger. 2014. 'Determining the Causes of the Rising South African Unemployment Rate: An Age, Period and Generational Analysis.' Studies in Economics and Econometrics 38 (1): 35-64.

Yartey, C. 2008. 'The Determinants of Stock Market Development in Emerging Economies: Is South Africa Different?' I MF Working Paper 2008-32, International Monetary Fund, Washington, DC.

This paper is published under the terms of the Attribution-

NonCommercial-NoDerivatives 4.o International (CC B Y-NC-ND 4.0)

License (http://creativecommons.org/licenses/by-nc-nd/4.o/). 


\title{
Business Model Concept: An Integrative \\ Framework Proposal
}

\author{
Marko Perić \\ University of Rijeka, Croatia \\ markop@fthm.hr \\ Vanja Vitezić \\ University of Rijeka, Croatia \\ vanjav@fthm.hr \\ Jelena Đurkin \\ University of Rijeka, Croatia \\ jelenad@fthm.hr
}

Every firm employs a particular business model seeking competitive advantage. However, this pursuit is difficult, and sometimes unsuccessful. The reasons for failure should be sought in the managers' lack of understanding of their organisations' business models, their unique building blocks, and the potential that they have. To help managers better understand business models, this paper reviews the extant literature and identifies the elements of business models cited therein. Further, considering the new needs on the changing markets and the prevailing search for sustainability beyond profit, this paper portrays essential business model elements in an integrated framework. An updated generic business model framework consists of four primary categories, namely, value proposition, value capture, value creation, and value network, and could be useful for a variety of organisations, profit and non-profit, with various mission and vision orientations and interaction with the environment.

Key Words: business model, value proposition, value creation, value capture, value network

JEL Classification: M10, L26

https://doi.org/10.26493/1854-6935.15.255-274

\section{Introduction}

Today, business model (в м) is a frequently used buzzword in business and management practice. Everyone talks about в $\mathrm{ms}$, associating the term with a firm's strategy, competitive advantage, e-commerce, innovation, or performance. A search (in December 2015) for the term business model on Google and Google Scholar produced 25 million hits and 450,000 hits, respectively. Since every viable organisation is built 
on a sound в м (Magretta 2002) and в м design has become a key to entrepreneurial performance and success (Zott and Amit 2007; Kesting and Günzel-Jensen 2015), constant scientific research on в м concept is important for the theoretical development, as well as for venture creation. This is particularly evident in the last 15 years, with academics from various fields of research trying to further explore what stands behind в $\mathrm{M}$ concept (Chen 2003; Lam and Harrison-Walker 2003; Seelos and Mair 2005; Chesbrough 2007; Johnson, Christensen, and Kagermann 2008; Zott, Amit, and Massa 2011; Arend 2013; Klang, Wallnöfer, and Hacklin 2014; Zandoval Bonazzi and Zilber 2014; Mosleh, Nosratabadi, and Bahrami 2015). Their efforts indicate that а в $\mathrm{M}$ is a particular conceptual tool reflected by the business's core value proposition(s) for customers, its configured value network to provide that value, and its continued sustainability (Osterwalder, Pigneur, and Tucci 2005; Voelpel et al. 2005). It is a concise representation of a firm's underlying core logic and strategic choices for creating sustainable competitive advantage (Morris, Schindehutte, and Allen 2005) and for creating and capturing value within a value network (Shafer, Smith, and Linder 2005; Teece 2010). Put simply, a в м is a simplified and aggregated representation of the relevant activities of a company (Wirtz et al. 2016), the way a company structures its own activities (Onetti et al. 2012), i.e. the story that explains how an enterprise works (Magretta 2002).

Despite the lacking consensus on в $\mathrm{M}$ definition that according to Shafer, Smith and Linder (2005) may be in part attributed to interdisciplinary scholarly perspectives and approaches, academics agree that а в $\mathrm{M}$ is an abstract description of how companies create and capture value. However, business practice on the one hand and organisational and system theory on the other do not tolerate ambiguity and vagueness in definitions. Therefore, both academics and practitioners are striving to make a 'big picture' by putting the pieces of business together. Identification of в $\mathrm{M}$ elements and their relationships is an attempt to make this abstract notion more operative and considerable efforts in defining these elements have been made in recent years (Hedman and Kalling 2003; Johnson, Christensen, and Kagermann 2008; Richardson 2008; Osterwalder and Pigneur 2010; Zott and Amit 2010; Arend 2013; Matzler et al. 2013; Bocken et al. 2014; Roome and Louche 2016). In addition, efforts have been made in reviewing the extant literature suggesting new, or confirming old, elements and grouping them into logical units (e.g. see Shafer, Smith, and Linder 2005; Morris, Schindehutte, 
and Allen 2005; Ghaziani and Ventresca 2005; Zott, Amit, and Massa 2011; Onetti et al. 2012; Klang, Wallnöfer, and Hacklin 2014; Wirtz et al. 2016). One proposal got quite attention in the recent years (especially among practitioners). Osterwalder and Pigneur (2010) focused on how the business model design and decision-making process can be supported and proposed a handy tool called the 'Business Model Canvas' (в МС). It consists of nine building blocks (customer segments, customer relationships, value propositions, channels, key activities, key resources, key partners, cost structure, and revenue streams) and reflects the communicative nature of the business model generation tool with a graphical outlook. As Faganel, Biloslavo and Janeš (2016) argue, the use of the B MC helps to assess where company's current business model stands in relation to its potential, and what should be appropriate next steps for the further development of that model. Despite the fact that many academics used (and modified) the B MC within their studies as a conceptual framework (e.g. Zolnowski et al. 2013; Kajanus et al. 2014; Mosleh, Nosratabadi, and Bahrami 2015; Faganel, Biloslavo, and Janeš 2016), overall findings and proposals are not consistent and indicate a variety of different в м elements, partial models, and possible interpretations. Such a high degree of complexity of the subject area surely requires more research.

Furthermore, new trends including demand for implementation of sustainability practices in every business sector, increase of non-for-profit organisations with entrepreneurial market strategies and overall blurring of boundaries between public, private and civil sector, are calling for new generic business model proposals. The emerging literature on sustainable business models and/or business models for sustainability (в мfs) in recent years (Boons and Lüdeke-Freund 2013; Bocken et al. 2014; Abdelkafi and Täuscher 2016; Faganel, Biloslavo, and Janeš 2016; Roome and Louche 2016; to list only a few) contributes to the discussion, but most of the studies are still focused on for-profit firms thus neglecting other types of organisations within the so-called hybrid spectrum; hybrid meaning exhibiting qualities of both non-profit and for-profit enterprises with the commitment to making positive social or environmental impacts. Hybrid organisations usually include social enterprises and non-for-profits with income generating activities (Monroe-White 2014) as more mission-oriented organisations, but can be extended to socially responsible businesses and corporations practicing social responsibility, which are profit-making motivated (Alter 2003). 
This paper builds on these recent works, proposing an updated в M framework based on the research results in terms of elements most frequently mentioned in the papers, as well as based on the new needs on the changing markets and the prevailing search for sustainability beyond profit. Having in mind the three main levels of abstraction in terms of BMS (Moyon and Lecocq 2013), the proposal made in this paper is a generic/ideal type model, not specific to a single sector or company, but comprehensive enough to be useful for a variety of organisations with various mission and vision orientations and interaction with the environment (for classic for-profit enterprises, non-profit organisations, social enterprises and other hybrid organisations).

\section{Methodology}

In this paper, critical analysis of previous research on в м models and their elements was conducted as a part of the research design, more precisely, as the first step in the creation of new в м proposal.

In conducting the analysis, a multistep process was used in terms of identifying research criteria, searching for resources, and accessing and evaluating resources. For the analysis to be scientifically traceable, this study examined the existing scientific contribution in the field of literature on в м definitions and elements. First, it searched for articles published in leading academic and practitioner-oriented management journals from the early publishing dates to December 2015. The list of journals included the Academy of Management Journal (A MJ), Academy of Management Review (AMR), Academy of Management Perspectives (AMP), Administrative Science Quarterly (A SQ), Journal of Management (JOM), Journal of Management Studies (JMS), Management Science (MS), MIS Quarterly, Organization Science (os), and Strategic Management Journal (SMJ) as academic journals, and the California Management Review (CMR), Harvard Business Review (H B R), and MIT Sloan Management Review (MSM) as the leading practitioner-oriented journals. Focusing on articles that contain the term business model in the title or keywords, this search revealed 277 articles on B Ms, of which only 21 had been published in academic journals, while 256 had appeared in practitioner-oriented journals.

Next, examining meta-science databases was confirmed as appropriate method for exploring extant literature on в мs (Ghaziani and Ventresca 2005; Morris, Schindehutte, and Allen 2005; Mäkinen and Seppänen 2007; Zott, Amit, and Massa 2011; Boons and Lüdeke-Freund 2013; 
Klang, Wallnöfer, and Hacklin 2014; Wirtz et al. 2016). The research was therefore extended to the ABI/INFORM database because international coverage makes this base one of the most complete sources on business studies. The database was searched for academic articles published in scholarly journals in the English language, from all dates but finishing with December 2015, and containing the term business model in the title or abstract. As a result of this process, 4,028 articles were obtained and added to the initial sample of 277 articles. As 16 of the newly found articles were already present in the initial sample, our overall sample contained 4,289 articles.

An initial cursory analysis of these 4,289 publications, performed by reading article titles, publication names, abstracts, and introductions, revealed that many of the selected publications would not be useful for further analysis. Many of these articles were case studies, reports, or studies in which the в $\mathrm{M}$ is not really the subject of the analysis. To identify relevant articles, the following three additional criteria were introduced. First, to be included in this analysis, an article must deal with the в м concept in a nontrivial and non-marginal way. Second, an article also must refer to the в $\mathrm{M}$ as a concept related to business firms (as opposed to economic cycles or models, for example). Finally, an article must directly refer to the constitute elements or components of a B M. As a result, 4,187 articles that did not fit the suggested criteria were eliminated, which left us with a sample of 102 articles. Through careful reading of these publications, further works on в MS were found, primarily books and working papers that appeared relevant for this review. The final sample, therefore, contained 108 publications.

To gain additional insight, the Shafer, Smith and Linder (2005) approach was followed by developing an affinity diagram to categorise the first- and second-order themes of в м that were cited four or more times. According to Pyzdek (2003), affinity diagrams are a popular business tool for organising ideas into categories based on their natural relationships and underlying similarity and help to identify patterns and establish related groups that exist in qualitative datasets. To develop the affinity diagram all three authors worked independently to (a) compare the models mentioned most often and study their components, (b) cluster into categories B $\mathrm{M}$ components, and (c) develop a descriptive name for each category. At that point, the preliminary clusters were shared, and the authors discussed the individually developed clusters to reach a consensus.

After the literature analysis and affinity diagram creation, main groups 
of в м elements were discussed with emphasis on their coverage and overlapping. The focus of discussion was on the creation of new в м framework suitable for various types of organisations. Results of the literature analysis were taken into consideration, but some elements were re-arranged and new elements and groups introduced in order to support innovative business model scheme, comprehensive and simple enough so that it can be easily understood, communicated, and remembered.

\section{Insights of Literature Analysis}

As described in the previous section, this study identified 108 different publications that deal with в $\mathrm{M}$ elements. Across these 108 publications, one can find 387 different first- and second-order themes, i.e. в м сотponents, unique building blocks or elements. Given the space and scope considerations for this article, however, only a brief review of these adjacent literatures is presented in table 1 (the full version is available upon request).

TABLE 1 Business Model Elements

\begin{tabular}{ll}
\hline Author(s) (year) & Business model themes \\
\hline Mahadevan (2000) & Value stream, logistical stream, and revenue stream. \\
\hline $\begin{array}{l}\text { Chesbrough and } \\
\text { Rosenbloom } \\
\text { (2002) }\end{array}$ & $\begin{array}{l}\text { Value proposition, target markets, internal value chain structure, } \\
\text { cost structure and profit model, value network, and competitive } \\
\text { strategy. }\end{array}$ \\
\hline $\begin{array}{l}\text { Hedman and } \\
\text { Kalling (2003) }\end{array}$ & $\begin{array}{l}\text { Customers, competitors, offering, activities and organization, } \\
\text { resources, suppliers of factor and production inputs, and scope of } \\
\text { management. }\end{array}$ \\
\hline $\begin{array}{l}\text { Voelpel, Leibold, } \\
\text { and Tekie (2004) }\end{array}$ & $\begin{array}{l}\text { New customer value proposition, a value network } \\
\text { (re)configuration (internal and external structures and processes, } \\
\text { core strategy, vision, mission, objective, technology, economics, } \\
\text { legal issues), and leadership capabilities. }\end{array}$ \\
\hline $\begin{array}{l}\text { Morris, Schinde- } \\
\text { hutte, and Allen }\end{array}$ & $\begin{array}{l}\text { Product offering, market factors, internal capability factors, com- } \\
\text { petitive strategy factors, economic factors, and growth/exit fac- } \\
\text { tooo5) }\end{array}$ \\
\hline $\begin{array}{l}\text { Shafer, Smith, and } \\
\text { Linder (2005) }\end{array}$ & $\begin{array}{l}\text { Strategic choices (customer, value proposition, capabilities/com- } \\
\text { petences, revenue/pricing, competitors, output, strategy, brand- } \\
\text { ing, differentiation, mission), value networks (suppliers, cus- } \\
\text { tomer information, customer relationship, information flows, } \\
\text { product/service flows), creating value (resources/assets, pro- } \\
\text { cesses/activities), and capturing value (cost, profit). }\end{array}$ \\
\hline
\end{tabular}

Continued on the next page 
TABLE 1 Continued from the previous page

\begin{tabular}{|c|c|}
\hline $\begin{array}{l}\text { Kandampully } \\
(2006)\end{array}$ & $\begin{array}{l}\text { Corporate intent, strategic direction, core capabilities (technol- } \\
\text { ogy, networks, relationships, employees), customer, and value } \\
\text { proposition. }\end{array}$ \\
\hline Chesbrough (2007) & $\begin{array}{l}\text { Value proposition, target market, value chain, revenue mecha- } \\
\text { nism(s), value network or ecosystem, and competitive strategy. }\end{array}$ \\
\hline $\begin{array}{l}\text { Johnson, Chris- } \\
\text { tensen, and Kager- } \\
\text { mann (2008) }\end{array}$ & $\begin{array}{l}\text { Customer value proposition - CVP (target customer, job to be } \\
\text { done, offering), key resources (people, technology, products, } \\
\text { facilities, equipment, information, channels, partnerships, al- } \\
\text { liances, brand), key processes (processes: design, product de- } \\
\text { velopment, sourcing, manufacturing, marketing, hiring and } \\
\text { training, IT; rules and metrics, and norms), and profit formula } \\
\text { (revenue model, cost structure, margin model, resource velocity). }\end{array}$ \\
\hline $\begin{array}{l}\text { Demil and Lecocq } \\
(2010)\end{array}$ & $\begin{array}{l}\text { Resources and competences, organizational structure, and propo- } \\
\text { sitions for value delivery. }\end{array}$ \\
\hline Kujala et al. (2010) & $\begin{array}{l}\text { Customer, value proposition for the customer, competitive strat- } \\
\text { egy, position in the value network, suppliers' internal organiza- } \\
\text { tion/key capabilities, and logic of revenue generation. }\end{array}$ \\
\hline $\begin{array}{l}\text { Osterwalder and } \\
\text { Pigneur (2010) }\end{array}$ & $\begin{array}{l}\text { Customer segments, customer relationships, value propositions, } \\
\text { channels, key activities, key resources, key partners, cost struc- } \\
\text { ture, and revenue streams. }\end{array}$ \\
\hline $\begin{array}{l}\text { Zott and Amit } \\
(2010)\end{array}$ & $\begin{array}{l}\text { Design elements (activity system content, structure and gover- } \\
\text { nance), and design themes (novelty, lock-in, complementarities, } \\
\text { efficiency). }\end{array}$ \\
\hline Arend (2013) & $\begin{array}{l}\text { Value, resources, capabilities, partners (e.g. In interdependent } \\
\text { networks), structures (e.g. Governance choices), and economic } \\
\text { engine. }\end{array}$ \\
\hline Matzler et al. (2013) & $\begin{array}{l}\text { Positioning (customer need), product and service logic (products } \\
\text { and services), value creation architecture (core competencies, } \\
\text { core processes), sales and marketing logic, and profit formula } \\
\text { (revenue model and cost model). }\end{array}$ \\
\hline
\end{tabular}

Research results confirm previously mentioned lack of consensus on B M elements. It seems that some of the components appear in only one definition, but others are seen time and time again. For instance, four elements (value proposition, customer, product, and resources) are mentioned in more than 20 publications, and 60 out of 387 elements are mentioned at least four times. In addition, 16 elements are mentioned three times, 49 elements two times and 262 elements are mentioned only once. However, regardless of the existing disagreement and large number of perspectives provided when в м elements are concerned, something 
consistently recognised was that definitions often included those elements that comprise the concept of value. Second, some elements could have similar or even overlapping meaning. For instance, value, value proposition, customer value proposition or value offering all indicate the value that is delivered to a customer, while revenues, revenue model, revenue stream, and revenue sources all refer to revenues within the financial aspect of a $\mathrm{B} \mathrm{M}$.

Identified elements are presented through affinity diagram with six major categories, namely value proposition, value network, value capture, resources, processes, and strategic elements (table 2).

The list of elements and their frequencies in the selected body of literature grouped in the form of affinity diagram is the starting point for further elaboration on important segments of a generic в м. Simplifying the underlying logic in overlapping elements and categories of в $\mathrm{M}$, as well as introducing new elements, important for successfully achieving goals beyond profit in the form of comprehensive and easily implemented generic в $\mathrm{M}$ framework is the task of the next chapter.

\section{Proposal of a Generic Business Model Framework}

The importance of the concept of value in в м literature is visible through an analysis of its frequency, but the context of using value-oriented elements differs and the concept should be implemented carefully in the general в м. Mostly defined as a desired product of business operations, or more precisely, as a result of exploitation of business opportunities (Amit and Zott 2010), value is at the heart of many aforementioned definitions of а в м. However, in order to create comprehensive в м framework, it is essential to distinguish between two of the most important types of value relevant for the enterprise:

1. Value that is created and delivered for the purpose of satisfying the needs of customers or other end-users (see more in Zolnowski et al. 2013; Mosleh, Nosratabadi, and Bahrami 2015).

2. Value created to be captured by the enterprise itself for innovating and/or achieving other goals set in the enterprise's strategy (see more in Shaffer, Smith, and Linder 2005; Osterwalder and Pigneur 2010).

Considering that the value does not occur by itself, it is crucial to provide sufficient resources, transform resources into valuable products and services, and deliver those to customers through different distribution channels. All of this occurs in a specific strategic context and previous 
TABLE 2 Affinity Diagram of Business Model Elements

\begin{tabular}{|c|c|c|c|c|c|}
\hline Element(s) & $f$ & $\%$ & Element(s) & $f$ & $\%$ \\
\hline Value proposition & & & Value capture & & \\
\hline Value proposition & 36 & 33.33 & Revenue model & 15 & 13.89 \\
\hline Customer & 23 & 21.30 & Cost structure & 10 & 9.26 \\
\hline Product & 23 & 21.30 & Value capture & 10 & 9.26 \\
\hline Target Customer & 8 & 7.41 & Cost & 9 & 8.33 \\
\hline Value & 6 & 5.56 & Financial aspects & 9 & 8.33 \\
\hline Customer segments & 5 & 4.63 & Revenue stream & 9 & 8.33 \\
\hline Services & 5 & 4.63 & Revenues & 7 & 6.48 \\
\hline Value offering & 5 & 4.63 & Price & 5 & 4.63 \\
\hline New cust. value proposition & 4 & 3.70 & Pricing & 5 & 4.63 \\
\hline Resources & & & Profit formula & 5 & 4.63 \\
\hline Resources & 21 & 19.44 & Revenue sources & 5 & 4.63 \\
\hline Technology & 16 & 14.81 & Financial model & 4 & 3.70 \\
\hline Core competencies & 10 & 9.26 & Processes & & \\
\hline Capabilities & 6 & 5.56 & Value creation & 9 & 8.33 \\
\hline Competences & 5 & 4.63 & Processes & 8 & $7 \cdot 41$ \\
\hline Key resources & 5 & 4.63 & Value configuration & 7 & 6.48 \\
\hline Assets & 4 & 3.70 & Infrastructure management & 6 & 5.56 \\
\hline Brand & 4 & 3.70 & Manufacturing & 5 & 4.63 \\
\hline Information & 4 & 3.70 & Activities & 4 & $3 \cdot 70$ \\
\hline Infrastructure & 4 & 3.70 & Value delivery & 4 & 3.70 \\
\hline Strategic resources & 4 & 3.70 & Strategic elements & & \\
\hline Value network & & & Mission & 7 & 6.48 \\
\hline Value network & 15 & 13.89 & Structure & 7 & 6.48 \\
\hline Relationship & 10 & 9.26 & Governance & 6 & 5.56 \\
\hline Customer interface & 8 & 7.41 & Network & 6 & 5.56 \\
\hline Partners & 8 & $7 \cdot 41$ & Organisation & 6 & 5.56 \\
\hline Channels & 6 & 5.56 & Scope & 6 & 5.56 \\
\hline Customer relationship & 6 & 5.56 & Competitive strategy & 5 & 4.63 \\
\hline Distribution Channel & 6 & 5.56 & Competitors & 5 & 4.63 \\
\hline Partner Network & 5 & 4.63 & Strategy & 5 & 4.63 \\
\hline Architecture of value & 4 & 3.70 & Management & 4 & 3.70 \\
\hline
\end{tabular}




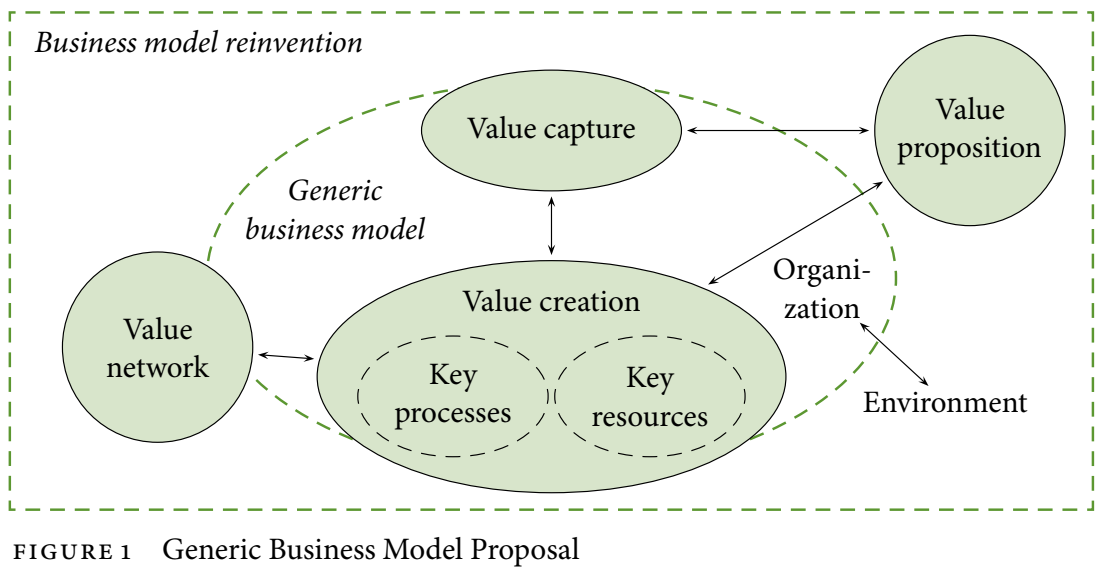

review indicated that strategic elements are mentioned very often in the context of business models.

However, a clear distinction between в м and strategy is needed. А в м emphasises the role of the customer (Zott, Amit, and Massa 2011) while strategy stresses the competitive environment and the need for positioning (Magretta 2002; Tikkanen et al. 2005; Casadesus-Masanell and Ricart 2010). The в м is just the reflection of the organisation's realised strategy and provides a link between strategy formulation and implementation (i.e. operations) (Mäkinen and Seppänen 2007; Richardson 2008; Casadesus-Masanell and Ricart 2010). It seems that в мs are more clearly explained when strategy is excluded from the defining elements (Onetti et al. 2012) and, consequently, strategic elements were not included in further conceptualisation of a generic в $\mathrm{M}$ framework.

Having in mind that many companies revise and transform their business model in order to contribute to sustainable development (Roome and Louche 2016), and at the same time respecting the need of 'sustainability-driven' organisations to have viable business models (Haigh and Hofmann 2012), the new generic в м framework is proposed (figure 1).

Four major categories that make the essence of this в M proposal are all oriented on the complex concept of value in terms of its creation, networking that is necessary for its creation and distribution, proposition of the value that organisation offers to the environment and finally value elements that organisation seeks to capture. Each category is placed within the scheme to graphically represent the actual position in relation to the organisation (internal) and environment (external). 
VALUE PROPOSITION

Value proposition is a concept that explains what benefits (products and services) an organisation provides and to whom it provides. For that reason, the perception of value proposition has wide currency in economics. Chesbrough and Rosenbloom (2002), Voelpel, Leibold and Tekie (2004), Osterwalder, Pigneur and Tucci (2005), Kandampully (2006) and Carayannis, Sindakis and Walter (2015) are only some of the authors defining value proposition concept as the core of organisations that are striving to become and remain sustainable, profitable, and scalable. Even more, in today's complex environment the value proposition should provide measurable ecological and/or social value built into the product/service offered, in synergy with economic value (Boons and LüdekeFreund 2013; Faganel, Biloslavo and Janeš 2016). In analysing consumers of a final product/service, for-profit motivated organisations use the concept of customers, traditional non-profits think of their consumer base as beneficiaries, while hybrid organisations, especially social enterprises, break the customer-beneficiary dichotomy by providing products and services that, when consumed, produce social value (Battiliana et al. 2012). Hence, within the value proposition in the generic в м proposal, both consumers and beneficiaries are listed as end-users of the products and services.

\section{VALUE CAPTURE}

Value capture defines how an operating mechanism of the organisation produces financial and non-financial gains, generating it from its value proposition. As one of the key issues in designing a business model, conception of value capture already shifted focus of some scholarly research (see Shafer, Smith, and Linder 2005; Teece 2010; Abdelkafi and Tauscher 2015; Roome and Louche 2016). Following Johnson (2010), the questions of how big an organisation must become in order to break even, what is the structure of fixed and variable costs, how much money can be made defining gross and net margins, and how fast the organisation turns over its assets are defined in an economic blueprint called the profit formula. In spite of the fact that some researchers equate the terms value capture and profit formula (Johnson, Christensen, and Kagermann 2008; Abdelkafi, Makhotin, and Posselt 2013; Matzler et al. 2013), we propose two elements under the heading of value capture, aforementioned profit-formula and non-profit formula. Therefore, the profit formula consists of costs, revenues, and margin model. Having in mind complex environment, sus- 
tainable development notion and need for innovativeness as a source of competitiveness, non-profit formula is the second value capture element. It deals with non-financial benefits, which an organisation aims to 'capture' and use for further development and fulfilment of mission objectives. Although non-profit formula represents a very wide range of elements relevant from the perspective of various types of organisations, the authors would like to highlight two key elements:

1. Intellectual 'added value' capital - referred to as knowledge that can be converted into future profits and encompasses various resources such as ideas, inventions, technologies, designs, processes, and software (Sullivan 1999; Liu 2011). Intellectual added value capital is accounted as the difference between the value of an organisation's output intellectual capital and the cost of the organisation's input intellectual capital. Unlike intellectual property (IP) which can be legally protected (patented), intellectual capital as a superset is more intangible (e.g. the owner of IP has to make a full disclosure of the property) and does not usually have a legal title of ownership attached to it. Intellectual capital does not have life expiration date and with proper management, it creates extra value. Therewith, increasing intellectual capital ensures the long-term viability of the organisation that goes beyond profit generation. Obviously, there is a strong coalition between intellectual capital and value creation, which is manifested within the interaction between assets, processes, and network gaining core competencies and the organisation's market value.

2. Public (social) value - a concept very important for non-profit and hybrid organisations because it captures the initial objective of their existence and principles related to their core purpose (in cases where it is only partially or not at all covered by value proposition). It is hard to provide a unified definition of social value(s) because it varies depending on the types of organisations, their mission drivers, and system of internal and external stakeholders. In case of cooperatives, their internal organisation and common principles (democracy, cooperation, contribution to the community, etc.) represent value for itself, while in some other organisations, increased public awareness related to the organisations' activities represents important value in terms of incentive for future efforts to stay worthy of social approval (Battiliana et al. 2012). Idea to put social values and stakeholder interests in business model context 
is not completely new, some researchers implemented it using concept of social value/social profit formula (e.g. Yunus, Moingeon, and Lehmann-Ortega 2010; Pels and Kidd 2015).

It is important to emphasize that the profit formula and non-profit formula are both important for various organisations, but probably with various intensity. Social enterprises are, regardless of their mission orientation, very concerned with profit formula elements in order to ensure economic sustainability. At the same time, profit-oriented organisations need to keep in mind that mere profit earning without contributing to the intellectual capital and broader public benefits might be a shortsighted way of doing business.

\section{VALUE CREATION}

Having value proposition and value capture already proposed as separate в м elements, the focus is now shifted on more operational issues, i.e. how these values are produced. Value creation is therefore operationalised as an organisation's capacity of creating value and derives from its key resources and key processes. Although the link between exploitation of resources and benefits created to be captured by the enterprise itself is obvious, the emphasis of the value creation is on operating mechanisms established to create and deliver value to the end-users of the products and services, i.e. customers and/or beneficiaries.

The definition of value creation implies the dynamism of a resource transformation, that is, the governance transactions designed to create value (Amit and Zott 2001; Voelpel, Leibold, and Tekie 2004; Zott and Amitt 2007; Zähringer et al. 2011; Abdelkafi, Makhotin, and Posselt 2013; Roome and Louche 2016). Indeed, what are the key bottleneck assets to own/control in order to create and capture value is one of the crucial issues of a sustainable в м (Teece 2010). Here we propose employees, infrastructure, technology, information, and IP as five inter-dependent key resources. The value of intangible assets has increased over time and these assets often constitute a significant proportion of business value (Gomezelj Omerzel and Gulev 2011). Nowadays intangibles often represent a major source of productivity growth with immense interest from investors. Despite having huge relevance, we found only a few elements in the whole sample, so including IP is very meaningful. IP is a result of all departments working together in a creative and innovative process, endeavouring to protect and foster the sustainable value of a brand. Moreover, beneficial partnerships and relationships can be developed by own- 
ing IP. With constant changes in product and service offerings, organisations must perpetually innovate their key processes. This includes not only manufacturing as an obvious resource transformation activity, but also marketing, ICT, HRM, infrastructure and innovation management, and even financing. Value creation and delivery are sometimes treated as one integral element of а в м (Abdelkafi and Täuscher 2016; Roome and Louche 2016). For instance, in hospitality industry, delivery is inseparable part of product/service creation. Delivery, as well as all other listed processes within the value creation category, is directly related to the value network.

\section{VALUE NETWORK}

It is very important for any organisation to focus on its core capabilities and outsource other activities or cooperate with partners. Organisations must develop new в мs, in which both value creation and value capture occur in a value network (Hamel 2000), creating a new value system within which different economic players (i.e. suppliers, partners, customers/beneficiaries, distribution channels, allies, and other forms of coalition) work together toward one goal, the co-production of value. Value network, called also as an ecosystem (see Chesbrough 2007) focuses therefore on stakeholder involvement (Voelpel, Leibold, and Tekie 2005; Kesting 2015). Additionally, from this network perspective, mostly external interactions occur that can have a great influence on the value creation and value capture of a company (Ge, Hisrich, and Dong 2009; Puslecki and Staszkow 2015; Wirtz et al. 2016).

The interaction of a value network and other в м categories in the form of two-way value-creating processes can have a direct effect on an organisation's processes and internal capabilities as well. For instance, distribution channels, although occasionally treated as a part of a customer dimension (Osterwalder, Pigneur, and Tucci 2005; Zähringer et al. 2011), belong to value network and represent an immediate link to delivery processes within the scope of value creation. This interdependence among в M categories can result in gaining expertise and competency in the form of increased relationship reliance and new knowledge focused on realising value as well as providing value.

\section{CONCLUSIONS}

Taking into consideration the significant disagreement and large number of perspectives on в $\mathrm{M}$ elements, the authors have created an affin- 
ity diagram to associate the key concepts most frequently mentioned in the literature. Based on in-depth analysis of identified affinity diagram clusters, the authors have proposed a generic conceptual в м for various types of organisations. The offered в м framework mechanism is described through four major categories strongly emphasizing the concept of value, namely, value proposition, value creation (involving key resources and processes), value capture, and value network. Summarising the essence of these four categories, а в $\mathrm{m}$ explains the interplay of organisation's resources and partnering ecosystem to create value for end-users and the organisation itself.

The novelty in this approach lies in integrating the principal в м considerations of all organisations with market-oriented activities (regardless of their pure for-profit, non-profit or hybrid nature) into single framework. This extended and integration approach in creating a 'one-for-all' в м proposal is in line with the notion that any organisation that wants to be relevant, to deliver the value at scale and to sustain itself, must clearly articulate its в м (Kaplan 2011). It is important to note that responding with innovations to constant global changes and challenges sometimes provokes в м reinvention, of course without interfering in organisation strategy. Furthermore, the capacity of an organisation to capture value will be severely compromised if there is no capacity to reinvent its в м or create new one. Unique and difficult to imitate в $\mathrm{MS}$ have greater chances to be successful and this should be the ultimate aim of every в м reinvention or innovation (see also Chesbrough 2007; Johnson, Christensen, and Kagermann 2008; Teece 2010; Zott, Amit, and Massa 2011; Matzler et al. 2013).

From a managerial viewpoint, this framework may be of particular interest to practitioners. Being aware of distinct pieces of business and their interrelationships is decisive when dealing with complex market and environmental challenges. This is true regardless of whether companies are already in business or just entering it (e.g. start-ups). Therefore, practitioners should work with this framework in order to evaluate the business idea together with different aspects, that is, to have a more holistic understanding of their businesses. Despite certain limitations (overgeneralising in an attempt to create a one-size-fits-all solution, dealing with divergent literature), the proposal given in this paper can be used for further scientific research or it can be tested (and, if necessary, revised) on a particular industry/sector or even on a specific organisational type (e.g. в м for family enterprises, museums, hospitals, etc.). 


\section{Acknowledgments}

This work has been supported in part by the Croatian Science Foundation (grant number UIP-2014-09-1214).

\section{References}

Abdelkafi, N., S. Makhotin, and T. Posselt. 2013. 'Business Models Innovation for Electric Mobility: What Can Be Learned from Existing Business Model Patterns?' International Journal of Innovation Management 17 (1): 1-41.

Abdelkafi, N., and K. Täuscher. 2016. 'Business Models for Sustainability from a System Dynamics Perspective.' Organization \& Environment 29 (1): 74-96.

Alter, K. S. 2003. 'Social Enterprise: A Typology of the Field Contextualized in Latin America.' Working Paper, Inter-American Development Bank, Washington, DC. http://idbdocs.iadb.org/wsdocs/getdocument.aspx? docnum $=383929$

Amit, R., and C. Zott. 2001. 'Value Creation in E-Business.' Strategic Management Journal 22 (6-7): 493-520.

Arend, J. R. 2013. 'The Business Model: Present and Future - Beyond a Skeumorph.' Strategic Organization 11 (4): 390-402.

Battiliana, J., M. Lee, C. Walker and C. Dorsey. 2012. 'In Search of the Hybrid Ideal.' Stanford Social Innovation Review 10 (3): 50-55.

Bocken, N. M. P., S. Short, P. Rana, and S. Evans. 2014. 'A Literature and Practice Review to Develop Sustainable Business Model Archetypes.' Journal of Cleaner Production 65:42-56.

Boons, F., and F. Lüdeke-Freund. 2013. 'Business Models for Sustainable Innovation: State-of-the-Art and Steps towards a Research Agenda.' Journal of Cleaner Production 45:9-19.

Casadesus-Masanell, R., and J. E. Ricart. 2010. 'From Strategy to Business Models and to Tactics.' Long Range Planning 43 (2-3): 195-215.

Carayannis, E. G., S. Sindakis, and C. Walter. 2015. 'Business Model Innovation as Lever of Organizational Sustainability.' The Journal of Technology Transfer 40 (1): 85-104.

Chen, S. 2003. 'The Real Value of "E-Business Models."' Business Horizons $46(6): 27-33$.

Chesbrough, H. 2007. 'Business Model Innovation: It's Not Just about Technology Anymore.' Strategy \& Leadership 35 (6): 12-17.

Chesbrough, H., and R. S. Rosenbloom. 2002. 'The Role of the Business Model in Capturing Value from Innovation: Evidence from Xerox Corporation's Technology Spin-off Companies.' Industrial and Corporate Change 11 (3): 529-55. 
Demil, B., and X. Lecocq. 2010. 'Business Model Evolution: In Search of Dynamic Consistency.' Long Range Planning 43 (2-3): 227-46.

Faganel, A., R. Biloslavo and A. Janeš. 2016. 'The Aquaculture Industry and Opportunities for Sustainable Tourism.' Academica Turistica 9 (2): 27-43.

Ge, B., R. D. Hisrich, and B. Dong. 2009. 'Networking, Resource Acquisition, and the Performance of Small and Medium-Sized Enterprises: An Empirical Study of Three Major Cities in China.' Managing Global Transitions 7 (3): 221-39.

Ghaziani, A., and M. J. Ventresca. 2005. 'Keywords and Cultural Change: Frame Analysis of Business Model Public Talk 1975-2000.' Sociological Forum 20 (4): 523-59.

Gomezelj Omerzel, D., and R. E. Gulev. 2011. 'Knowledge Resources and Competitive Advantage.' Managing Global Transitions 9 (4): 335-54.

Hamel, G. 2000. Leading the Revolution. Cambridge, MA: Harvard Business School Press.

Haigh, N., and A. J. Hoffman. 2012. 'Hybrid Organizations: The Next Chapter of Sustainable Business.' Organizational Dynamics 41 (2): 126-34.

Hedman, J., and T. Kalling. 2003. 'The Business Model Concept: Theoretical Underpinnings and Empirical Illustrations.' European Journal of Information Systems 12 (1): 49-59.

Johnson, M. W. 2010. Seizing the White Space: Business Model Innovation for Growth and Renewal. Boston, m A: Harvard Business Press.

Johnson, M. W., C. M. Christensen, and H. Kagermann. 2008. 'Reinventing Your Business Model.' Harvard Business Review 86 (12): 50-9.

Kandampully, J. 2006. 'The New Customer-Centred Business Model for the Hospitality Industry.' International Journal of Contemporary Hospitality Management 18 (3): 173-87.

Kajanus, M., A. Iire, T. Eskelinen, M. Heinonen, and E. Hansen. 2014. 'Business Model Design: New Tools for Business Systems Innovation.' Scandinavian Journal of Forest Research 29 (6): 603-14.

Kaplan, S. 2011. 'Business Models Aren't Just for Business.' Harvard Business Review, 19 April. https://hbr.org/2011/o4/business-models-arentjust-for

Kesting, P., and F. Günzel-Jensen. 2015. 'smes and New Ventures Need Business Model Sophistication.' Business Horizons 58 (3): 285-93.

Klang, D., M. Wallnöfer, and F. Hacklin. 2014. 'The Business Model Paradox: A Systematic Review and Exploration of Antecedents.' International Journal of Management Reviews 16 (4): 454-78.

Kujala, S., K. Artto, P. Aaltonen, and V. Turkulainen. 2010. 'Business Models in Project-Based Firms.' International Journal of Project Management 28 (2): 96-106. 
Lam, L. W., and L. J. Harrison-Walker. 2003. 'Toward an Objective-Based typology of E-Business Models.' Business Horizons 46 (6): 17-26.

Liu, C. C. 2011. 'Developing Measures of Intellectual Capital for the Venture Capital Industry in Taiwan.' Managing Global Transitions 9 (1): 81-100.

Magretta, J. 2002. 'Why Business Models Matter?' Harvard Business Review $80(5): 3-8$.

Mahadevan, B. 2000. 'Business Models for Internet-Based E-Commerce.' California Management Review 42 (4): 55-69.

Mäkinen, S., and M. Seppänen. 2007. 'Assessing Business Model Concepts with Taxonomical Research Criteria.' Management Research News 30 (10): 735-48.

Matzler, K., F. Bailom, S. F. von den Eichen, and T. Kohler. 2013. 'Business Model Innovation: Coffee Triumphs for Nespresso.' Journal of Business Strategy 34 (2): 30-7.

Monroe-White, T. 2014. 'Creating Public Value: An Examination of Technological Social Enterprise.' In Emerging Research Directions in Social Entrepreneurship, edited by L. Pate. and C. Wankel, 85-111. Dordrecht: Springer Science+Business Media.

Morris, M., M. Schindehutte, and J. Allen. 2005. 'The Entrepreneur's Business Model: Toward a Unified Perspective.' Journal of Business Research 58 (6): 726-35.

Mosleh, A., S. Nosratabadi, and P. Bahrami. 2015. 'Recognizing the Business Models Types in Tourism Agencies: Utilizing the Cluster Analysis.' International Business Research 8 (2): 173-80.

Moyon, E., and X. Lecocq. 2011. 'Adopting a Business Model View to Study Industry Change: The Case of the French Record Industry. Paper presented at the Xxi I Conférence Internationale de Management Stratégique, Clermont-Ferrand, 10-12 June. http://www .businessmodelcommunity.com/fs/Root/azvso-MOYON_et _lecocq.pdf

Onetti, A., A. Zucchella, M. V. Jones, and P. P. McDougall-Covin. 2012. 'Internationalization, Innovation and Entrepreneurship: Business Models for New Technology-Based Firms.' Journal of Management \& Governance 16 (3): 337-68.

Osterwalder, A., and Y. Pigneur. 2010. Business Model Generation: A Handbook for Visionaries, Game Changers, and Challengers. Hoboken, NJ: Wiley.

Osterwalder, A., Y. Pigneur, and C. L. Tucci. 2005. 'Clarifying Business Models: Origins, Present, and Future of the Concept.' Communications of the Association for Information Systems 16:1-25.

Pels, J., and T. A. Kidd. 2015. 'Business Model Innovation: Learning from a High-Tech-Low-Fee Medical Health Care Model for the в ор.' Inter- 
national Journal of Pharmaceutical and Health Care Marketing 9 (3): 200-18.

Puslecki, L., and M. Staszkow. 2015. 'New Cooperation Modes: An Opportunity for Polish Biotechnological Clusters.' Managing Global Transitions 13 (2): 171-88.

Pyzdek, T. 2003. The Six Sigma Handbook. New York: McGraw-Hill.

Richardson, J. 2008. 'The Business Model: An Integrative Framework for Strategy Execution.' Strategic Change 17 (5-6): 133-44.

Roome, N., and C. Louche. 2016. 'Journeying Toward Business Models for Sustainability: A Conceptual Model Found inside the Black Box of Organisational Transformation.' Organization \& Environment 29 (1): 1135.

Seelos, C., and J. Mair. 2005. 'Social Entrepreneurship: Creating New Business Models to Serve the Poor.' Business Horizons 48 (3): 241-6.

Shafer, S. M., H. J. Smith, and J. C. Linder. 2005. 'The Power of Business Models.' Business Horizons 48 (3): 199-207.

Sullivan, P. H. 1999. 'Profiting From Intellectual Capital.' Journal of Knowledge Management 3 (2):, 132-42.

Teece, D. J. 2010. 'Business Models, Business Strategy and Innovation.' Long Range Planning 43 (2-3): 172-94.

Tikkanen, H., J.-A. Lamberg, P. Parvinen, and J.-H. Kallunki. 2005. 'Managerial Cognition, Action and the Business Model of the Firm.' Management Decision 43 (6): 789-809.

Voelpel, S. C., M. Leibold, and E. B. Tekie. 2004. 'The Wheel of Business Model Reinvention: How to Reshape Your Business Model to Leapfrog Competitors.' Journal of Change Management 4 (3): 259-76.

Voelpel, S. C., M. Leibold, E. B. Tekie, and G. von Krogh. 2005. 'Escaping the Red Queen Effect in Competitive Strategy: Sense-Testing Business Models.' European Management Journal 23 (1): 37-49.

Wirtz, B. W., A. Pistoia, S. Ullrich, and V. Göttel. 2016. 'Business Models: Origin, Development and Future Research Perspectives.' Long Range Planning 49 (1): 36-54.

Yunus, M., B. Moingeon, and L. Lehmann-Ortega. 2010. 'Building Social Business Models: Lessons from the Grameen Experience.' Long Range Planning 43 (2-3): 308-25.

Zandoval Bonazzi, F. L., and M. A. Zilber. 2014. 'Innovation and Business Model: A Case Study about Integration of Innovation Funnel and Business Model Canvas.' Review of Business Management 16 (53): 616-37.

Zähringer, D., J. Niederberger, K. Blind, and A. Schletz. 2011. 'Revenue Creation: Business Models for Product-Related Services in International Markets - The Case of Zwick GmbH \& Co. KG.' The Service Industries Journal 31 (4): 629-41, 
Zolnowski, A., M. Semmann, S. Amrou, and T. Böhmann. 2013. 'Identifying Opportunities for Service Productivity Improvement Using a Business Model Lens.' The Service Industries Journal 33 (3-4): 409-25.

Zott, C., and R. Amit. 2007. 'Business Model Design and the Performance of Entrepreneurial Firms.' Organization Science 18 (2): 181-99.

—. 2010. 'Business Model Design: An Activity System Perspective.' Long Range Planning 43 (2-3): 216-26.

Zott, C., R. Amit, and L. Massa. 2011. 'The Business Model: Recent Developments and Future Research.' Journal of Management 37 (4): 1019-42.

This paper is published under the terms of the Attribution-

NonCommercial-NoDerivatives 4.o International (CC BY-NC-ND 4.0)

License (http://creativecommons.org/licenses/by-nc-nd/4.o/). 


\title{
Clusters in the Renewable Energy Sector in Poland
}

\author{
Michał Staszków \\ Poznan University of Economics and Business, Poland \\ michal.staszkow@ue.poznan.pl \\ Michał Borychowski \\ Poznan University of Economics and Business, Poland \\ michal.borychowski@ue.poznan.pl \\ Filip Nowacki \\ Poznan University of Economics and Business, Poland \\ filip.nowacki@ue.poznan.pl
}

The paper is a review work, which presents the problem of a renewable energy in Poland supplemented with a case study. To reduce gas emission and to improve energy efficiency the European Union's Member States are obliged to obtain more energy from renewable sources. Our goal is to test how cluster may help in achieving the provisions of $3 \times 20 \%$ package. The case study of Baltic Eco-Energy Cluster is presented as a successful example of the biggest energy cluster in the country, which can be treated as a benchmark for other sector clusters that are willing to contribute positively to changes in Polish energy sector.

Key Words: clusters, renewable energy, $3 \times 20 \%$ package

JEL Classification: E00, O13, P28, Q20, Q4

https://doi.org/10.26493/1854-6935.15.275-29o

\section{Introduction}

The very concept of a cluster is not new, but there is a lack of scientific studies that explore clusters in the renewable energy sector. Polish law does not specify clearly the concept of the cluster, and the law on renewable energy sources came into force in February 2015. In the presented paper, the authors conduct a critical literature review on the topic of clusters and renewable energy industry. Analysis of the literature concerns scientific papers, regulations and law provided by the European Union, as well as the websites of the Polish Agency for Enterprise Development and the various clusters in Poland and the European Union. The adopted time range of analysis is 2004-2014, mainly due to the date of Poland's accession to the European Union. The authors prepared a case study of 
the Baltic Eco-Energy Cluster (B E EC) based on the website of the Polish Agency for Enterprise Development. Despite the fact that in each region of Poland there are different clusters focused on the topic of renewable energy, it seems that only this one presented cluster has a great potential for success.

Baltic Eco-Energy Cluster located in the north of Poland (which contributes mostly to the production of a renewable energy in the country) is the biggest energy cluster and the most active one. Therefore, this cluster is a subject of prepared case study, which aims to present a tips and solutions for other clusters that may benchmark against B EEC and improve their own organization model. The case study is based on secondary data from websites and branch reports. The data for a whole paper will be supplemented with secondary data, mainly from the Central Statistical Office of Poland and the data available on the website of the European Commission (Eurostat).

The main aim of this paper is to identify and present the concept of clusters in the renewable energy sector in Poland. In 2007, the European Commission presented the climate and energy package briefly named $3 \times$ $20 \%$ package. It imposes a reduction in greenhouse gas emissions by at least $20 \%$, compared to year 1990 . The other objective of the package is to increase the share of renewable energy in final energy consumption by $20 \%$ (for Poland it is reduced to $15 \%$ ) and increase in energy efficiency by $20 \%$. All of these goals are to be met by 2020 . In the paper, the authors would like to examine whether the clusters in the renewable energy sector in Poland have a chance to support fulfilling the goals of the $3 \times 20 \%$ package.

Preliminary literature review allows creating some hypothesis on the subject addressed. The location of cluster will not be probably determined by natural factors (existence of water bodies or favourable wind conditions), but economic and political factors, associated with the $\mathrm{E} U$ funds. Thanks to those funds, clusters in the renewable energy sector have the opportunity for further development, and thus can become an effective tool for the implementation of the $3 \times 20 \%$ package. Another problem are the global benefits of artificially imposed European Union's climate and energy package. It can occur that the energy-intensive production will be transferred to countries, which are not restricted with climate package. Such situation surprisingly could cause more problems (mainly economic) for Eu Member States than not fulfilling the goals of climate and energy package. 


\section{Clusters: Literature Review}

In Poland, there are many ongoing initiatives and projects referring to the concept of cluster. Objectives and structure of these projects, however, have a large variation. The most common definition of a cluster was developed by Porter (1998), according to whom a cluster is a group of companies existing in a geographical neighbourhood along with the institutions, which are related to them and deal with a particular activity, connected by similarities and competing with one another. The most important in this definition are relationships, cooperation and territorial bonds, which in consequence should generate added value and lead to a competitive advantage on the market (Ratajczak-Mrozek and Herbeć 2013).

Following papers of Jankowska and Pietrzykowski (2013), Ketels (2004) defined main attributes of clusters:

- Proximity: the entities need to be sufficiently and spatially close to permit positive spill-over and enable the sharing of common resources to occur;

- Linkages: their activities need to share a common goal for them to be able to profit from proximity and interactions;

- Interactions: being close and working on related issues does not seem to be enough - some level of interaction is essential;

- Critical mass: a sufficient number of participants being present is required for the interactions to have a meaningful impact on companies.

Similar definition was provided by European Commission (2003): Clusters are groups of independent companies and associated institutions that are:

- Collaborating and competing;

- Geographically concentrated in one or several regions, even though the cluster may have global extensions;

- Specialized in a particular field, linked by common technologies and skills;

- Either science-based or traditional;

- Clusters can be either institutionalized (they have a proper cluster manager) or non institutionalized.

According to above-mentioned definitions, there are usually several parties in cluster initiatives. Those are first of all entrepreneurs, but also 


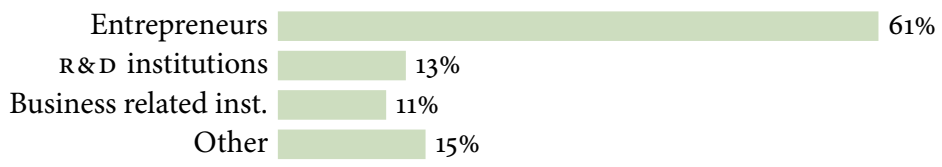

FIGURE 1 Entities Identified as Participants in Clusters and Cluster Initiatives Related to Energy in Poland (adapted from Feltynowski and Rzeńca 2012)

financial institutions, public entities - such as local authorities, universities, media and organizations stimulating cooperation (Jankowska 2011). The situation in which the initiative to establish the cluster goes out of firms and is managed by them is so-called bottom-up approach, in contrary to top-down approach, where activities are undertaken by public authorities. Bottom-up model seems to be more effective because it arises from the need of the market (as can be seen in case study of Baltic EcoEnergy Cluster, paragraph 3). This does not exclude cooperation with public authorities and public institutions, but allows building trust, which in effect brings specific benefits (Cook and Morgan 2002):

- Improving the economic efficiency by saving time and effort related to specific activities, because they can rely on the word of partner;

- Reduction of the risk associated with the activity;

- The development of the ability to learn by the fact that institutions and companies are parties in the process of information exchange.

The results of research conducted by Feltynowski and Rzeńca (2012) (see figure 1) indicate that the structure of the participants of clusters in Poland favours and confirms bottom-up model.

In addition to mentioned benefits, cluster development can contribute to faster economic growth, increase productivity and profits, attract FDI (foreign direct investment), increase exports and create new jobs thanks to the dynamic growth in the number of enterprises. The resulting competitive advantage given location manifests itself nationally and often internationally. Feltynowski and Rzeńca (2012) determined goals of clusters active in renewable energy sources (RES) sector:

- The use and promotion of the region's potential in the field of RES;

- Maximizing the use of existing local potential energy (wind power development, based on biomass and others);

- Stimulating activities to improve energy efficiency in businesses, households, public buildings; 
- Improving energy efficiency leading to energy savings in three areas: final usage, in industry and in the distribution and finally in manufacture;

- Improving local energy security;

- Promotion of Polish energy and environmental technologies;

- Promoting innovation in environmental protection and energy;

- Minimizing financial, organizational, technical and mental barriers;

- Environmental education in all mentioned areas.

Poland provides favourable conditions for the development of innovations and entrepreneurship. In recent years, mainly thanks to the $\mathrm{EU}$ funds, in Poland were created many business-related institutions aimed at supporting the business and science in the implementation of various types of business ventures and $\mathrm{R} \& \mathrm{D}$ (research and development). These institutions offer, among others, office space, specialized laboratories equipment and specialized business consulting. In 2010, a total of 735 work centres for innovation and entrepreneurship were active, including 24 technology parks, 40 business incubators, 90 technology transfer centres and 317 training, consulting and information services (Polska Agencja Rozwoju 2012). According to Polish Enterprise Development Agency, until end of 2015 there were 130 established clusters in Poland (Buczyńska, Frączek, and Kryjom 2016).

Analysis of the structure of Polish cluster initiatives shows that clusters exist in sectors that are considered innovative, as well as more traditional. The most common sector is ICT (information and communications technology) (19 clusters), eco-energy (16) and construction (12), medicine and biotechnology (11). As can be seen, the eco-energy sector is highly ranked among clusters in Poland, as well as the biotechnological clusters that have been described by Puślecki and Staszków (2015). To understand the reason, it is important to explain the role of so-called climate and energy package.

\section{Renewable Energy Sector in the European Union}

As a result of the adoption in 2007 by the European Union the so-called climate and energy package $(3 \times 20 \%)$ the $\mathrm{EU}$ is required to achieve until year 2020 three following key objectives (European Parliament and the Council 2009): (1) to reduce greenhouse gas emissions by at least $20 \%$ compared to $1990 ;$ (2) to improve energy efficiency by $20 \%$; (3) to increase 
the share of renewable energy in total energy consumption to $20 \%$, including $10 \%$ of biofuels in overall fuel consumption in transport. Renewable energy sources include wind, solar, hydro, geothermal, biomass. In fact, $20 \%$ for three objectives is valid in the European Union as a whole, and in the member states, the objectives differ from $20 \%$. This applies to both the size of the planned reduction of carbon dioxide (or even planned increase of emissions) and to improve energy efficiency and the share of energy from renewable sources in gross final energy consumption. Only the target for the share of biofuels in transport fuels of $10 \%$ is applicable in all member states.

In Poland, the share of renewable energy in the total energy consumption by 2020 is expected to reach $15 \%$ due to limited resources and the efficiency of renewable energy sources (RES). At the same time there is a possibility that in Poland by 2020 compared to 2005 greenhouse gas emissions will increase in selected sectors of the economy (up by 14\%) due to lower Gross Domestic Product (GDP) per capita than the average in the EU (Energia i Środowisko n. d.). As a result, the Polish economy is to remain more competitive (using smaller environmental constraints). This is to allow catching up with more developed Eu countries. There are some reasons for development of the renewable energy sector, among others (European Parliament and the Council 2009; Rifkin 2012):

- The ability to reduce its dependence on energy imports (mainly crude oil, natural gas) and strengthening energy security;

- Significant economic benefits and positive stimulus for the economy - progress and technological development, creation of new jobs in the internal market (in the $\mathrm{EU}$ ), including rural areas;

- Environmental protection and indirect responsibility for the environment in the countries exporting energy resources to the $\mathrm{EU}$;

- Renewable nature and natural origin.

According to the directive, these objectives are appropriate and achievable. They offer companies also stability of their potential investments. Those goals must be achieved cost-effectively (European Parliament and the Council 2009), suggesting that economic factors should be more important than imposed from administrative regulations. Meanwhile the cost-effectiveness (economical and environmental) of certain investments in renewable energy sources is questionable and sometimes undermined. Other issues and concerns referring to the package $3 \times 20 \%$, and regarding Poland are as follows (PA P 2015): 
- Lack of diversification of energy supply sources and the dominance of coal as an energy source (in Poland - more than 90\% of electricity is produced from coal and lignite);

- Economic development is associated with an increase in demand for energy, thus increasing environmental requirements may even inhibit economic development;

- The risk of non-competitive renewable energy sector in comparison to the traditional energy sector, which could lead to the transfer of energy-intensive production outside the $\mathrm{EU}$;

- Consequences of political instability and unpredictability - in Poland the law on renewable energy sources came into force only in February 2015 thus this industry was not properly regulated for a long time.

Except of a number of ongoing discussions on the above package, set were further targets for climate and energy in the range of competitive, secure and low-carbon EU economy for the year 2030. They plan to cut greenhouse gas emissions by $40 \%$ below 1990 levels and to increase the share of energy from renewable sources to $27 \%$ (this target is not a binding target for each Member State, but for the whole EU) (European Commission 2014). In August 2014, the Committee of the Regions ${ }^{1}$ stated that it should adopted more ambitious targets for the new climate and energy package. It is about reducing greenhouse gas emissions by $50 \%$ compared to 1990 , achieving the share of energy from renewable sources at $40 \%$ and the reduction of primary energy consumption by $40 \%$ compared to 2005 (Opinion 2014). These objectives are aimed to avoid warming exceeding 2 degrees Celsius and achieve long-term EU target for reducing greenhouse gas emissions by $80-95 \%$. It seems that these demands are not available in some Member States, because there are problems now - with implementation of the package $3 \times 20 \%$. Finally, during the negotiations at the European Council in October 2014 from the Polish point of view they managed to achieve relatively favourable results, i.e. reducing emissions by $40 \%$ compared to 1990 and the share of RES of $27 \%$ by 2030 . In terms of energy efficiency improvements at the level of the $\mathrm{EU}$ was established indicative target of at least 27\% (European Council 2014).

Table 1 presents some data on the implementation of one of the basic objective of the package $3 \times 20 \%$ - the share of energy from renewable sources in all Members States of the European Union in 2013 and targets for 2020. By calculating these indicators the energy consumption in ev- 
ery country was taken into account, and as mentioned, the value of this indicator in different countries differ from each other, as they depend on the state of economic development and the potential for growth in the production of energy from renewable sources (resource capabilities).

It is worth noting that the objective of the share of renewable energy in 2020 at the level of more than $20 \%$ (the average share of the $\mathrm{EU}$ ) have both some developed countries and less developed countries. On the other hand, the level of $20 \%$ or the lower level was planned in some rich and poor countries when the level of GDP per capita is taken into account. The share of energy from renewable sources in excess of $20 \%$ is realized, inter alia, in the Scandinavian countries (Sweden $49 \%$, Finland 38\%, Denmark $30 \%$ ), in Austria (34\%) and France (23\%), but also in the Baltic States (Estonia 25\%, Lithuania 23\%, Latvia 40\%), in Portugal (31\%), Romania (24\%) and Slovenia (25\%). The share of less than $20 \%$ is in some old Member States, among others: Belgium, Germany, Great Britain, Greece, Ireland, Italy, the Netherlands, as well as in the new Member States (which joined the EU in 2004 and later) - Bulgaria, Czech Republic, Hungary, Poland, Slovakia.

It is worth to look also at the degree of achievement of expected demands. Some of the countries already in 2013 reached 2020 plan including Sweden, Austria, Bulgaria and Estonia. Especially the first two countries are leaders in the development of the renewable energy sector. However in other situations (very low level of implementation of the targeted share of renewable energy) are inter alia the Netherlands (4.8\% compared with $14 \%$ of the plan, resulting in the degree of implementation at the level of $34 \%$ ) and the UK (the share of $4.9 \%$ to $15 \%$ of the plan, which gives the degree of implementation of less than $33 \%$ ). In Poland, currently close to $11.5 \%$ of the energy is produced from renewable sources. This means that the plan for 2020 is implemented in around $76 \%$, which poses a real chance that Poland will achieve its goal in a few years. In similar situations are Germany, Hungary, Slovakia and Spain. The higher degree of implementation (over 90\%) have two Scandinavian countries - Denmark and Finland and three new Member States - Latvia, Lithuania and Romania. It can be assumed that the continuation of the development of renewable energy sector in these countries will let to fulfil and maintain their own objectives to 2020.

According to data from the Central Statistical Office, the share of renewable energy in total energy consumption is growing. It can be seen mainly in northern Poland (see figure 2), which is associated on the one 
TA B LE 1 Renewable Energy Sources Share in European Union in 2013 and Target for $2020(\%)$

\begin{tabular}{|c|c|c|c|}
\hline Specification & $\begin{array}{r}\text { The share of } \\
\text { renewable energy } \\
\text { sources in } 2013\end{array}$ & $\begin{array}{r}\text { The targeted share } \\
\text { of renewable energy } \\
\text { sources in } 2020\end{array}$ & $\begin{array}{l}\text { The current level of } \\
\text { implementation }\end{array}$ \\
\hline Austria & 34.5 & 34 & 101.5 \\
\hline Belgium & $7 \cdot 4$ & 13 & 56.9 \\
\hline Bulgaria & 17.2 & 16 & 107.5 \\
\hline Croatia & 17.9 & 20 & 89.5 \\
\hline Cyprus & 6.8 & 13 & 52.3 \\
\hline Czech Republic & 11.4 & 13 & 87.7 \\
\hline Denmark & 27.6 & 30 & 92.0 \\
\hline Estonia & 26.1 & 25 & 104.4 \\
\hline Finland & $34 \cdot 9$ & 38 & 91.8 \\
\hline France & 13.7 & 23 & 59.6 \\
\hline Germany & 12.9 & 18 & 71.7 \\
\hline Greece & 15.8 & 18 & 87.8 \\
\hline Hungary & 9.8 & 13 & 75.4 \\
\hline Ireland & 8.2 & 16 & 51.3 \\
\hline Italy & 14.6 & 17 & 85.9 \\
\hline Latvia & 36.0 & 40 & 90.0 \\
\hline Lithuania & 22.0 & 23 & 95.7 \\
\hline Luxembourg & $3 \cdot 3$ & 11 & 30.0 \\
\hline Malta & 1.8 & 10 & 18.0 \\
\hline Netherlands & 4.8 & 14 & $34 \cdot 3$ \\
\hline Poland & 11.4 & 15 & 76.0 \\
\hline Portugal & 25.8 & 31 & 83.2 \\
\hline Romania & 23.8 & 24 & 99.2 \\
\hline Slovakia & 10.7 & 14 & 76.4 \\
\hline Slovenia & 20.7 & 25 & 82.8 \\
\hline Spain & 14.9 & 20 & 74.5 \\
\hline Sweden & 56.0 & 49 & $114 \cdot 3$ \\
\hline United Kingdom & 4.9 & 15 & 32.7 \\
\hline EU 28 & 14.9 & 20 & 74.5 \\
\hline
\end{tabular}




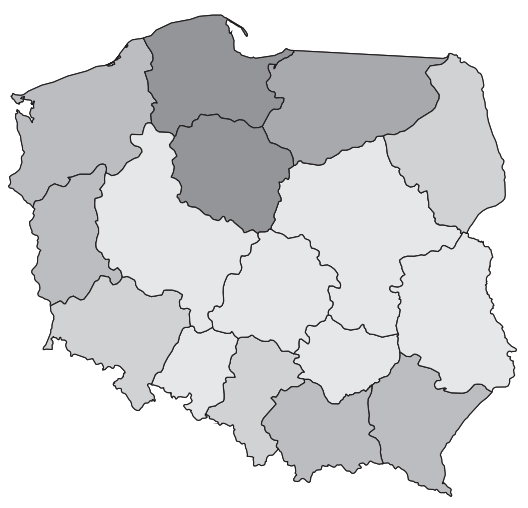

Less than $1 \%$ $1.00-3.00 \%$ $3.01-7.50 \%$

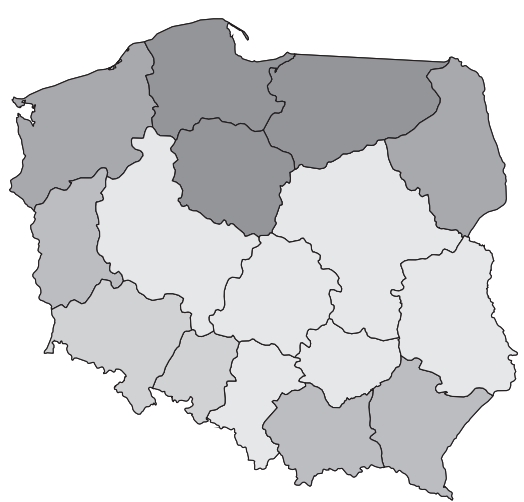

$7.51-16.00 \%$
More than $16 \%$

FIgURE 2 The Share of Renewable Energy in Total Energy Production in Regions in 2005 and 2009 (adapted from Feltynowski and Rzeńca 2012)

TABLE 2 Structure of Use of Renewable Energy Sources in Poland in 2004-2015 (\%)

\begin{tabular}{lrrrr}
\hline Year & $\begin{array}{r}\text { Renewable energy } \\
\text { sources }- \\
\text { Electricity }\end{array}$ & $\begin{array}{r}\text { Renewable energy } \\
\text { sources - } \\
\text { Transport }\end{array}$ & $\begin{array}{r}\text { Renewable energy } \\
\text { sources } \\
\text { and Cooling }\end{array}$ & $\begin{array}{r}\text { Renewable energy } \\
\text { sources }\end{array}$ \\
\hline 2004 & 2.1 & 0.9 & 10.2 & 6.9 \\
2005 & 2.7 & 0.8 & 10.1 & 6.9 \\
2006 & 3.0 & 1.1 & 10.2 & 6.9 \\
2007 & 3.5 & 1.5 & 10.4 & 6.9 \\
2008 & 4.4 & 4.0 & 10.9 & 7.7 \\
2009 & 5.8 & 5.3 & 11.6 & 8.7 \\
2010 & 6.6 & 6.6 & 11.7 & 9.2 \\
2011 & 8.2 & 6.8 & 13.1 & 10.3 \\
2012 & 10.7 & 6.5 & 13.4 & 10.9 \\
2013 & 10.7 & 6.6 & 14.1 & 11.4 \\
2014 & 12.4 & 6.2 & 14.0 & 11.5 \\
2015 & 13.4 & 6.4 & 14.3 & 11.8 \\
\hline
\end{tabular}

NOTES Based on data from Eurostat (http://ec.europa.eu/eurostat).

hand with favourable natural conditions, while on the other with the activity of energy clusters, such as Baltic Eco-Energy Cluster.

Table 2 analyses the structure of energy consumption from renewable sources divided into the consumption of electricity, heating and cooling, and transport, in relation to the total energy consumption in a given area. 
Relatively minor importance in the early years were RES for electricity and transport. With time, however, it was changed. In 2004, electricity was obtained primarily from the water, followed by solid biofuels, but over time, this trend was reversed. Currently, the most important renewable source of electricity are just solid biofuels, then wind and hydro. The share of renewable energy sources in gross final consumption in Poland is currently (in 2013) of $11.3 \%$. According to the strategy of indirect objectives (indicative trajectory) designated by the EU, Poland should achieve in 2013-2014 the share of 9.5\%. This means that Poland is well on the way to 2020 to achieve its target for renewable energy.

\section{Baltic Eco-Energy Cluster Case Study}

Even despite the fact that in Poland are located more than 20 clusters focused on a renewable energy sector (Feltynowski and Rzeńca 2012), only a few of them are active entities. Some of the existing clusters are not conducting any activities, while some others are active to a very limited extent. The cluster, which is a distinguishing one, which other clusters may even benchmark against, is the Baltic Eco-Energy Cluster.

The Baltic Eco-Energy Cluster was established in 2007, so it is not the oldest one. Therefore, it may be presumed that the factor of the length of the existence on the market is not the dominating element of a success. However, most of the clusters in renewable energy were established in years 2006-2009, when Polish Agency for Enterprise Development was financially supporting a positive attitude against such cluster initiatives. It may be the reason of the existence of a number of inactive clusters that were established on the wave of their boom and positive prosperity. Even though the Baltic Cluster is located in Gdańsk, like it was stated earlier, the city of location is not a very strict factor. It is only the main head office of cluster's coordinator. In the cluster included are entities from three regions, namely Kujawsko-Pomorskie, Pomorskie and WarmińskoMazurskie, so Gdańsk is important city but does not play a dominant role within the cluster.

In each of mentioned regions, energy production from renewable resources was very important. In 2009 in Warmińsko-Mazurskie 42\% of produced energy came from renewable resources, while in KujawskoPomorskie over one-third and Pomorskie almost one-third (Feltynowski and Rzeńca 2012). It confirms the great importance of renewable energy in this region of Poland and a positive attitude against new technologies. Therefore, it is not surprising that within two years of a time of creation, 
Baltic Eco-Energy Cluster was the most important cluster in the region.

According to the most relevant data (http://www.imp.gda.pl/projekty/ bkee/uczestnicy), the BEEC consists of 174 entities, including:

- 133 enterprises;

- 14 government entities (small communities, towns and municipal offices);

- 14 science entities (high schools and universities);

- 13 other institutions (foundations, etc.).

While it is believed that due to a maintenance and management issues a number of participants of energy cluster should not exceed 40 entities (Mazowiecka Agencja Energetyczna 2013) this cluster stays in opposition. The reason is that, this cluster is administrated by Gdański Instytut Maszyn Przemysłowych (Gdansk Institute for Industrial Machinery), that coordinates all cluster activities. Therefore the large number of participants instead of being a problem for a cluster determines its strength. The coordinator cannot dominate over other entities and be a competitive unit. In case of B EE C, Gdansk Institute for Industrial Machinery helps in raising external financial funds and establishing collaboration between science and business. Also small clusters may achieve a competitive advantage from specialization. They should focus on some niche as Ekologiczny Dom Energooszczędny (Ecological Energy Efficient Home), where market is not so strongly saturated and then strive for perfection in this specific area.

One of the main companies involved in BEEC is Energa, one of the biggest energy companies in the country. In most of the cases such, a big partner could act as a threat for other smaller companies. In Baltic Cluster, the relations between engaged companies and institutions were solved to satisfy all participants. Energa is included only in the biggest research projects, so smaller companies can gain experience through cooperation and play the main role in smaller projects. Thanks to that, all companies are satisfied and potential of each of them is fully exploited.

In some cases participants of a cluster (mostly in its initial stage), may suffer from not possessing a legal personality. It may be solved by the usage of a legal personality of a coordinator of a cluster or one of its participants (what happened at the beginning also in BEEC). It is even easier when a cluster consists of a large number of participants.

The main aim of Baltic Cluster is to introduce and promote a widely understood idea of distributed co-generation, understood as simultane- 
ous small and medium scale production of thermal energy and electricity from renewable energy sources, mainly biomass, but also by converting water, solar and wind energy. The advantage of big clusters like BEEC is a possibility of being active in many areas. $\mathrm{BEEC}$, due to a large number of involved entities is active in four main spheres of activities:

- Raw materials based mostly on using biomass;

- Research and Development focused on development of new technologies and competitiveness of involved companies in terms of machinery;

- Creating energy from renewable resources and development of small biomass producers;

- Production of machinery for a purpose of bio energy.

The Baltic Cluster is active through all stages of work - in - projects as it is involved both, in development of new research projects and their implementation. It is also active in international environment, taking active part in meetings of European Commission advisory groups, international projects, conferences or workshops. The cluster is also aware of the importance of good Public Relations. Therefore, it cares about a promotion and organizes conferences, seminars and competitions for junior schools.

For the success of BEEC, very important role-plays a support from involved governmental entities. In case when a cluster does not consist of such entities, it is necessary to ensure a formal cooperation with cities and institutions. Another important factor is a strong support from science to BEEC. Because this cluster works together with the best local technology universities, high schools of economy and management and machinery institutes, it has a direct access to knowledge resources. It may not suffer from a scarcity of well-educated people, who strongly contributes to the newest technologies used in renewable energy sector. Clusters based on an expertise that comes from Research and Development work has a great possibility of receiving attractive funds from grants. More applications for grants does cluster send, increased is its experience. BEEC is also an example of open cluster, which co-operates also with other clusters (from their proximity). Because to some extent all energy clusters are working on similar tasks, it is much easier for them to co-operate and even together apply for some external financial resource. The successful collaboration between BEEC and relatively very small (with 16 entities) Nadwiślański Klaster Energii Odnawialnej (Vistula River Valley Energy Cluster) may encourage other clusters to consider working together. Big 
clusters gain knowledge from niche market, while small entity has access to greater resources. The only important thing is to have a common goal, which both clusters want to achieve.

Based on Baltic Eco-Energy Cluster, clusters focused on renewably energy that are interested in success should follow the following rules:

- Cluster has to be open place, without limit of number of participants and willing to collaborate with other clusters and institutions;

- Applying for external funds is very important for the functioning of the cluster;

- The role of coordinator needs to be made carefully to choose entity, which will not dominate other participants.

\section{Conclusions}

The idea of clusters was known many years, but in Poland, it was developed mainly in the last decade thanks to the $\mathrm{EU}$ funds. Clusters are considered to be a tool which helps developing innovativeness and improving the competitiveness of companies, cities or entire regions. Boom on clusters however causes that this term is overused and often used unduly. Some clusters are dead formations, created with funds from the $\mathrm{EU}$, in which innovation and cooperation does not have a chance to be developed. At the end of 2015, there were 130 clusters in Poland, of which 16 supposed to represent eco-energy sector. This is an area where the concept of clustering has greater sense of existence and where well-managed clusters can be a tool for achieving the objectives of the climate package. The case study of Baltic Eco-Energy Cluster is presented as example of successful and the biggest energy cluster in the country, which may act as a benchmark for other sector clusters that are willing to contribute positively to changes in Polish energy sector.

\section{Notes}

1 Committee of the Regions is a consultative body for the institutions of the European Union (European Commission, Council of the European Union, the European Parliament), which represents local and regional authorities in the $\mathrm{EU}$.

\section{References}

Buczyńska, G., D. Frączek, and P. Kryjom. 2016. Raport z inwentaryzacji klastrów w Polsce 2015. Warsaw: Polska Agencja Rozwoju Przedsiębiorczości. 
Cooke, P., and K. Morgan. 2002. The Associational Economy: Firms, Regions and Innovation. New York: Oxford University Press.

Energia i Środowisko. N. d. 'Pakiet klimatyczno-energetyczny.' http://www .energiaisrodowisko.pl/zarzadzanie-energia-i-srodowiskiem/pakietklimatyczno-energetyczny

European Commission. 2003 'Final Report of the Expert Group on Enterprise Clusters and Networks.' European Commission, Brussels.

- 2014. '2030 Climate and Energy Goals for a Competitive, Secure and Low-Carbon E U Economy' Press release, 22 January. http://europa .eu/rapid/press-release_IP-14-54_en.htm

European Council. 'Conclusions on 2030 Climate and Energy Policy Framework.' EUCO 169/14, European Council, Brussels.

European Environment Agency. 2015. Renewable Energy in Europe: Approximated Recent Growth and Knock-on Effects. Luxembourg: Publications Office of the European Union.

European Parliament and the Council. 2009. 'Directive 2009/28/EC of the European Parliament and of the Council of 23 April 2009 on the Promotion of the Use of Energy from Renewable Sources and Amending and Subsequently Repealing Directives 2001/77/EC and 2003/30/EC.' Official Journal of the European Union, L 140.

European Union. 2014. 'Opinion: A Policy Framework for Climate and Energy in the Period from 2020 to 2030.' ENVE-V-047, Committee of the Regions. https://webapi.cor.europa.eu/documentsanonymous/COR -2014-02691-oo-oo-AC-TRA-EN.doc/content

Feltynowski, M., and A. Rzeńca. 2012. Klastry energetyczne w Polsce. Szczecin: Uniwersytet Szczeciński.

Jankowska, B. 2011. 'Klastry na usługach innowacyjności przedsiębiorstw.' In Przedsiębiorstwo na rynku międzynarodowym, edited by J. Schroeder, 67-77. Poznan: Wydawnictwo Uniwersytetu Ekonomicznego w Poznaniu.

Jankowska, B., and M. Pietrzykowski. 2013. 'Clusters as Absorbers and Diffusers of Knowledge.' Poznań University of Economics Review 13 (1): 6888.

Ketels, C. H. M. 'European Clusters.' In Innovative City and Business Regions, vol. 3, edited by T. Mentzel, 1-5. Bollschweil: Hagbarth.

PA P. 2015. 'Sejm uchwalił ustawę o odnawialnych źródłach energii.' wnp.pl Portal Gospodarczy, 16 January. http://energetyka.wnp.pl/sejm-uchwalil -ustawe-o-odnawialnych-zrodlach-energii,242496_1_o_o.html

Polska Agencja Rozwoju. 2012. Klastry w Polsce: Katalog. 2012. Warsaw: Polska Agencja Rozwoju Przedsiębiorczości.

Mazowiecka Agencja Energetyczna. 2013. 'Analiza rynku klastrów energetycznych i innych w środowisku polskim, niemieckim i francuskim - 
raport z badania Desk Research.' http://www.mae.com.pl/files/analizaklastrow_www-tryb-zgodnosci.pdf

Porter, M. E. 1998. 'Clusters and the New Economics of Competition.' Harvard Business Review 76 (6): 77-90.

Puślecki, Ł., and M. Staszków. 2015. 'New Cooperation Modes: An Opportunity for Polish Biotechnological Clusters.' Managing Global Transitions 13 (2): 171-18.

Ratajczak Mrozek, M., and M. Herbeć. 2013. 'Actie and Inactive Clusters in Polish Furniture Industry: The Industrial Network Approach.' Intercathedra 29 (3): 85-94.

Rifkin, J. 2012. Trzecia rewolucja przemysłowa. Katowice: Sonia Draga.

This paper is published under the terms of the Attribution-

NonCommercial-NoDerivatives 4.o International (CC BY-NC-ND 4.0)

License (http://creativecommons.org/licenses/by-nc-nd/4.o/). 


\title{
The Growth Challenge of Western sMES \\ in Emerging Markets: An Exploratory \\ Framework and Policy Implications
}

\author{
Mitja Ruzzier \\ University of Primorska, Slovenia \\ mitja.ruzzier@fm-kp.si \\ Yusaf H. Akbar \\ Central European University, Hungary \\ akbary@business.ceu.edu \\ Guido Bortoluzzi \\ University of Trieste, Italy \\ guido.bortoluzzi@deams.units.it \\ Andrea Tracogna \\ University of Trieste, Italy \\ andrea.tracogna@deams.units.it
}

In this paper, we explore the main inhibiting factors associated with the process of entry and escalation of SMEs in international markets, with a focus on Emerging Markets. We identify and propose seven main categories of Institutional Voids and three main types of resources that may critically determine SMEs' performances on EMs, namely, internationalization knowledge, social capital resources and marketing capabilities. Institutional Voids and resources are brought together within a conceptual framework suggesting that resource-scarce sMEs will hold back in their attempts to commit further to Emerging Markets and will be further dissuaded the higher the Institutional Voids in the market. The paper contributes to the policy literature on SME internationalization by focusing on two areas of public policy action that could have a clear and manifest impact on smes conduct in Emerging Markets, the first related to the resources available to and exploitable by SMES and the latter associated with Institutional Voids.

Key Words: smes, emerging markets, institutional voids, resources

JEL Classification: $\mathrm{F} 23, \mathrm{M} 16, \mathrm{O} 31$

https://doi.org/10.26493/1854-6935.15.291-314

\section{Introduction}

SMES are generally believed to be fundamental to the long-term economic development of both developed and developing countries. In the 
Western world, several public programs and policies are aimed at supporting the start and establishment of SMES, as well as their growth, wherever it takes place, both at the national and at the international level.

Due to economic slowdown in developed countries, a growing number of SMEs is today entering and trying to establish in Emerging Markets (EMS). Yet, after the first market access, these firms are discovering that the process of growth is particularly challenging. This is due to two factors. First, sMEs are typically resource-constrained when compared with their larger brethren. Second, E MS are characterized by 'unfamiliar conditions and problems' (Arnold and Quelch 1998, 8) that Khanna, Palepu and Sinha (2005) first termed as Institutional Voids.

Past research has thoroughly investigated the factors affecting firm growth on international markets from different perspectives. The adoption of the Resource-Based Theory (в в $)$ ) in the study of firm internationalization in general (e.g., Erramilli, Agarwal, and Dev 2002; Brouthers and Hennart 2007), and of sMes in particular (Ruzzier, Hisrich, and Antoncic 2006; Wright, Westhead, and Ukbasaran 2007), has produced important results, and notably that resources matter in the success of a firm's internationalization strategy, especially when entering E Ms. Further, current research on EMS has shown that Institutional Voids impact the effectiveness of the firms' resources and can impede or even block the progress of these firms in international markets (Meyer et al. 2009; Khanna and Palepu 2010).

Our study aims at further investigating the features of the evolution of Western SMEs' internationalization strategies in EMs, beyond the entry mode and the impact of resource-based advantages and institutional factors in that process. The aim of this paper is to generate and evaluate specific policy frameworks that can facilitate the success of SMES in EMS. We identify the different obstacles that can limit the growth of sMES in the EMS and suggest a set of effective policies to support such companies in their attempts to escalate in these markets. To do so, we combine the Resource-Based Theory of the firm (в в T) with an EMs' institutional perspective.

Our paper is structured as follows. First, we discuss Western smes' weaknesses in EMs, through the theoretical lenses of the Uppsala model (Johanson and Vahlne 1977) and the Resource-Based Theory (Barney 1991). Second, we describe EMS regarding their fundamental characteristics, and with a focus on Institutional Voids. Third, we focus on the role of sMEs' resources and capabilities in determining their international per- 
formance. Then, we describe how escalation of commitment of sMEs in EMS might be constrained by the presence of a weak resource and capabilities base and of significant Institutional Voids. Lastly, we derive a set of policy proposals for governments in their efforts to promote $\mathrm{sME}$ development in EMS.

\section{Background}

\section{SMES AND THEIR LIABILITIES WHEN ENTERING} EMERGING MARKETS

The stage-based model of internationalization (Uppsala model) is one of the most enduring frameworks in the International Business theory (Johansson and Vahlne 1977; Petersen and Pedersen 1997). According to it, firms choose their optimal mode of serving a foreign market by considering their costs and risks in this particular market and their own available resources (Hood and Young 1979). The level of market-entry commitment is related to the firm's familiarity with the market: the more psychically distant the market, the riskier it becomes for the firm to serve this market; hence, the firm tries to minimize its investments by choosing a less resource-intensive mode of operation. Later on, firms learn from their current operations and activities in the foreign market, and, over time, this learning reduces the level of uncertainty and allows firms to strengthen their market position and eventually escalate their commitment. This process of increasing commitment is not designed to be deterministic: indeed, it has been recently suggested that commitment might decline or even cease if performance prospects are not sufficiently promising (Johanson and Vahlne 2009).

Since the pioneering work of Johanson and Vahlne (1977) on the role exerted by the accumulation of market knowledge in reducing the psychic distance of firms in foreign markets, the Resource-Based Theory (Wernerfelt 1984; Barney 1991) has drawn increasing attention in the International Business literature (Ruzzier, Hisrich, and Antončič 2006) and has been successfully applied also to the case of SMEs entering E MS (Balboni, Bortoluzzi, and Grandinetti 2013; Bortoluzzi et al. 2014). The difficulties faced by small firms in the international markets have been traditionally described and discussed as 'the cost of doing business abroad' (Hymer 1976) and as the 'liability of foreigners' (Zaheer 1995). The Resource-Based Theory posits that the generation and the preservation of a competitive advantage is related to the firm's ability to develop 
and control specific assets that are valuable, rare, difficult for competitors to imitate, and difficult if not impossible to replace with other resources and capabilities (Barney 1991; Teece, Pisano, and Shuen 1997). Therefore, a difference in the endowment of resources and capabilities explains why firms operating in the same sector - thus subject to the same competitive dynamics at the industry level - exhibit different performance levels in a market (Grant 1991).

The same resource-based explanation can be applied to the process of a firm's expansion in international markets. Cuervo-Cazurra, Maloney, and Manrakhan (2007) identify three different categories of resourcebased challenges in international markets: the loss of an advantage when transferring a valuable resource into a new country; the creation of a disadvantage due to the transfer of resources into a new country; the lack of complementary resources to operate abroad. The last category in turn generates three sub-categories, or 'liabilities': liability of expansion, related to the need to operate at a larger scale than before; liability of newness (Stinchcombe 1965; Shepherd, Douglas, and Shanley 2000), due to the need to learn and adapt to a new market, and liability of foreignness, which is mainly related to the difficulties in operating within a new institutional environment.

Such liabilities appear to be particularly significant for SMES as they generate competitive advantages based on tacit resources (knowledge) that are not easily transferrable to other markets. Furthermore, their limited resource endowment and their lack of investment capacity generate additional obstacles in entering and being established in new markets. On top of this, weak managerial and marketing resources may generate further problems, explaining their preference for less demanding forms of presence (export-based modes).

The limits of an SME's resource and capabilities base are clearly observable when they try to enter Ems. Compared to developed markets, SMES encounter very different institutional environments in EMS and often lack the needed market and cultural understanding, as well as the business and non-business relationships and the associated social capital (in the form of reputation, established relationships and brands). In this paper, we argue that SMEs suffer more such limitations in EMS than in developed markets and comparatively more than larger multinational firms, compounded by their weak base of resources and capabilities and the significant contextual differences they must deal with (Vianelli, de Luca, and Bortoluzzi 2012). Due to such intrinsic weaknesses, there is a 
need for specific policies aimed at supporting and promoting their entrance and growth in EMS.

\section{EMERGING MARKETS AND INSTITUTIONAL VOIDS}

While historically being considered as locations for cost-saving opportunities for Western firms (Cavusgil, Knight, and Riesenberger 2012), EMS are now experiencing a remarkable growth of purchasing power along with mounting expectations of local consumers. These changes push an increasing number of Western firms to enter those markets to exploit their potential opportunities involving increased exports, as well as the re-location of capital and production and the shift of supplier networks at the global level (Jansson 2007). Yet, despite a positive EMs dynamic, a limited group of European sMEs export to EMS (approximately seven to ten per cent of smes according to the European Commission 2011). To explain the phenomenon, some scholars studying developed country firms entering EMS have drawn attention to the peculiarity and idiosyncratic nature of EM contexts and to the degree of (under)-development of their institutions. Arnold and Quelch $(1998,8)$ stated that E Ms are characterized by 'unfamiliar conditions and problems', which include poorly functioning or non-existent logistical infrastructure (highways, railways, harbours, airports, IC T networks), weak market systems and channels (i.e. sales and distribution networks) and important differences in buyer behaviour that developed country companies may find difficult to understand and adapt to.

The business strategies of firms from developed countries are frequently predicated on institutions that guarantee protection of their tangible and intangible resources. The absence of such institutions generates obstacles to being established in EMs. Such Institutional Voids relate to unfamiliar conditions and problems that characterize these markets and can deter firms from entering them or call for a modification of the entry modes (Arnold and Quelch 1998; Steenkamp 2005; Khanna and Palepu 2010).

Notable taxonomies of Institutional Voids include Khanna, Palepu and Sinha (2005) 'dimensions of institutional contexts' and the World Bank's 'Ease of Doing Business' survey. The World Bank has ten indices that measure the ease with which companies can do business in a country. Khanna, Palepu and Sinha (2005) developed an exhaustive taxonomy of potential Institutional Voids that they gathered into five categories. The first group is the 'political and social system' that includes political stabil- 
ity of the country, the degree of protection of private property and intellectual rights and the efficacy of the judiciary system. The second group, called 'openness', considers the existence of discriminatory legal restrictions and constraints facing foreign investors. The third describes Institutional Voids in 'product markets' and relates to the ease of access to valuable information on consumers and market trends, the existence of an adequate distribution system and the extent of product-related environmental and safety regulations. The fourth group is concerned with the conditions and flexibility of the 'labour market' and deals with the availability and quality of human capital in a specific institutional setting. The fifth and last category represents the 'capital market' and examines the extent and quality of financial intermediaries, venture capital investors, stock markets and regulatory systems (Welter and Smallbone 2011; Gao, Ballantyne, and Knight 2010; Meyer et al. 2009).

The core implication of these Institutional Voids taxonomies is that while the direct cost of doing business in E M may be lower relative to developed country markets, Institutional Voids raise both risk and transaction costs of doing business. Institutional Voids are believed to create both barriers for firms entering EMS and to impose limitations on their commitment even if they decide to enter. A weak institutional environment, in terms of high Institutional Voids, may dissuade firms from committing time and resources in the market, as noted both by Broadman et al. (2004) and Welter and Smallbone (2011). Further, as reported by Khanna and Palepu (2010), a major problem in operating in EMS is the lack of 'intermediaries' (such as market research firms, development agencies, headhunting firms, business schools, advisors, regulators, legislators, judiciary system) who can reduce or eliminate Institutional Voids. This is a problem especially for foreign smes, which - due to their limited resource base and lack of experience - would very much like to refer to such intermediaries to enter and be established in the EMs. For instance, Sousa and Bradley (2008) found that the institutional environment, expressed in terms of communication and marketing infrastructure, technical requirements, legal regulations and economic/industrial development, exerts a significant impact on the export performance of the firm. In a later study comparing the internationalization processes of SMES in EU, China and Russia, Hilmersson and Jansson (2012) found the institutional setting of EMS to limit the positive effect provided by the internationalization knowledge on the internationalization process of the firm. In a recent qualitative study analysing three European firms, Bor- 
toluzzi et al. (2014) found Institutional Voids to severely affect the way entering firms set their distribution channels in EMS and the decision to invest in the use of more resource-demanding modes of presence. Further research also confirmed the role of institutional heterogeneity (and dysfunction) relative to developing country contexts and their impact on a firm's entry decisions and the effectiveness of subsequent steps in EMS (Khanna and Palepu 2010; Ferreira, Li, and Yong Suk 2009; Henisz 2004; $\mathrm{Xu}$ and Shenkar 2002; Kostova and Zaheer 1999). Overall, this research stream has led to a broad-based acceptance that institutions that support markets play a greater role in firm performance (Oliver 1997), 'directly determine what arrows a firm has in its quiver' (Ingram and Silverman 2002, 20), and represent 'one leg that helps sustaining a [firm's] strategy tripod' along with the firm's resources and capabilities and industry conditions (Peng, Wang, and Jiang 2008, 921).

\section{Towards Developing a New Framework of smes' Escalation in Emerging Markets}

THE DRIVERS OF SME ESCALATION IN EMERGING MARKETS

Past research has primarily addressed the theme of Institutional Voids to investments made by multinationals, frequently contrasting whollyowned subsidiary (wos) with joint venture (Jv) modes (e.g. Brouthers 2002; Brouthers and Hennart 2007; Hill, Hwang, and Kim 1990; Puck, Holtbrugge, and Mohr 2009) thus perpetuating a simplified view of the reality, in which SMEs typically enter foreign markets through exportbased modes. Such studies have taken into consideration the limits and constraints of sMEs going abroad, suggesting that such firms are less likely to pursue high-commitment forms of presence while preferring to approach foreign markets through direct or indirect exports (Gankema, Snuif, and Zwart 2000; Jansson and Sandberg 2008). Furthermore, while many SMES enter EMS, only a few of them escalate to more resourcecommitted forms of presence (Akbar, Bortoluzzi, and Tracogna 2014).

In this paper, we refer to two types of escalation of commitment in foreign markets: the first (between-modes) occurs through the adoption of riskier modes of operation, as typically described by the stagebased internationalization theory (Johanson and Vahlne 1977); the second (within-modes) results in the escalation of resource commitment within the initial mode of operation. This latter type of escalation relates to the degree to which additional resources, both organisational and 
managerial, are allocated to operations within a specific EM after the entry phase. Such a concept of escalation is not new to the international business literature: indeed, stage-based theories of internationalization are built around the process of committing additional resources in a market, because of the accumulation of international experience and market knowledge (Johanson and Vahlne 1977). However, this process of gradual establishment in a market (within-modes) is rarely considered as a key dimension of the internationalization process of firms and has been even less analysed in the context of EMS relative to the first type of escalation of commitment (between-modes), which results in the adoption of a higher mode in the establishment chain, ranging from: indirect export; direct export; strategic alliance (non-equity based agreements including also franchising); joint ventures (equity-based agreements) and Foreign Direct Investment (F DI) (Swoboda, Olejnik, and Morschett 2011).

Within the framework we are developing, and based on the R B T, three variables have a major direct and positive effect on the escalation of SMES in the EMS: the international knowledge of the firm or entrepreneurs (A), the social capital resources of entrepreneurs and their firms (в) and the marketing capabilities (C). We will refer to the above as the 'resource and capabilities base' (RCB) of sMEs.

Several studies confirm the existence of a positive relationship between accumulated internationalization knowledge (A) and a firm's international achievements. Internationalization knowledge is the outcome of a learning process-taking place through and after the entry in foreign markets (Cavusgil, Knight, and Riesenberger 2012; Dean, Mengüç, and Myers 2000; Johanson and Vahlne 1977). According to Eriksson et al. (1997), such knowledge informs a firm's entry decision into a foreign market. It includes, for instance, the specific rules and customs of the market, the attitudes and preferences of local consumers, and the specific information about local suppliers and distributors. Internationalization knowledge accumulates over time, as the firm continues to operate in foreign markets (Blomstermo, Eriksson, and Sharma 2004; Autio, Sapienza, and Almeida 2000). Conversely, should a firm exit foreign markets, its accumulated knowledge rapidly obsolesces. The gradual accumulation of internationalization knowledge supports the further internationalization of firms, encouraging them to enter new, distant markets, and to escalate their existing commitments in already served markets (Francis and Collins-Dodd 2004; Prasad, Ramamurthy, and Naidu 2001). Francis and Collins-Dodd (2004) found a significant relationship between a 
firm's degree of export commitment, as a proxy of its accumulated experience, and its ability to further expand in foreign markets. Prasad, Ramamurthy, and Naidu (2001) found that the international knowledge of a firm moderates the relationship between its marketing capabilities and its international achievements. In other words, when a firm accumulates international knowledge, it becomes more able to exploit with success its marketing resources and capabilities in international markets. Internationalization knowledge allows managers to better understand foreign markets (Axinn 1989) and to better detect additional international opportunities there (White, Griffith, and Ryans 1998). This is especially relevant for SMES whose expansion processes are typically more gradual than those of MNES (Hilmersson and Jansson 2012). Thus, we can expect that internationalization knowledge positively impacts a firm's international market performance and establishment (Akbar, Bortoluzzi, and Tracogna 2014). In other words, SMES endowed with greater amounts of internationalization knowledge will be better positioned to expand their business and to succeed also in the context of EMs.

The importance of social capital resources (в) in the internationalization process of SMEs was identified in different studies (Ruzzier and Antončič 2007; Birley 1985; Ostgaard and Birley 1994) and will represent our second main driver of SME escalation in EMs. Social capital, being a resource itself, is usually embedded within, available through, and derived from the network of relationships at the individual and firm level (Nahapiet and Ghoshal 1998). Regarding the network content, entrepreneurs' social networks can provide entrepreneurs and their firms with information and access to other scarce resources (Ostgaard and Birley 1994; Liao and Welsch 2003), and facilitate their identification, collection and allocation (Birley 1985). Social networks help firms expose new opportunities, obtain knowledge and learn from experiences (Chetty and Holm 2000), and establish formal relationships with lending institutions (Honig 1998). Peng and Luo (2000) stated that the social capital embedded in managerial ties may be more important in situations of imperfect competition, characterized by weak institutional support and distorted information (such as the EMs). The more uncertain the environment, the more likely informal ties with managers in other firms will be mobilized (Pfeffer and Salancik 1978).

It is broadly accepted that marketing capabilities (c) are a primary driver of a firm's competitiveness (Merrilees, Rundle-Thiele, and Lye 2011; Vorhies and Morgan 2005; Weerawardena 2003), while a wide literature 
recognizes the relevance of such capabilities also when firms enter foreign markets (Morgan, Katsikeas, and Vorhies 2012). Marketing capabilities refer to a firm's general ability to manage product offerings, business partners and distribution systems, as well as advertising and communication activities and pricing (Zhou, Wu, and Barnes 2012; O'Cass and Julian 2003). Cavusgil and Nevin (1981) were among the first to demonstrate that the export propensity of a firm is related to its ability to develop effective marketing plans. Zou and Stan (1998) explored ten years of empirical literature in this subject and found that the organization of marketing resources within a firm and its capacity to manage market research and its distribution network are important explanatory variables of the international presence of firms. More recent studies sharing a similar conceptual tradition include Hitt et al. (2000), Isobe et al. (2000), Minbaeva et al. (2003), Ruzzier, Hisrich, and Antoncic (2006), Hsu and Pereira (2008). Other studies, that explicitly adopted the R B T approach, confirmed this finding. Haar and Ortiz-Buonafina (1995) found that marketing capabilities positively impact the export development of Brazilian firms. Along the same lines, Lu et al. (2009) found that SMEs in possession of more adaptive marketing capabilities perform better in foreign markets. We can thus conclude that smes that are better equipped with marketing capabilities will also better perform in the context of EMs.

THE FRAMEWORK

The set of resources described above do not only show a direct positive effect on the escalation processes of SMES in EMS. Indeed, their effect on escalation is negatively moderated by the presence of Institutional Voids. In other words, resources and capabilities have a value that is contingent on the institutional conditions in which they are leveraged: Institutional Voids decrease the contextual value of the resources and capabilities and eventually determine, other conditions being equal, a lower-commitment presence and a less rapid escalation in the market.

Based on the above, we can introduce a set of propositions, which conceptually link SMEs' escalation in EMs to the resource and capabilities vector (RCB), with Institutional Voids playing both a direct and a moderating role:

proposition 1 The Resource and Capabilities Base (всв) positively affects SMES' escalation in EMS.

PROPOSITION 2 Higher institutional voids exert a negative effect on SMES escalation in EMS. 
Resources and capabilities base

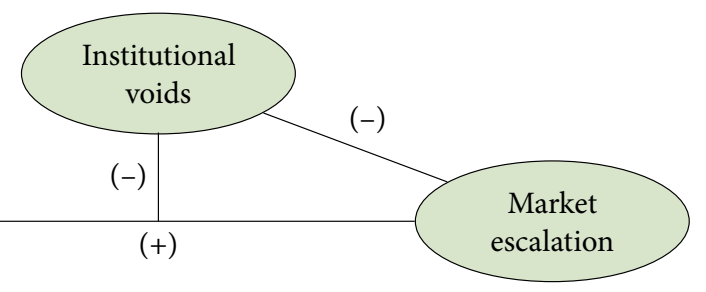

FIGURE 1 Framework of SMEs' Escalation in Emerging Markets

PROPOSITION 3 Institutional Voids negatively moderate the direct positive relation of $R C B$ on SMES' escalation in EMS.

\section{The Impact of Institutional Voids on SM Es' Escalation in Emerging Markets}

In delineating and characterizing Institutional Voids, we have referred to the World Bank's Ease of Doing Business Index. For the purposes of our research, we have selected 4 out of 10 sub-indices, namely:

1. Starting (and developing) a business, that is related to the time, costs and red tape that are needed to open a new business;

2. Protecting investors, which measures the strength of shareholder protection including transparency and the ability to sue officers and directors for misconduct;

3. Trading across borders, which is related to the ease of managing import/export activities (time, documents and costs);

4. Enforcing contracts, that refers to the ease of procedures and the time and costs needed to enforce a commercial contract.

Furthermore, we have enlarged the list of institutional factors to include other variables, which are relevant in influencing the mode of presence and operations, and namely:

5. Availability of data and information on the market, related to the ease (and cost) of access to relevant information and data that can drive firms' decisions;

6. Intellectual Property (IP) laws and regulations, that refers to the level of protection guaranteed to foreign firms' intellectual capital;

7. Labour contract laws, dealing with the existence of restrictive rules and regulations to hire (and fire) workers. 
TABLE 1 Effects of Institutional Voids on SMES Escalation in Emerging Markets

\begin{tabular}{|c|c|}
\hline $\begin{array}{l}\text { Starting and } \\
\text { developing a } \\
\text { business }\end{array}$ & $\begin{array}{l}\text { The factor is relevant to the theme of escalation when a firm who } \\
\text { was previously exporting in EMs decides to establish a direct, local } \\
\text { presence in the market (hence escalating from lower to higher } \\
\text { resource commitment modes). In this case, significant difficulty } \\
\text { in starting and developing a business locally can discourage a firm } \\
\text { from growing. }\end{array}$ \\
\hline $\begin{array}{l}\text { Protecting in- } \\
\text { vestors }\end{array}$ & $\begin{array}{l}\text { A lack of protection of foreign investors has a heavy impact on a } \\
\text { firm's escalation process. In such cases, firms will tend to keep an } \\
\text { export-based presence in the market and avoid any investment in } \\
\text { proprietary facilities (shops, plants, warehouses, other facilities) } \\
\text { given the difficulties in recovering or liquidating assets in the coun- } \\
\text { try. }\end{array}$ \\
\hline $\begin{array}{l}\text { Trading across } \\
\text { borders }\end{array}$ & $\begin{array}{l}\text { Restrictive trading legislation and practices could have very dif- } \\
\text { ferent impacts on firms' resource commitment decisions. Trading } \\
\text { restrictions could hamper firms from escalating to heavier modes } \\
\text { (i.e., switching from export to FDI) or, conversely, could force firms } \\
\text { to have a local presence right from the beginning due to trade bar- } \\
\text { riers that discourage the import of specific goods. Such barriers } \\
\text { normally discourage smaller firms, more than bigger ones. In some } \\
\text { cases, restrictive trade rules could disguise the real magnitude of } \\
\text { firms' escalation in a market. For example, rather than pursuing a } \\
\text { wholly owned FD I project, the firm may prefer or be required to } \\
\text { form a Joint Venture instead - implicitly limiting its escalation. }\end{array}$ \\
\hline $\begin{array}{l}\text { Enforcing con- } \\
\text { tracts }\end{array}$ & $\begin{array}{l}\text { An unreliable judiciary system represents a serious impediment to } \\
\text { the international commitment of firms. Firms are less willing to ex- } \\
\text { pand their presence in a market if they are not sure to be protected } \\
\text { in case of disputes related to contracts and agreements. In these } \\
\text { instances, they will prefer to manage sales and supply activities } \\
\text { through spot contracts. }\end{array}$ \\
\hline
\end{tabular}

Continued on the next page

Such seven institutional factors can deter firms from entering them or call for a modification of the modes of presence (Steenkamp 2005; Khanna and Palepu 2010). In particular, high levels of Institutional Voids might explain why firms adopt a lower-commitment entry mode in international markets (Meyer et al. 2009), because of the higher risks and uncertainties posed on the firm's investments. Moreover, persistent high levels of Institutional Voids may also discourage further escalation of commitment once a firm has already entered a market.

In table 1, we have described more specifically how each identified Institutional Void affects the escalation of SMES in EMS. 
TABLE 1 Continued from the previous page

\begin{tabular}{ll}
\hline Institutional void & Potential impact on market escalation \\
\hline $\begin{array}{l}\text { Availability of } \\
\text { data and infor- } \\
\text { mation on the } \\
\text { market }\end{array}$ & $\begin{array}{l}\text { A lack of data and information can prevent firms from exploiting } \\
\text { emerging opportunities in foreign markets hence delaying invest- } \\
\text { ments in the development of a proprietary distribution system (i.e., } \\
\text { franchising, directly operated stores, showrooms) }\end{array}$ \\
\hline $\begin{array}{l}\text { Intellectual } \\
\text { Property (IP) } \\
\text { protection and } \\
\text { regulations }\end{array}$ & $\begin{array}{l}\text { A special attention is here given to firms that tend to relocate in } \\
\text { better meet local specificities. Usually, production activities are } \\
\text { associated with the disclosure of trade secrets and knowledge trans- }\end{array}$ \\
& $\begin{array}{l}\text { fers. However, weak IP protection could hamper smaller firms from } \\
\text { moving their activities in E } \text { s, thus limiting their commitment of } \\
\text { financial, technological and human resources. }\end{array}$ \\
\hline $\begin{array}{l}\text { Labour Law } \\
\text { staff such as sales agents, area managers and quality controllers. }\end{array}$ & $\begin{array}{l}\text { If labour norms and regulations are too complex, firms will be } \\
\text { discouraged in escalating their mode of presence. Conversely, when }\end{array}$ \\
& $\begin{array}{l}\text { labour norms and regulations are not well defined, smes might } \\
\text { find it too risky to enter into ill-defined transactions. }\end{array}$
\end{tabular}

\section{Public Policy Proposals to Support smes Escalation in EMS}

Our conceptual framework of smes escalation in EMs holds several managerial and public policy implications. About the managerial implications, smes based in advanced economies need to confront the institutional 'reality' that their marketing capabilities and knowledge-based resources - originally built in developed countries - may need to be supplemented with new ones to cope with institutional weaknesses inherent in EMS. In practice, SMES must be aware of the effect that Institutional Voids will have on their resources and capabilities and hence be available to make additional investments to reinforcing them. This implies that smes both develop existing resources and capabilities but also supplement them with new ones (Bortoluzzi et al. 2014). An effective means of resource adjustment and development is through networking, especially to accelerate the process of knowledge sharing and transfer between firms (Sandberg 2014). Thus, marketing and export partnerships should be encouraged between SMES confronting similar challenges in EMS as well as the building of local marketing networks.

Regarding public policy implications, if governments wish for SMEs to be able to fully exploit their current array of marketing and knowledgebased resources and capabilities, there is an onus on them to more ac- 
tively develop resources that can help sMEs thrive in EMs. Indeed, the lack of specific resources and capabilities and the existence of numerous Institutional Voids in EMS, and their possible negative impact on SMES, call for a dedicated set of public policies aimed at supporting firms and helping them overcome several liabilities when approaching foreign markets (Cuervo-Cazurra, Maloney, and Manrakhan 2007). Effective public policy must address SME weaknesses across numerous dimensions (e.g. attitudinal, experiential, informational and organizational) and provide firms with supplementary assets to compensate for them. Of course, precautions should be in place to avoid such policies induce SMEs that are not yet 'international ready' to move prematurely and consequently fail in EMS.

Past research has abundantly evaluated the role of government programs in helping firms entering new markets (e.g. Diamantopoulos, Schlegelmilch, and Inglis 1991; Crick and Czinkota 1995). Most of the noteworthy research on this topic dates to the early nineties, a period in which the world was changing rapidly due to the consequences of the fall of the Berlin Wall and the sudden opening of new supply, production and (potential) consumption markets to Western firms' in postCommunist economies (Arnold and Quelch 1998). However, world trade has been changing significantly since then, both in terms of geography (new 'emerging markets' have 'emerged' in the global scenario) and in the magnitude of firms' internationalization processes (more SMES today enter EMS, some of them even escalate in their mode of presence). Yet, the debate over supporting policies has not kept pace (Gillespie and Riddle 2004; Francis and Collins-Dodd 2004; Cuervo-Cazurra, Maloney, and Manrakhan 2007). Common weaknesses in government policies supporting the internationalization of SMEs include:

- Prioritizing the entry phase of the firm process of internationalization, instead of looking at their whole process of international expansion;

- Providing support to the firms' export activities, instead of looking at further modes of entry and presence;

- Aggregating 'foreign' markets instead of distinguishing between supports needed to enter mature markets and those relevant for EMS.

Many policies equally fail to consider that the higher the international experience of a firm in a market the higher its propensity to be involved 
in more advanced stages of the internationalization process (from low to high-resource commitment modes of presence). Similarly, most policies fail to take into consideration the nature of the obstacles such firms face to achieve their international objectives (Kotabe and Czinkota 1992). Furthermore, additional research on the topic has noticed that excess government support to export activities could prevent firms to follow different and more profitable internationalization strategies (Acs, Morck, and Yeung 2001). As envisaged by Wright, Westhead, and Ukbasaran (2007), an effective set of public policies for SMES entering EMS should:

- Facilitate the drive for an SME's early internationalization in EMS;

- Frame the internationalization processes as a dynamic activity (i.e. an activity that goes beyond the initial market entry) and grade the level and type of support appropriately;

- Supplement and complement the relative lack or scarcity of resources available to SMES;

- Foster and encourage entrepreneurial attitudes and orientation towards internationalization in EMS;

- help smes leverage international resources through the development of networks and cooperative arrangements.

Whilst entering and escalating in a foreign market could be closely related, the kind of support that is needed to facilitate the firms' entry and escalation could differ significantly. First, companies that aim to escalate are already in the market and thus have already developed some form of presence and committed resources there. Second, escalating firms are not 'new to the market.' Hence, they have already developed some marketrelated knowledge and obtained some feedback from the market.

In their attempts to support market escalation of SMES in EMS, policy makers should intervene both at the level of firms' resources and capabilities and at the level of Institutional Voids. Since foreign firms and institutions cannot readily replace Institutional Voids, policy makers should focus on ways to help SMEs deal with existing voids.

Table 2 summarizes a set of proposals of supporting policies aimed at helping Western SMES in their escalation efforts in EMS.

The above set of policy proposals, which include educational programmes, information provision, mentoring and consulting services, can, in our view, effectively support the escalation processes of SMEs' in EMS. 
TABLE 2 Supporting Policy Proposals Aimed at Helping smes in Their Escalation Efforts in EMS

\begin{tabular}{|c|c|}
\hline Target $^{*}$ & Policy proposals \\
\hline $\begin{array}{l}\text { Internation- } \\
\text { alization } \\
\text { knowledge }\end{array}$ & $\begin{array}{l}\text { Different educational programs should be targeted to both start- } \\
\text { ing and experienced entrepreneurs to promote periods of stay and } \\
\text { mentorship programs in EMS, such as Erasmus for entrepreneurs } \\
\text { in Europe. Often, firms undervalue the importance of training in } \\
\text { dealing with specific markets, institutions and cultures. Here, there is } \\
\text { room for policies aimed at providing specific training and prepara- } \\
\text { tion for managers of sMES, emphasizing the sharing and adoption of } \\
\text { best practices that have succeeded in specific EMS. }\end{array}$ \\
\hline Social capital & $\begin{array}{l}\text { The promotion of networking is a way to accelerate the process of } \\
\text { knowledge sharing and transfer between firms. This could be fur- } \\
\text { ther underpinned by inviting experts in the field (such as scholars } \\
\text { and consultants from EMs) to accelerate the process of experience } \\
\text { acquisition, supporting sMES in the absorption and integration of } \\
\text { knowledge from others. Policy makers should encourage network- } \\
\text { ing between sMEs that operate in a certain market, irrespective of } \\
\text { their industry, to foster knowledge and information exchange. Policy } \\
\text { makers could also organize collective 'market excursions', where costs } \\
\text { would be co-financed. This way, sMES could develop/establish new } \\
\text { networks and knowledge about functioning of EMS. }\end{array}$ \\
\hline & $\begin{array}{l}\text { Policy makers should strengthen and foster an SME's understanding } \\
\text { of EMS through the financing of the collection of specific market } \\
\text { data and the preparation of marketing research studies. Policy mak- } \\
\text { ers should also find ways for supporting those firms' communication } \\
\text { activities in a market to promote a firm (or a country of origin) brand } \\
\text { more effectively. Marketing capabilities could be developed also by } \\
\text { organizing and co-financing presence in foreign trade fairs and exhi- } \\
\text { bitions. }\end{array}$ \\
\hline $\begin{array}{l}\text { Institutional } \\
\text { Void: Starting } \\
\text { and developing } \\
\text { a business }\end{array}$ & $\begin{array}{l}\text { Direct or indirect support should be offered by policy makers to } \\
\text { smEs that want to escalate their form of presence, especially when } \\
\text { red tape is particularly difficult and/or when an institutional support } \\
\text { could be important to speed-up the process. Direct support could } \\
\text { come in the form of political pressure to encourage liberalization and } \\
\text { harmonization of business legislation. Indirect support could come } \\
\text { from providing and/or co-financing external consulting to SMES } \\
\text { from EM experts. Visits to selected EMs would also help sMES come } \\
\text { to terms with the realities and challenges of foreign markets. }\end{array}$ \\
\hline
\end{tabular}

Continued on the next page

\section{Conclusions}

In this paper, we have explored and framed our conceptual understanding of the main inhibiting factors associated with the process of escalation 
TAB LE 2 Continued from the previous page

\begin{tabular}{|c|c|}
\hline Target $^{*}$ & Policy proposals \\
\hline $\begin{array}{l}\text { Institutional } \\
\text { Void: Protect- } \\
\text { ing investors }\end{array}$ & $\begin{array}{l}\text { Policy makers should educate SMES about the best methods and ap- } \\
\text { proaches to protect their investments. Seminars, mentoring, consult- } \\
\text { ing services, sharing of best practices appear to be the most appropri- } \\
\text { ate forms. Governments should also provide investors' insurance in } \\
\text { foreign markets. }\end{array}$ \\
\hline $\begin{array}{l}\text { Institutional } \\
\text { Void: Trading } \\
\text { across borders }\end{array}$ & $\begin{array}{l}\text { When trade barriers are too high, policy makers should help sMES } \\
\text { in finding alternative solutions. An example is leveraging on 'trian- } \\
\text { gulation' which means reaching a targeted market indirectly, through } \\
\text { a 'parent' market that can boast advantageous custom agreements. } \\
\text { While current trade legislation and procedural knowledge may be } \\
\text { strong in larger firms, sMEs may not have the time or resources to } \\
\text { learn how to address all such specific challenges and therefore there } \\
\text { is a role of public policy in providing targeted training on trade rules. }\end{array}$ \\
\hline $\begin{array}{l}\text { Institutional } \\
\text { Void: Enforcing } \\
\text { contracts }\end{array}$ & $\begin{array}{l}\text { Policy makers should help smes navigate foreign judicial systems } \\
\text { through specific training and even direct support when needed. }\end{array}$ \\
\hline $\begin{array}{l}\text { Institutional } \\
\text { Void: Availabil- } \\
\text { ity of data and } \\
\text { information on } \\
\text { the market }\end{array}$ & $\begin{array}{l}\text { SMES do not normally have sophisticated marketing information } \\
\text { systems or databases. That is why policy makers should help them } \\
\text { with market studies, meetings with experts and consultants. Online } \\
\text { platforms could also help, supporting the collection and exchange of } \\
\text { information to enter and operate on foreign markets. Such platforms } \\
\text { could be used also as networking media, as well as for creating a } \\
\text { collaborative entry of groups of firms into EMs, thus sharing the } \\
\text { costs of entry and the potential associated risks. }\end{array}$ \\
\hline $\begin{array}{l}\text { Institutional } \\
\text { Void: Intellec- } \\
\text { tual Property } \\
\text { (IP) laws and } \\
\text { regulations }\end{array}$ & $\begin{array}{l}\text { Policy makers should help sMEs better understand the risks con- } \\
\text { nected with IP rights. Providing information on the theme and de- } \\
\text { veloping connections with trustworthy foreign experts in the field } \\
\text { can help SMES. }\end{array}$ \\
\hline $\begin{array}{l}\text { Institutional } \\
\text { Void: Labour } \\
\text { Market Law }\end{array}$ & $\begin{array}{l}\text { SMES are encouraged to hire workers in an EM when they have } \\
\text { the support of trustworthy local experts. Policy makers should help } \\
\text { SMES identify those professionals and get firms in contact with them. } \\
\text { This can be done through the development and maintenance of a } \\
\text { database of EM experts. }\end{array}$ \\
\hline
\end{tabular}

NOTES ${ }^{*}$ Resource and institutional void.

of SMEs in international markets, with a special focus on EMs. The increasing attractiveness of EMS, compared with developed markets, has encouraged aspiring and growth-oriented SMES to consider them as important targets. Yet, EMS are associated with specific conditions related to institutional characteristics, particularly Institutional Voids, which af- 
fect (moderate) market entry and market escalation strategies of sMEs.

Based on well-established classifications of Institutional Voids and our personal research, we have identified and proposed seven main categories of Institutional Voids relevant for smes. We have presented in detail their potential influence on entry and escalation of sMEs in EMs. Further, our paper has identified three main types of resources and capabilities that critically determine a firm's performance on EMS, namely, internationalization knowledge, social capital resources and marketing capabilities. We have brought together resources and Institutional Voids into a conceptual framework of sMEs escalation in EMS. The model suggests that resource-scarce SMES will hold back in their attempts to commit further to EMS and will be further dissuaded the higher the Institutional Voids are present in the market.

Finally, we considered a set of policy proposals for governments in their efforts to promote sMEs entry and escalation in EMs, which represent a good basis for enhanced policy development and support, especially with the proper understanding of SMEs escalation in EMS.

\section{References}

Acs, Z. J., R. K. Morck, and B. Yeung. 2001. 'Entrepreneurship, Globalization, and Public Policy'. Journal of International Management 7 (3): 23551.

Akbar Y., G. Bortoluzzi, and A. Tracogna. 2014. 'Beyond Entry Mode SME Escalation in Emerging Markets: A Conceptual Framework'. Journal for International Business and Entrepreneurship Development 7 (4): 326-40.

Arnold, D. J., and J. A. Quelch. 1998. 'New Strategies in Emerging Markets'. Sloan Management Journal 40 (1): 7-20.

Autio, E., H. J. Sapienza, and J. G. Almeida. 2000 'Effects of Age at Entry, Knowledge Intensity, and Imitability on International Growth.' Academy of Management Journal 43 (5): 909-24.

Axinn, C. N., 1989. 'Export Performance: Do Managerial Perceptions Make a Difference?' International Marketing Review 5 (2): 61-71.

Balboni, B., G. Bortoluzzi, and G. Grandinetti R. 2013. 'On the Relationship between Size, Capabilities and Internationalization: An Explorative Analysis of Italian Subcontracting smes'. International Journal of Globalisation and Small Business 5 (1-2): 114-32.

Barney, J. B. 1991. 'Firm Resources and Sustainable Competitive Advantage.' Journal of Management 17:99-120.

Birley, S. 1985. 'The Role of Networks in the Entrepreneurial Process.' Journal of Business Venturing 1 (1): 107-17. 
Blomstermo A, K. Eriksson, and D. D. Sharma 2004. 'Domestic Activity and Knowledge Development in the Internationalization Process of Firms.' Journal of International Entrepreneurship 2 (3): 239-58.

Bortoluzzi, G., M. Chiarvesio, E. Di Maria, and R. Tabacco, R. 2014. 'Exporters Moving toward Emerging Markets: A Resource-Based Approach.' International Marketing Review 31 (5): 506-25.

Broadman, H. G., J. Anderson, C. A. Claessens, R. Ryterman, S. Slavova, and M. Vagliasindi. 2004. Building Market Institutions in South Eastern Europe: Comparative Prospects for Investment and Private Sector Development. Washington, DC: World Bank.

Brouthers, K. 2002. 'Institutional, Cultural and Transaction Cost Influences on Entry Mode Choice and Performance.' Journal of International Business Studies 33 (2): 203-21.

Brouthers, K., and J.-F. Hennart. 2007. 'Boundaries of the Firm: Insights from International Entry Mode Research.' Journal of Management 33 (3): 395-425.

Cavusgil, S. T., G. Knight, and J. Riesenberger. 2012. International Business: The New Realities. Upper Saddle River, NJ: Pearson Education.

Cavusgil, S. T., and J. R. Nevin. 1981. 'Internal Determinants of Export Marketing Behavior: An Empirical Investigation'. Journal of Marketing Research 18 (1): 114-9.

Chetty, S., and B. D. Holm. 2000. 'Internationalization of Small to MediumSized Manufacturing Firms: A Network Approach.' International Business Review 9 (1): 77-93.

Crick, D., M. R. Czinkota. 1995. 'Export Assistance: Another Look at Whether We Are Supporting the Best Programs.' International Marketing Review 12 (3): 61-72.

Cuervo-Cazurra A., M. Maloney, and S. Manrakhan. 2007. 'Causes of the Difficulties in Internationalization'. Journal of International Business Studies 38 (5): 709-25.

Dean, D. L., B. Mengüç, and C. P. Myers. 200o. 'Revisiting Firm Characteristics, Strategy, and Export Performance Relationship: A Survey of the Literature and an Investigation of New Zealand Small Manufacturing Firms.' Industrial Marketing Management 29 (5): 461-77.

Diamantopoulos, A., B. B. Schlegelmilch, and K. Inglis. 1991. 'Evaluation of Export Promotion Measures: A Survey of Scottish Food and Drink Exporters.' In Export Development and Promotion: The Role of Public Organizations, edited by F. H. R. Seringhaus and P. Rosson, 189-216. Norwall, M A: Kluwer.

Eriksson, K., J. Johanson, A. Majkgård, and D. Sharma, D. 1997. 'Experiential Knowledge and Cost in the Internationalization Process.' Journal of International Business Studies 28 (2): 337-6o. 
Erramilli, M. K., S. Agarwal, and C. S. Dev. 2002. 'Choice Between NonEquity Entry Modes: An Organizational Capability Perspective.' Journal of International Business Studies. 33 (2): 223-42.

European Commission. 2011. Opportunities for the Internationalisation of European smes: Final Report. Brussels: European Commission.

Ferreira, M. P., D. Li., and J. Yong Suk. 2009, 'Foreign Entry Strategies, Strategic Adaptation to Various Facets of the Institutional Environments.' Development and Society 38 (1): 27-55.

Francis, J., and C. Collins-Dodd. 2004. 'Impact of Export Promotion Programs on Firm Competencies, Strategies and Performance.' International Marketing Review 21 (4): 474-95.

Gankema, H., H. Snuif, and P. Zwart. 200o. 'The Internationalization Process of Small and Medium Sized Enterprises: An Evaluation of Stage Theory.' Journal of Small Business Management 38 (4): 15-27.

Gao, H., D. Ballantyne, and J. G. Knight. 2010, 'Paradoxes and Guanxi Dilemmas in Emerging Chinese-Western Intercultural Relationships.' Industrial Marketing Management 39 (2): 264-72.

Gillespie, K., and L. Riddle. 2004. 'Export Promotion Organization Emergence and Development: A Call to Research.' International Marketing Review 21 (4): 462-73.

Grant, R. M. 1991. 'The Resource-Based Theory of Competitive Advantage, Implications for Strategy Formulation.' California Management Review 33 (3): $114-35$.

Haar, J., and M. Ortiz-Buonafina. 1995. 'The Internationalization Process and Marketing Activities: The Case of Brazilian Export Firms.' Journal of Business Research 32 (2): 175-81.

Henisz, W. J. 2004. 'The Institutional Environment for International Business.' In What is International Business? Edited by P. J. Buckley, 85-109. London: Palgrave.

Hill, C., P. Hwang, and W. C. Kim. 1990. 'An Eclectic Theory of the Choice of International Entry Mode.' Strategic Management Journal 11:117-28.

Hilmersson, M., and H. Jansson. 2012. 'International Network Extension Processes to Institutionally Different Markets, Entry Nodes and Processes of Exporting smes.' International Business Review 21 (4): 68293.

Hitt, M. A., M. T. Dacin, E. Levitas, J. L. Arregle, and A. Borza. 20oo. 'Partner Selection in Emerging and Developed Market Contexts: ResourceBased and Organizational Learning Perspectives.' Academy of Management Journal 43 (3): 449-67.

Honig, B. 1998. 'What Determines Success? Examining the Human, Financial, and Social Capital of Jamaican Microentrepreneurs.' Journal of Business Venturing 13 (5): 371-94. 
Hood, N., and S. Young. 1979. The Economics of Multinational Enterprise. London: Longman.

Hsu, C., and A. Pereira. 2008. 'Internationalization and Performance: The Moderating Effects of Organizational Learning.' Omega 36 (2): 188-205. Hymer, S. 1976. The International Operation of National Firms. Cambridge, MA: Mit Press.

Ingram, P. L., and B. S. Silverman. 2002. The New Institutionalism in Strategic Management. Greenwich, CT: JA I Press.

Isobe, T., S. Makino, and D. B. Montgomery. 200o. 'Resource Commitment, Entry Timing and Market Performance of Foreign Direct Investments in Emerging Economies: The Case of Japanese International Joint Ventures in China.' Academy of Management Journal 43 (3): 46884.

Jansson, H. 2007. International Business Marketing in Emerging Country Markets: The Third Wave of Internationalization of Firms. Cheltenham: Edward Elgar.

Jansson, H., and S. Sandberg. 2008. 'Internationalization of Small and Medium Sized Enterprises in the Baltic Sea Region.' Journal of International Management 14 (1): 65-77.

Johanson, J., and J. E. Vahlne. 1977. 'The Internationalization Process of the Firm: A Model of Knowledge Development and Increasing Foreign Market Commitments.' Journal of International Business Studies 8 (1): 23-32.

- 2009. 'The Uppsala Internationalization Process Model Revisited: From Liability of Foreignness to Liability of Outsidership. Journal of International Business Studies 40 (9): 1411-31.

Khanna, T., and K. Palepu. 2010. Winning in the Emerging Economies: A Road Map for Strategy and Execution. Cambridge, M A: Harvard Business Press.

Khanna, T., K. Palepu, and J. Sinha. 2005. 'Strategies That Fit Emerging Markets.' Harvard Business Review 83 (6): 63-76.

Kostova, T., and S. Zaheer. 1999, 'Organizational Legitimacy under Conditions of Complexity: The Case of The Multinational Enterprise'. Academy of Management Review 24 (1): 64-81.

Kotabe, M., and M. R. Czinkota. 1992. 'State Government Promotion of Manufacturing Exports: A Gap Analysis.' Journal of International Business Studies 23 (4): 637-58.

Liao, J., and H. Welsch. 2003. 'Social Capital and Entrepreneurial Growth Aspiration: A Comparison of Technology- and Non-Technology-Based Nascent Entrepreneurs.' Journal of High Technology Management Research 14:149-70.

Lu, Y., L. Zhou, G. Bruton, and W. Li 2009. 'Capabilities as a Mediator Link- 
ing Resources and the International Performance of Entrepreneurial Firms in an Emerging Economy'. Journal of International Business Studies 41 (3): 419-36.

Merrilees, B., S. Rundle-Thiele, and A. Lye 2011. 'Marketing Capabilities, Antecedents and Implications for в 2 в Sм E Performance'. Industrial Marketing Management 40 (3): 368-75.

Meyer, K. E., S. Estrin, S. K. Bhaumik, and M. W. Peng. 2009. 'Institutions, Resources, and Entry Strategies in Emerging Economies.' Strategic Management Journal 30 (1): 61-80.

Minbaeva, D., T. Pederson, I. Bjorkman, C. Fey, and H. Park. 2003. 'MNC Knowledge Transfer, Subsidiary Absorptive Capacity and H R M.' Journal of International Business Studies 34 (6): 586-99.

Morgan, N. A., C. S. Katsikeas, and D. W. Vorhies 2012. 'Export Marketing Strategy Implementation, Export Marketing Capabilities, and Export Venture Performance.' Journal of the Academy of Marketing Science 40 (2): 271-89.

Nahapiet, J., and S. Ghoshal. 1998. 'Social Capital, Intellectual Capital, and the Organizational Advantage.' Academy of Management Review 23 (2): 242-66.

O'Cass, A., and C. Julian 2003. 'Examining Firms and Environmental Influences on Export Marketing Mix Strategy and Export Performance of Australian Exporters.' European Journal of Marketing 37 (3-4): 366-84.

Oliver, C. 1997, 'Sustainable Competitive Advantage: Combining Institutional and Resource-Based Views'. Strategic Management Journal 18 (9): 697-713.

Ostgaard, T., and S. Birley. 1994. 'Personal Networks and Firm Competitive Strategy: A Strategic or Coincidental Match?' Journal of Business Venturing 9 (4): 281-305.

Peng, M. W., and Y. Luo. 2000. 'Managerial Ties and Firm Performance in a Transition Economy: The Nature of a Micro-Macro Link.' Academy of Management Journal 43 (3): 486-501.

Peng, M. W., D. Y. Wang, and Y. Jiang. 2008. 'An Institution-Based View of International Business Strategy: A Focus on Emerging Economies.' Journal of International Business Studies 39 (5): 920-36.

Petersen, B., and T. Pedersen. 1997. 'Twenty Years after: Support and Critique of the Uppsala Internationalisation Model. In The Nature of the International Firm, edited by I. Björkman and M. Forsgren, 117-34. Copenhagen: Munksgaard.

Pfeffer, J., and G. Salancik. 1978. The External Control of Organizations. New York: Harper and Row.

Prasad, V. K., K. Ramamurthy, and G. M. Naidu. 2001. 'The Influence of Internet-Marketing Integration on Marketing Competencies and Ex- 
port Performance.' Journal of International Marketing 9 (4): 82-110. Puck, J. F., D. Holtbrugge, and A. T. Mohr. 2009. 'Beyond Entry Mode Choice: Explaining the Conversion of Joint Ventures into Wholly Owned Subsidiaries in the People's Republic of China.' Journal of International Business Studies 40:388-404.

Ruzzier, M., and B. Antoncic. 2007. 'Social Capital and sme Internationalization: An Empirical Examination.' Transformations in Business and Economics 6 (1): 122-38.

Ruzzier, M., R. D. Hisrich, and B. Antoncic. 2006. 'sme Internationalization Research: Past, Present, and Future.' Journal of Small Business and Enterprise Development 13 (4): 476-97.

Sandberg, S. 2014, 'Experiential Knowledge Antecedents of the sme Network Node Configuration in Emerging Market Business Networks.' International Business Review 23 (1): 20-9.

Shepherd, D. A., E. J. Douglas, and M. Shanley. (2000). 'New Venture Survival: Ignorance, External Shocks, and Risk Reduction Strategies.' Journal of Business Venturing 15 (5): 393-410.

Sousa, C. M., and F. Bradley. 2008. 'Antecedents of International Pricing Adaptation and Export Performance.' Journal of World Business 43 (3): 307-20.

Steenkamp, J. B. E. M. 2005. 'Moving out of the U.S. Silo: A Call to Arms for Conducting International Marketing Research.' Journal of Marketing 69 (4): 6-8.

Stinchcombe, A. L. 1965. 'Social Structure and Organizations.' In Handbook of Organizations, edited by J. March, 142-93. Chicago: Rand McNally.

Swoboda, B., E. Olejnik, and D. Morschett. 2011. 'Changes in Foreign Operation Modes: Stimuli for Increases Versus Reductions.' International Business Review 20 (5): 578-90.

Teece, D., G. Pisano, and A. Shuen. 1997. 'Dynamic Capabilities and Strategic Management.' Strategic Management Journal 18 (7): 509-33.

Vianelli, D., P. De Luca, and G. Bortoluzzi. 2012. 'Distribution Channel Governance and Value of "Made in Italy" Products in the Chinese Market.' In International Marketing and the Country of Origin Effect, edited by G. Bertoli, and R. Resciniti, 133-53. Cheltenham: Edward Elgar.

Vorhies, D., and N. Morgan. 2005. 'Benchmarking Marketing Capabilities for Sustainable Competitive Advantage.' Journal of Marketing 69 (1): $80-94$.

Weerawardena, J. 2003. 'The Role of Marketing Capability in InnovationBased Competitive Strategy' Journal of Strategic Marketing 11 (1): 15-35.

Welter, F., and D. Smallbone. 2011, 'Institutional Perspectives on Entrepreneurial Behavior in Challenging Environments.' Journal of Small Business Management 49 (1): 107-25. 
Wernerfelt, B. 1984. 'A Resource-Based View of the Firm.' Strategic Management Journal 5:171-80

White, D. S., D. A. Griffith, and J. K. Ryans 1998. 'Measuring Export Performance in Service Industries.' International Marketing Review 15 (3): 188-204.

Wright M., P. Westhead, and D. Ucbasaran. 2007. 'Internationalization of Small and Medium-Sized Enterprises (smes) and International Entrepreneurship: A Critique and Policy Implications.' Regional Studies $41(7): 1013-29$.

$\mathrm{Xu}, \mathrm{D}$., and O. Shenkar. 2002. 'Institutional Distance and the Multinational Enterprise.' Academy of Management Review 27 (4): 608-18.

Zaheer, S. 1995. 'Overcoming the Liability of Foreignness.' Academy of Management Journal 38 (2): 341-63.

Zhou, L., A. Wu, and B. R. Barnes. 2012. 'The Effects of Early Internationalization on Performance Outcomes in Young International Ventures: The Mediating Role of Marketing Capabilities.' Journal of International Marketing 20 (4): 25-45

Zou, S., and S. Stan. 1998. 'The Determinants of Export Performance: A Review of the Empirical Literature between 1987 and 1997'. International Marketing Review 15 (5): 333-56.

This paper is published under the terms of the Attribution-

NonCommercial-NoDerivatives 4.o International (CC B Y-NC-ND 4.0)

License (http://creativecommons.org/licenses/by-nc-nd/4.o/). 
Povečanje učinka oblikovanja odločitev in učinkovitosti upravljanja: razumevanje, kako maksimiranje in lokus nadzora vplivata na učinkovitost managerjev na delovnem mestu

Brandon William Soltwisch in Keiko Krahnke

Študija preučuje vpliv maksimiranja stila odločanja na učinkovitost upravljanja s skupino 319 delovnih vodij v ZDA. Ugotovitve kažejo, da so bili menedžerji, ki uporabljajo obliko maksimiranega stila odločanja, učinkovitejši od tistih, ki ga ne uporabljajo. Ugotovljeno je bilo tudi, da lokus kontrole v tem odnosu igra posredniško vlogo. Maksimizatorji, ki imajo notranji lokus nadzora, so bili znatno učinkovitejši na svojih položajih. Rezultati kažejo, da kombinacija maksimiranja in celovitosti kontrole zagotavlja močan recept za uspeh vodstva. V zvezi s sedanjimi ugotovitvami se razpravlja o rezultatih, posledicah in prihodnjih raziskovalnih usmeritvah.

Ključne besede: maksimizacija, zadovoljstvo, odločanje, učinkovitost vodenja

Klasifikacija JEL: L2, M12

Managing Global Transitions 15 (3): 215-230

Razmerje med trgom brezposelnosti in borznimi trgi v Južni Afriki: dokazi iz simetričnih in asimetričnih modelov kointegracije Andrew Phiri

$\mathrm{V}$ študiji preučujemo linearno in nelinearno kointegracijo in vzročne zveze med brezposelnostjo ter donosi borznih trgov v Južni Afriki s pomočjo četrtletnih podatko,v zbranih med prvim četrtletjem 1994 in prvim četrtletjem 2016. Empirični rezultati kažejo na pomembne učinke kointegracije med časovnima nizoma v linearnih in nelinearnih modelih, čeprav oba okvira v končni fazi zavrneta pojem kakršnih koli vzročnih razmerij med spremenljivkami. Generalno je naša študije zavrnila, da bi bil pojem brezposelnost dober napovedovalez za donos na borznem trgu in da razvoj na borznem trgu ne vpliva na stopnjo brezposelnosti. Takšni dokazi se zavzemajo za šibko obliko učinkovitosti v cenah lastniških vrednostnih papirjih JSE, pri čemer podatki o brezposelnosti investitorjem ne morejo pomagati napovedati gibanja prihodnjih cen delnic in nadalje nakazujejo, da se oblikovalci politike ne morejo zanesti na razvoj borznega trga kot sredstva za zniževanje prevladujočih 
visokih stopenj brezposelnosti, kot je določeno v trenutnih ciljih makroekonomske politike.

Ključne besede: donos na borzi, brezposelnost, kointegracija, vzročni učinki, model MTAR, Južna Afrika

Klasifikacija JEL: C13, C22, C52, E24, E 44

Managing Global Transitions 15 (3): 231-254

\section{Koncept poslovnega modela: predlog integriranega okvira} Marko Perić, Vanja Vitezić in Jelena Đurkin

Vsako podjetje zaposluje glede na nek določen model, ki išče konkurenčne prednosti. Vendar je to prizadevanje težavno in včasih neuspešno. Razloge za neuspeh bi morali iskati pri pomanjkanju razumevanja poslovnih modelov njihovih organizacij, njihovih edinstvenih gradnikov in potenciala, ki ga imajo. Da bi lahko pomagali upraviteljem bolje razumeti poslovne modele, se članek ukvarja s pregledom obstoječe literature in identificira elemente poslovnih modelov, ki so navedeni v njej. $\mathrm{V}$ nadaljevanju, ob upoštevanju novih potreb na spreminjajočih se trgih in prevladujočega iskanja trajnosti, ki presega dobiček, predstavljamo bistvene elemente poslovnega modela $\mathrm{v}$ integriranem okviru. Posodobljen splošni okvir poslovnega modela sestavljajo štiri primarne kategorije, in sicer vrednostna, zajemanje vrednosti, ustvarjanje vrednosti in vrednostno omrežje, kar bi lahko koristilo različnim organizacijam, profitnim ali neprofitnim, $\mathrm{z}$ različnimi usmeritvami glede namena in vizij ter interakcij z okoljem.

Ključne besede: poslovni model, vrednostni predlog, ustvarjanje vrednosti, zajemanje vrednosti, omrežje vrednosti

Klasifikacija JEL: M1O, L26

Managing Global Transitions 15 (3): 255-274

\section{Grozdi v sektorju obnovljivih virov energije na Poljskem Michał Staszków, Michał Borychowski in Filip Nowacki}

Prispevek je pregled del, ki predstavljajo probleme obnovljive energije na Poljskem, in je dopolnjen s študijo primera. Da bi zmanjšale emisijo plinov in izboljšale energetsko učinkovitost, morajo države Evropske unije pridobiti več energije iz obnovljivih virov. Naš cilj je preizkusiti, kako lahko grozd pomaga pri doseganju določb paketa $3 \times 20 \%$. Študija primera baltskega ekološkega grozda je predstavljena kot uspešen primer največjega energetskega grozda v državi, kar se lahko obravnava kot merilo za druge sektorske grozde, ki so pripravljeni pozitivno prispevati k spremembam poljskega energetskega sektorja. 
Ključne besede: grozdi, obnovljiva energija, paket $3 \times 20 \%$ Klasifikacija JEL: E0O, O13, P28, Q20, Q4

Managing Global Transitions 15 (3): 275-290

Izziv rasti zahodnega MSP na nastajajočih trgih: raziskovalni okvir in politične implikacije

Mitja Ruzzier, Yusaf H. Akbar, Guido Bortoluzzi in Andrea Tracogna

$\mathrm{V}$ članku raziskujemo glavne dejavnike, ki so povezani s procesom vstopa in stopnjevanja malih in srednjih podjetij na mednarodnih trgih, $s$ poudarkom na nastajajočih trgih. Identificiramo in predlagamo sedem glavnih kategorij institucionalnih praznin in tri glavne vrste virov, ki lahko kritično določajo predstave malih in srednje velikih podjetij na področju EM, in sicer internacionalizacijsko znanje, socialni kapitalski viri in tržne zmogljivosti. Institucionalne praznine in viri se združujejo v okviru konceptualnega okvira, ki kaže, da bodo mala in srednje velika podjetja $\mathrm{z}$ omenjenimi viri zadržala svoja prizadevanja, da bi se še naprej zavzemala za nastajajoče trge in bodo še bolj zadrževala to, da bodo institucionalne praznine na trgu višje. Članek prispeva k politični literaturi o internacionalizaciji malih in srednje velikih podjetij z osredotočanjem na dve področji ukrepov javnega reda, ki bi lahko imeli jasen in očiten vpliv na ravnanje MSP na nastajajočih trgih, kar je bilo prvič povezano $\mathrm{z}$ viri, ki jih MSP ponujajo in lahko izkoristijo $\mathrm{z}$ insitucionalnimi prazninami.

Ključne besede: MsP, nastajajoči trgi, institucionalne praznine, viri, politika internacionalizacije

Klasifikacija JEL: F23, M16, O31

Managing Global Transitions 15 (3): 291-314 